University of Rhode Island

DigitalCommons@URI

Open Access Master's Theses

2020

\title{
ASSOCIATIONS BETWEEN AGE, MENOPAUSAL STATUS, AND PHYSICAL FUNCTION IN MIDDLE-AGED WOMEN
}

Sydney Sweck

University of Rhode Island, sydneysweck@gmail.com

Follow this and additional works at: https://digitalcommons.uri.edu/theses

\section{Recommended Citation}

Sweck, Sydney, "ASSOCIATIONS BETWEEN AGE, MENOPAUSAL STATUS, AND PHYSICAL FUNCTION IN MIDDLE-AGED WOMEN" (2020). Open Access Master's Theses. Paper 1830.

https://digitalcommons.uri.edu/theses/1830

This Thesis is brought to you for free and open access by DigitalCommons@URI. It has been accepted for inclusion in Open Access Master's Theses by an authorized administrator of DigitalCommons@URI. For more information, please contact digitalcommons-group@uri.edu. 


\begin{abstract}
ASSOCIATIONS BETWEEN AGE, MENOPAUSAL STATUS, AND PHYSICAL FUNCTION IN MIDDLEAGED WOMEN

BY SYDNEY SWECK
\end{abstract}

A THESIS SUBMITTED IN PARTIAL FULFILLMENT OF THE REQUIREMENTS FOR THE DEGREE OF MASTER OF SCIENCE

IN

KINESIOLOGY 


\section{MASTER OF SCIENCE THESIS}

$\mathrm{OF}$

SYDNEY SWECK

\section{APPROVED:}

Thesis Committee:

Major Professor Christie Ward-Ritacco

Natalie Sabik

Deborah Riebe

Nasser H. Zawia

DEAN OF THE GRADUATE SCHOOL

UNIVERSITY OF RHODE ISLAND

2020 


\begin{abstract}
\end{abstract}
Importance and Objective: Physical function limitations affect approximately one fifth of middle-aged women. However, correlates of these limitations are poorly understood; limited research investigates the associations between menopausal status, physical function, physical activity, and body composition, and the research available is equivocal about these associations. Methods: Using a cross-sectional approach, 107 $(53.31 \pm 6.14 \mathrm{yr})$ middle-aged women completed six objective assessments of physical function (transfer task, 8-foot up-and-go, 30-second chair stands, 6-minute walk test, lift and carry, and lower extremity physical function composite score) and one subjective assessment of physical function (36-Item Short Form Survey physical functioning subscale). Muscular strength was measured using handgrip dynamometry. Physical activity (average steps per day, average minutes of moderate plus vigorous physical activity per day, and average minutes of total physical activity per day) was measured via accelerometry. Body composition (percent fat and percent mineral-free lean mass) was measured with Dual Energy X-Ray Absorptiometry. Women selfidentified menopausal status (premenopausal, perimenopausal, and postmenopausal). Discussion: Age was significantly different between menopausal status groups $(\mathrm{p}<0.05)$. When controlling for age and number of chronic medical conditions, no significant differences between menopausal status groups were found for any outcomes (all p>0.05). In a multiple linear regression controlling for number of chronic medical conditions, menopausal status was not significantly associated with any outcome (all p>0.05). However, age was independently associated with two 
outcomes: (1) transfer task time ( $\mathrm{p}=0.015)$, explaining $11.1 \%$ of observed variability, and (2) handgrip strength ( $\mathrm{p}=0.002$ ), explaining $14.7 \%$ of observed variability.

Conclusion: Middle-aged women, regardless of menopausal status, have similar body composition, physical activity levels, and physical function ability.

Key Words: Menopausal status - Middle-age - Physical function - Physical activity Body composition - Grip strength. 


\section{ACKNOWLEDGMENTS}

I would like to thank the primary investigators of the University of Rhode Island's Women's Health Improvement Initiative (WHII) study, Dr. Christie WardRitacco and Dr. Natalie Sabik, for providing me with a position on the study's research team and for their continued support throughout the thesis process. I am especially grateful for the invaluable knowledge, feedback, and guidance provided by my thesis advisor, Dr. Ward-Ritacco.

I would also like to thank my fellow study coordinators, Sydney Reigle and Olivia Finnegan, for their tireless work on the WHII study. Both have been a source of incredible encouragement and support.

Thanks to the generosity, skill, and knowledge of these women, I have been able to complete this thesis and contribute to the body of research in physical function and menopausal status. 


\section{TABLE OF CONTENTS}

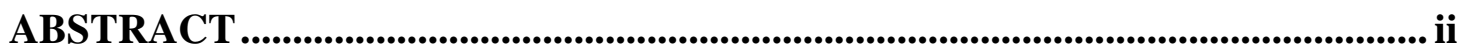

ACKNOWLEDGMENTS .................................................................................................... iv

TABLE OF CONTENTS................................................................................ v

LIST OF TABLES ....................................................................................................... vi

LIST OF FIGURES ................................................................................................................ vii

LIST OF APPENDICES ................................................................................. vii

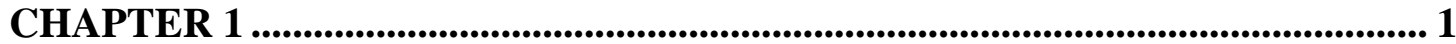

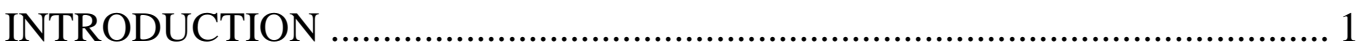

CHAPTER 2 ...................................................................................................................... 7

REVIEW OF LITERATURE ................................................................ 7

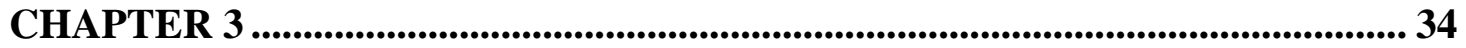

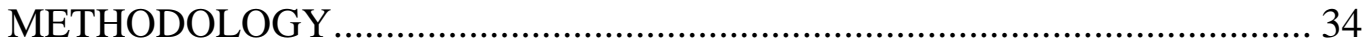

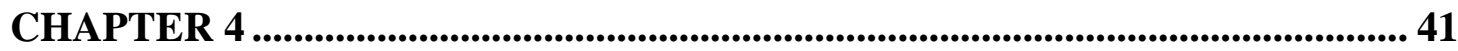

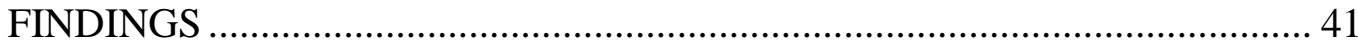

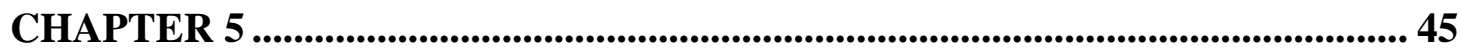

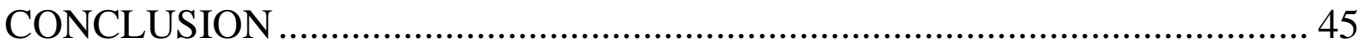

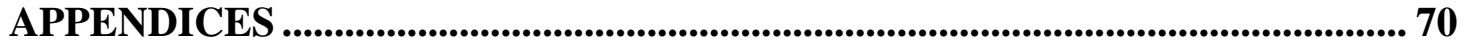

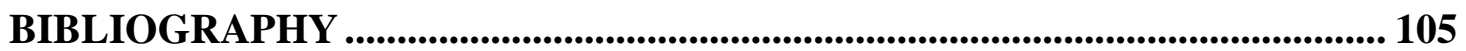




\section{LIST OF TABLES}

TABLE

PAGE

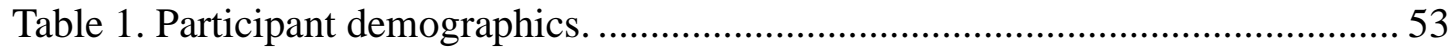

Table 2. Demographics by menopausal status group .............................................. 54

Table 3a. Multiple regression for body composition and physical activity ............... 55

Table 3b. Multiple regression for physical function and strength............................ 56

Table 4a. Correlation matrix for premenopausal women ..................................... 57

Table 4b. Correlation matrix for perimenopausal women …................................. 58

Table 4c. Correlation matrix for postmenopausal women ...................................... 59 


\section{LIST OF FIGURES}

FIGURE

PAGE

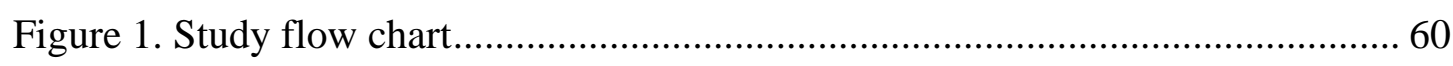

Figure 2a. Transfer task performance by menopausal status. .................................. 61

Figure 2b. 8 -foot up-and-go performance by menopausal status............................... 62

Figure 2c. 30 -second chair stands performance by menopausal status..................... 63

Figure 2d. 6-minute walk test performance by menopausal status ..........................6 64

Figure 2e. Lift and carry performance by menopausal status .............................. 65

Figure $2 \mathrm{f}$. Lower extremity physical function composite score by menopausal status 66

Figure 2g. SF-36 physical functioning subscores by menopausal status ................... 67

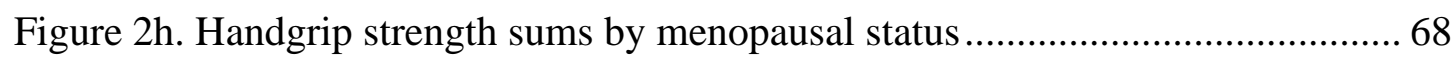




\section{LIST OF APPENDICES}

APPENDIX

PAGE

Appendix A. Women's Health Improvement Initiative screening questionnaire........ 69

Appendix B. Women's Health Improvement Initiative informed consent................. 89

Appendix C. Physical Activity Readiness Questionnaire (PAR-Q) ........................... 94

Appendix D. Mini-Mental Status Examination ............................................... 95

Appendix E. ActiGraph Accelerometer Instructions............................................ 97

Appendix F. ActiGraph Accelerometer Record of Wear........................................ 98

Appendix G. 36-Item Short Form Survey (SF-36) ............................................ 99 


\section{CHAPTER 1}

\section{INTRODUCTION}

A major health concern associated with aging is physical function performance. Physical function performance, often referred to as "functional ability" or simply "physical function", is an individual's ability to perform basic actions involving strength, mobility, and endurance that are essential for maintaining independence and carrying out more complex activities (1).

Physical function is not only an issue impacting older adults (those $\geq 65$ years of age): there is evidence that men and women experience declines in physical function during middle-age (approximately ages 40-64). An estimated 18-22\% of this population has significant physical function limitations $(2,3)$, with a higher percentage of women experiencing limitations compared to age-matched men (2). Recent evidence suggests that these physical function limitations are associated with health issues earlier in life than previously thought; a study of 45-year-old men and women showed that slower gait speed (a measure of physical function) is associated with markers of poorer cognitive health (such as lower IQ and smaller brain volume), as well as accelerated biological aging across multiple organ systems (4). Therefore, it is important to assess for and treat physical function limitations that might occur in middle-age (5).

Resolving any issues in physical function during middle-age may be important for preserving physical function in older adulthood (6). While adequate physical function ability is important at all ages, it is of particular significance for older adults. 
Physical function is a significant determinant of their ability to "age in place", or to continue to live independently despite health issues often associated with advancing age (7). Previous studies in older adults show that age, physical activity, and body composition are associated with physical function performance $(8,9)$. Further, with increased age, older adults experience a decline in physical activity level (10), an increase in adipose tissue (11), a decrease in lean mass (11), and a decline in functional ability (9). These age-related changes tend to be more pronounced in women, with more women than men experiencing physical function limitations (12). This gender gap may be due to older women tending to have lower physical activity levels (12) and higher prevalence of depressive symptoms (12), arthritis (13), and obesity (13) compared to age-matched men.

In addition to physical function, many other aspects of health seem to decline in middle-age. For example, during middle-age in both genders, age has a positive linear association with number of total health deficits including long-term disability and arthritis (14). Additional health changes in middle-aged women are associated with menopause, which typically begins when a woman is in the mid-40s, and is marked by the permanent cessation of menstruation due to loss of ovarian follicular activity (15). Menopause is driven by hormonal changes such as decreased estradiol (E2) and increased follicle stimulating hormone (FSH) and is associated with health issues including fatigue, anxiety, depression, dips in cognitive performance, loss of bone mineral density, increases in body fat, lower physical activity levels, and worse physical function (5). Menopausal status has many categorizations but can be most simply divided into "premenopausal", "perimenopausal", and "postmenopausal". Most 
measures of menopausal status are self-report measures, which ask women about the frequency and regularity of their menstrual period. This study utilized the Study of Women's Health Across the Nation (SWAN) criteria, a frequently used self-report definition of menopausal stages.

Despite the number of health changes associated with middle-age in women, research in this population is limited for a number of reasons. Middle-aged women experience hormonal fluctuations in both the short term (days to weeks) due to menstrual cycles, and in the long term (months to years) due to menopause (5). There are indications that these hormonal fluctuations are correlated with body composition, physical activity, physical function, and other variables studied in the field of exercise science (16), possibly explaining why males account for $61 \%$ of subjects in exercise science research (17). Furthermore, middle-aged women have a high potential for pregnancy, which can make it possibly unsafe for subjects to perform certain procedures, including Dual Energy X-Ray Absorptiometry (DXA) assessments of body composition (18). Pregnancy can also impact physical activity levels and physical function (19), making pregnant women not representative of the overall population of middle-aged women. Finally, researchers often have difficulty sampling middle-aged adults due to time constraints including juggling work with caregiving for children or elderly parents (6). Conversely, young adults are easy to recruit from universities, and older adults are easy to recruit through senior housing, senior organizations, or healthcare providers' offices.

Despite the low volume of research in middle-aged women, research completed in the last decade is beginning to fill in some of the gaps in knowledge. For 
example, the associations between age and physical function, physical activity, and body composition in this population have been investigated $(9,10,20-23)$. The majority of research suggests that, with increased age, middle-aged women experience decreased physical function $(9,20)$, decreased physical activity $(21)$, increased sedentary time (10), and increased subcutaneous and visceral abdominal fat $(22,23)$. Associations between menopausal status and physical function, physical activity, and body composition are less clear, due to lack of research and measurement technique standardization. There are preliminary indications that reduced physical function is associated with menopausal status. Specifically, when controlling for age and a variety of other potential covariates in middle-aged women, self-reported menopausal status is associated with the objective physical function measures of 3 stair ascent time (24), sit-to-stand time (24), and maximal gait velocity (24) as well as the strength outcome of handgrip strength (25-27) and the self-report physical functioning outcome of the 36-Item Short Form Survey (SF-36) physical functioning subscale $(24,28,29)$. However, there are conflicting results, showing that when controlling for age, there are no significant associations between self-report menopausal status and the physical function measures of natural gait velocity $(26,28)$, single-leg stand time (25), and repeated chair stands $(25,26)$. Furthermore, when controlling for age, menopausal status measured using hormonal methods was associated with handgrip strength, but not associated with maximal gait velocity and 6-minute walk test performance (16).

There are also indications that negative changes in body composition like increased visceral abdominal fat $(22,30)$, increased total fat mass (31), and decreased 
lean mass (31) are associated with menopausal status when controlling for age.

However, most research using body mass index (BMI) as a body composition estimate has found no associations with menopausal status when controlling for age $(32,33)$.

Finally, there are preliminary indications that, even when controlling for age, the menopausal transition is associated with reduced physical activity levels when using accelerometry (34). However, other studies have found no association between menopausal status and physical activity that has been self-reported $(16,26)$.

Overall, the findings regarding the associations between menopausal status and physical function, physical activity, and body composition are often inconsistent in their methods and results. Thus, the differences in age, physical function ability, physical activity levels, and body composition among premenopausal, perimenopausal, and postmenopausal women are not well characterized. Furthermore, it is not known to what degree changes in physical function and the associated variables of physical activity and body composition observed during middle-age are related to menopausal status versus chronological age. Therefore, more research is needed to clarify the relationships between menopausal status and physical function, physical activity, and body composition in middle-aged women.

Thus, the primary aim of this study is to describe the differences in age, physical function performance, physical activity, and body composition among premenopausal, perimenopausal, and postmenopausal women. The primary hypothesis is that there will be significant differences in age, physical function, physical activity, and body composition among the three menopausal groups. Specifically, physical activity levels, lean mass, and physical function performance will decrease as women 
progress through the menopausal transition, whereas age and fat mass will increase as women progress through the menopausal transition.

The secondary aim of this study is to examine the strength of the independent associations between menopausal status and chronological age and physical function performance, physical activity, and body composition in middle-aged women. It is hypothesized that compared to chronological age, menopausal status will be more highly associated with physical function performance, physical activity, and body composition in middle-aged women.

Through these aims, this study will build on the existing literature by adding measures of physical function that have been previously unstudied in relation to menopausal status (transfer task, 8-foot up-and-go, 30-second chair stands, and liftand-carry), as well as previously studied measures (6-minute walk test, handgrip strength, and the SF-36 physical functioning subscale) in order to provide a comparison with existing research. Further, it will add to the single study comparing accelerometer-measured physical activity between menopausal groups (34) and will help clarify differences in BMI, fat mass, and lean mass that have exhibited little agreement in previous studies (22,30-33,35-41). Finally, by examining the associations between age and menopausal status with physical function, physical activity, and body composition, this study will help clarify the potential contributors to negative changes in health often seen in middle-age. 


\section{CHAPTER 2}

\section{REVIEW OF LITERATURE}

\section{Introduction:}

Advanced age is associated with many health issues including decreased physical function, decreased physical activity, and poorer body composition; while these are often seen as issues only impacting older adults (those 65 and older), middleage (ages 40-64) may actually be the time in which these factors begin to worsen $(2,3,10,20-22,35)$. Therefore, middle-age may offer an opportunity to prevent or delay detrimental changes in health (6). Middle-age is also a unique physiological time for women as this is when menopause occurs, which, in addition to age, also seems to negatively impact health in many ways, ranging from increased anxiety, depression, fatigue, and lean mass to decreased physical activity, physical function, and fat mass (5). Despite the potential for middle-age to be an optimal time to promote healthy behaviors in women before they worsen during older adulthood (6), women are understudied in exercise science (17). Specifically, there are many gaps and little agreement in the literature regarding the associations between menopausal status and physical function (16,24-29), physical activity $(16,26,34)$, and body composition $(31,42,43)$ in middle-aged women. The following literature review explores the existing evidence regarding the relationships between age, menopausal status, physical function ability, body composition, and physical activity levels. 


\section{Defining Menopausal Status:}

Menopause is the permanent cessation of menstruation, resulting from the loss of ovarian follicular activity, typically beginning around age 45 (15). A variety of characteristic hormonal and physiological changes occur throughout the menopausal transition. Notably, El Khoudary et al. (5) performed a recent review of studies utilizing data from the longitudinal project, the Study of Women's Health Across the Nation (SWAN), following middle-aged women to explore the relationship between menopause and many of its covariates, including hormonal change. They found that decreases in estradiol (E2) start approximately 2 years before the final menstrual period (FMP), and continue for two years afterwards (44). Further, follicle stimulating hormone (FSH) increases from approximately 7 to 2 years before the FMP, with these patterns in hormonal change stable across body composition, race, and age of FMP (44). Driven by these hormonal changes, menstrual cycle length increases over the course of the menopausal transition starting approximately 7.5 years before the FMP and accelerating around 4 years before the FMP, with different trends in menstrual cycle change seen in different races/ethnicities as well as in different ages of menopausal transition onset (45).

Burger et al. (15) offers a more comprehensive exploration of the hormonal changes during menopause, finding a variety of other changes in addition to those discussed above $(44,45)$. Using data from the Melbourne Women's Midlife Health Project, another large longitudinal study following middle-aged women, Burger et al. found that an early hormonal signal of menopause is a decrease in inhibin B and antiMullerian hormone $(\mathrm{AMH})$, leading to the increase in FSH and decrease in E2, as well 
as an increase in luteinizing hormone (LH) and the failure of LH to surge in response to estrogen, which would normally stimulate ovulation (15).

Although age and menopausal status are related, there are a host of other factors associated with the timing of the menopausal transition besides chronological age. For example, when controlling for socioeconomic and health status, later age of the final menstrual period (FMP) is significantly associated with higher level of education, higher weight, past oral contraceptive use, present employment, not smoking, consuming alcohol less frequently, being less physically active, and having better self-reported health, although timing of the FMP is not associated with race/ethnicity (41). Furthermore, studies in Iran (46) and Finland (47) have found that mean age at menopause is increasing over time across the world. Specifically, for Iranian women born in the 1930 's, the mean age of menopause was 48.5 , increasing to 49.9 for women born in the 1950's (46), and in Finland mean age at menopause was 50 in 1997, increasing to 51 in 2007 (47). This indicates that the relationship between age and menopausal status is changing over time, and therefore age is not a standalone predictor of menopausal status and its correlates such as physical function.

Hormonal changes drive a variety of symptoms during the menopausal transition, which can also impact physical function (48). Lovejoy et al. (2008) found that the menopausal transition is associated with negative metabolic changes as it progresses (22). Specifically, when following premenopausal women for 4 years and comparing those who remained premenopausal at follow-up with those who became postmenopausal, both groups experienced decreased energy expenditure during waking hours (daily energy expenditure) and decreased energy expenditure during 
sleep (sleeping energy expenditure); however, these decreases were larger in those that became postmenopausal (9.3\% decrease in daily energy expenditure compared to a $7 \%$ decrease in those that remained premenopausal, and a 7.9\% decrease in sleeping energy expenditure compared to a 5.3\% decreases in those that remained premenopausal), although differences were not significant ( $p>0.05$ ). Additionally, there was a significant decrease in fat oxidation $(32.4 \%, \mathrm{p}<0.05)$ in women who were postmenopausal at follow up, but no significant change (9.8\% decrease, $p>0.05)$ in those remaining premenopausal.

Vasomotor symptoms (hot flashes and night sweats) are also a common symptom during menopause. Vasomotor symptoms were reported by $80 \%$ of SWAN participants (49). This number is impacted by race and ethnicity as well as socioeconomic status, as Black women report worse and more prevalent symptoms than White and Hispanic women, Asian women report the least symptoms, and women of lower socioeconomic status report worse and more symptoms regardless of race (49). Significant associations between the menopausal transition and increases in reported sleep difficulties, depressive symptoms, anxiety, poor cardiovascular health, decreased bone mineral density, and decreased sexual functioning have also been reported by studies examining SWAN data (5).

In addition to physiological factors, researchers have also found that the social determinants of health during menopause impact this transition in middle-aged women (50). Menopause and the loss of youth it signifies are generally seen as negative in western cultures, however, in other countries such as Iran and China, there are more positive perceptions of menopause and these positive attitudes are associated with 
improved quality of life during this transition (50). Notably, the severity of menopausal symptoms and quality of life during menopause can be impacted indirectly by cultural influences on diet, body composition, smoking, and exercise (50). Practicing a religion, increased social support, increased level of education, and being married are also associated with lower severity and improved perceptions of menopausal symptoms, underscoring the impact of women's emotional and mental health on their physical health during middle-age (50). Importantly, menopausal symptoms such as depressive symptoms have been associated with poorer physical function in middle-aged women and therefore might account for some of the differences in physical function observed between menopausal status groups (28).

Menopausal status has a variety of categorizations utilizing different phases and sub-phases. However, menopausal status is most simply divided into premenopausal, perimenopausal, and postmenopausal. Menopausal status can be assessed as a self-report bleeding measure as in this study, or via blood draws looking at FSH and other biomarkers (15). Self-report bleeding measures of menopausal status involve asking women about the frequency and regularity of their menstrual period. This study utilized the SWAN criteria, the most frequently used definition of menopausal stages in existing literature. Like the majority of preexisting literature, this study combined both perimenopausal stages (stages 2 and 3). The SWAN criteria is as follows: stage 1) premenopausal is defined as no change in menstrual bleeding patterns; stage 2) early transition/perimenopause is defined as a change in length of bleeding or the interbleed interval; stage 3) late transition/perimenopause is defined as amenorrhea (no menstrual bleeding) for the last 3-11 months; and stage 4) 
postmenopause, which is divided into natural postmenopause, defined as amenorrhea for the past 12 months not due to hysterectomy (surgical removal of the uterus), and surgical postmenopause, defined as a bilateral oophorectomy (surgical removal of the ovary) with or without hysterectomy (5).

An additional self-report measure of menopausal status is the Staging of Reproductive Aging Workshop (STRAW) criteria, born out of an expert consensus between researchers in predominant studies of menopause and clinicians (51). This criteria uses the same four stages as stated above for the SWAN criteria, with slightly different definitions: premenopause is defined as regular menstrual cycles with no change in cycle length, early transition is defined as a persistent difference of seven or more days in consecutive menstrual cycle, late transition is defined as 2-11 months of amenorrhea, and postmenopause is defined again as no menstrual bleeding for 12 or more months.

Gracia et al. (52) created the PENN-5 criteria, a third definition of menopausal status based on self-reported menstrual bleeding. This criteria adds a fifth stage (late premenopause) to attempt to define more subtle changes seen at the start of menopause. This definition states that premenopause involves regular menstrual cycles with no change in cycle length, late premenopause involves a persistent difference of seven or more days in consecutive menstrual cycle, early transition involves at least two cycle length changes of at least 7 days, late transition involves 311 months of amenorrhea, and postmenopause involves at least 12 months of amenorrhea. This study also found that the new stage of "late premenopause" was associated with a significant drop in inhibin B and a significant rise in $\mathrm{FSH}$, 
suggesting that significant hormonal changes occur early in the menopausal transition, even with very minor changes in cycle length.

Menopausal status can also be defined using hormonal levels, which requires a more invasive approach. A popular method for this involves using an algorithm from the Women's Ischemia Syndrome Evaluation (WISE) study, which uses fasting blood draw measures of E2 and FSH as well as time since last menstrual period (LMP), age, and history of hysterectomy or oophorectomy in a complex algorithm to determine whether a woman is premenopausal, perimenopausal, or postmenopausal (53).

There is little research into the agreement between self-report measures and hormonal measures of menopausal status. However, one study found $76.7 \%$ concordant classification between SWAN and WISE criteria when examining 3,000 middle-aged women, and $72.7 \%$ concordant classification when looking at the same sample five years later (54).

Overall, age is not a standalone predictor of menopausal status, as ANM is changing over time $(46,47)$ and is associated with a variety of socioeconomic and physiologic conditions (41). Further, the symptoms associated with menopause are highly variable due to a variety of socioeconomic and physiologic influences (41), and these symptoms can influence physical function (48). Therefore, it may be prudent to compare the differential impact of menopause and chronological age on indicators of health in middle-aged women, such as physical function performance, physical activity, and body composition. 


\section{Physical Function Performance in Middle-Age: Relationships with Age}

Physical function is an individual's ability to perform basic actions involving strength, mobility, and endurance that are essential for maintaining independence and carrying out more complex activities (1). Adequate physical function ability is often perceived as only important for older adults, however many middle-aged adults experience limitations in physical function $(2,3)$, emphasizing a need to examine these outcomes across the lifespan. It is also important to note that there may be small but statistically significant sex differences in physical functional ability across middle and older age. For example, Gardener et al. (2) surveyed a sample of 11,216 middle-aged (50-64) British adults and found that $19 \%$ of women self-reported a functional limitation in mobility (walking), in this case difficulty walking a quarter of a mile, compared to $18 \%$ of men of the same age.

Similarly, Brown et al. (3) found evidence of physical function limitations in middle-age, with $22 \%$ of 6,874 subjects aged 50-64 developing self-reported limitations in activities of daily living (ADLs), a measure of physical function. The most common ADL impairment reported was difficulty dressing (14\%). This study demonstrated the potential for these functional declines to accelerate with age, but also highlighted the potential for reversing these declines; when a 2 year follow-up was performed after subjects initially reported ADL impairment, 4\% had died, 9\% experienced additional ADL decline, and 50\% had sustained ADL impairment, but $37 \%$ were able to recover functional abilities. Similar patterns were observed with independent activities of daily living, another measure of physical function. 
Most recently, Hartmann Rasmussen et al. (4) suggests that physical function may impact health even at the very beginning of middle-age; a study of 904 45-yearold men and women showed that slower gait speed during a 6-meter walk (a measure of physical function) is associated with markers of poorer cognitive health (such as lower IQ $[\beta 0.23, \mathrm{p}<0.001]$ and smaller brain volume $[\beta 0.10, \mathrm{p}=0.02])$, in addition to accelerated biological aging across multiple organ systems $(\beta-0.27, \mathrm{p}<0.001)$. This indicates that interventions to improve physical function in middle-age may offer both immediate and long-term benefits.

In older adults, it is well established that physical function declines, and that this decline is more pronounced in women than in men $(55,56)$. A survey of nearly 2,000 men and women ages 65 to 74 in five sites across the globe assessed selfreported mobility difficulty (difficulty walking 400m or climbing stairs), self-reported ADL disability (difficulty performing at least one ADL), and the short physical performance battery (SPPB), a set of physical function tasks (12). In four out of five sites, women had significantly higher incidence of mobility difficulties and ADL disabilities, and performed significantly worse on the SPPB compared to men $(\mathrm{p}<0.05$ for all) (12). Even after controlling for age, chronic diseases, education, sufficiency of income, and depressive symptoms, the differences between male and female results remained significant for mobility difficulties.

Leigh et al. (9) examined longitudinal self-report physical function data for over 4,500 women and found four distinct patterns for change in physical function with age in older women (73-90). Physical function was assessed using the self-report SF-36 physical functioning subscale. Physical function groups ranged from poor initial 
physical function worsening further over time, to high initial physical functioning worsening slightly over time. Self-reported exercise level was the strongest predictor of physical function groups (odds ratio for "high" exercisers being in the lowest physical function group compared to the highest was 0.04). All four of these physical function groups experienced significant declines in physical function with time, demonstrating the adverse impact of age on physical function.

In middle-aged women, Ward-Ritacco et al. (20) explored the relationship between physical function and age. In 64 postmenopausal women ages 45 to 65 , age was a significant independent predictor of both 8 -foot up-and-go $(\mathrm{F}=3.47, \mathrm{p}=0.009)$ and 30-second chair stand $(\mathrm{F}=4.95, \mathrm{p}=0.001)$, but not 6-minute walk test performance (p>0.05). Other significant predictors of the 8 -foot up-and-go were muscle quality and leg power, whereas other significant predictors of the 30 -second chair stand were muscle quality and leg strength. Significant predictors of the 6-minute walk test included muscle quality, leg strength, total number of medical conditions, steps per day, and adiposity.

It is clear that declines in physical function impact older adults, however recent research suggests that around one fifth of middle-aged adults are also impacted $(2,3)$. There is a decline in physical function seen with age, including throughout middle-age $(9,10,20)$, and there is evidence that this decline is associated with poorer health (4). Therefore, there is a need to better understand the correlates of physical function in middle-aged women, enabling healthcare professionals to improve physical function and prevent associated adverse health outcomes in this population. 


\section{Objectively Measured Physical Function Performance in Middle-Age:}

\section{Relationships with Menopausal Status}

While physical function clearly declines with age, it is less clear to what degree physical function changes are associated with menopausal status. Additionally, it is not well understood which measures of physical function have an association with which measures of menopausal status. Establishing these associations may provide insight into the causes of decreased physical function often observed during middle-

age in women. Several studies have investigated the associations between menopausal status and objective measures of physical function (16,24-27), with all studies finding at least one significant association between menopausal status and a measure of physical function (most frequently handgrip strength) when controlling for age. Cooper et al. (25) examined the associations between self-reported menopausal status and timing of hysterectomy (surgical menopause) with muscular strength (handgrip strength), balance (single-leg stance time with eyes closed) and physical function (time to complete 10 chair stands) in 1,386 53-year-old British women who were not undergoing hormone replacement therapy (HRT). They found that postmenopausal women had weaker handgrip strength than premenopausal and perimenopausal women $(\mathrm{p}=0.07)$, although this difference was not statistically significant, even when accounting for body size ( $\mathrm{p}=0.12)$. For those who underwent surgical menopause, lower age at hysterectomy was significantly associated with lower grip strength $(\mathrm{p}<0.05)$, even after adjustment for covariates including height and weight at age 53, father's occupational class, head of household occupational class, cognitive function at age 8 , smoking status at age 53 , hormone therapy, and parity at age 53 . There were no 
significant associations between either menopausal status or timing of hysterectomy and chair rise or standing balance time ( $p>0.05)$.

Similarly, Da Câmara et al. (26) explored the relationship between menopausal status and physical function in 389 Brazilian women ages 40 to 65 years. Menopausal status was self-reported according to the STRAW criteria. Muscular strength (handgrip strength) and physical function (a 4-meter walk at the subject's natural pace and time to complete 5 chair stands) were objectively measured. When adjusting for age, premenopausal women had higher handgrip strength $(\mathrm{p}=0.036)$ and faster chair stand times $(\mathrm{p}=0.29)$ compared to perimenopausal and postmenopausal women, but there were no statistically significant differences in gait speed between groups $(\mathrm{p}=0.91)$. However, once additional covariates (socioeconomic status, BMI, walking time per week, sitting time per week, reproductive history, and hypertension) were included, only the difference in grip strength remained significant, with premenopausal women having significantly higher grip strength than postmenopausal women $(\mathrm{p}=0.019)$.

Kurina et al. (27) examined 564 SWAN study participants ages 42-52 at enrollment and at a 3-year follow-up. Menopausal status was defined according to the SWAN criteria. Outcome measures were handgrip strength and pinch strength. Statistical analysis adjusted for age, BMI, income, smoking status, and physical activity level. Compared to women who remained premenopausal at follow-up, women who became postmenopausal by follow-up showed a $1.04 \mathrm{~kg}$ decline in grip strength (although this was not statistically significant, at $\mathrm{p}=0.10$ ) and a $0.57 \mathrm{~kg}$ decline in pinch strength $(\mathrm{p}=0.002)$, women who became early perimenopausal 
showed a $0.20 \mathrm{~kg}$ decline in pinch strength $(\mathrm{p}=0.04)$, and women who transitioned to late perimenopause showed a $0.93 \mathrm{~kg}$ decline in grip strength (although this was not statistically significant, at $\mathrm{p}=0.07)$.

The Estrogenic Regulation of Muscle Apoptosis (ERMA) study by Bondarev et al. (16) used a cross-sectional design to further investigate associations between physical function and menopausal status in 903 Finnish women ages 47 to 55 . Unlike the previous studies, menopausal status was determined with the use of fasting serum samples of FSH levels, in combination with self-reported menstrual cycle regularity according to the STRAW criteria. Handgrip strength and physical function (maximal walking speed over 10 meters and 6-minute walk test distance covered) were measured. After controlling for age, fat mass, height, physical activity, and education, the only significant association found between these variables was that postmenopausal women had lower handgrip strength $(\mathrm{p}<0.001)$ compared to premenopausal women.

As part of the Michigan Bone Health and Metabolism Study, Sowers and Tomey et al. (24) explored the relationship between physical function and menopausal status in 530 middle-aged women (mean age 44.8 44.8 ) as a part of a 5-year longitudinal study. Menopausal status was self-reported using the following stages: premenopausal (10 or more menstrual cycles in the past 12 months), perimenopausal (9 or less menstrual cycles in the past 12 months), and postmenopausal (no menstrual period in the last 12 or more months). Physical function measures included the SF-36 physical functioning subscale, 40-foot brisk walk velocity, timed 3-stair ascent, and time to stand from being seated in a chair. Handgrip strength was also assessed. 
Controlling for age, BMI, and smoking status, women who underwent natural menopause had significantly poorer hand grip strength $(p<0.0005)$, walk velocity $(\mathrm{p}<0.05)$, and SF-36 physical functioning scores $(\mathrm{p}<0.05)$ compared to women who were premenopausal and women who were perimenopausal at the 5-year follow-up. With the same control variables, women who underwent menopause surgically with hormone replacement or ovary conservation had significantly poorer walk velocity $(\mathrm{p}<0.05)$, SF-36 physical functioning scores $(\mathrm{p}<0.01)$, chair stand time $(\mathrm{p}<0.01)$, and stair ascent time $(p<0.01)$ compared to premenopausal and perimenopausal women. Again with the same control variables, women who underwent menopause surgically without hormone replacement also had significantly poorer walk velocity $(\mathrm{p}<0.05)$, SF-36 physical functioning scores $(\mathrm{p}<0.01)$, chair stand time $(\mathrm{p}<0.01)$, and stair ascent time $(\mathrm{p}<0.01)$ compared to premenopausal and perimenopausal women. These findings indicate that, regardless of whether menopause occurs naturally or surgically and regardless of hormone replacement or ovary conservation, physical function tends to be worse in postmenopausal women compared to premenopausal and perimenopausal women.

The findings from these studies (16,24-27) indicate that perhaps muscular strength as measured by hand grip strength may be the first physiological factor to change as a result of menopause. This change in muscular capacity may occur first and over time, resulting in the changes in balance and physical function that are observed in some of these studies. The present study looks at handgrip strength and a variety of objective physical function tasks, and may aid our understanding of whether or not 
changes in handgrip strength occur in tandem with changes in physical function performance over the menopausal transition.

\section{Subjectively Measured Physical Function Performance in Middle-Age:}

\section{Relationships with Menopausal Status}

The present study also incorporates a subjective (self-reported) measure of physical function in order to compare results with objective measures of physical function. Several studies have explored only subjective measures of physical function and their association with menopausal status $(28,29)$. In 2012 , Tseng et al. performed a cross sectional analysis using data from the longitudinal SWAN study (28). 2,236 women ages 45 to 57 self-reported menopausal status according to the SWAN criteria and completed the SF-36. Physical function limitation was defined as "substantial" (SF-36 physical functioning subscale scores of 50 or below), "moderate" (scores of 51-85), and "none" (scores of 86-100). The association between menopausal status and self-reported physical function was assessed while controlling for age, ethnicity, research site, education, BMI, diabetes, hypertension, arthritis, depressive symptoms, smoking, and hormone use. Postmenopausal women were over three times more likely to have substantial functional limitations compared to premenopausal and perimenopausal women, regardless of whether menopause was natural (odds ratio = 3.82, $\mathrm{p}<0.05$ ) or surgical (odds ratio $=3.54, \mathrm{p}<0.05$ ). However, moderate limitations in physical function were not associated with menopausal status, as the odds ratio of moderate limitations compared to premenopausal and perimenopausal women was 1.62 in naturally postmenopausal women and 1.09 in surgically menopausal women (both $\mathrm{p}>0.05$ ). 
In 2014, El Khoudary et al. (29) performed a longitudinal study that examined the associations between menopausal status and subjective physical function in 2,495 women ages 45 to 57 years. Physical function limitations were defined as by Tseng et al. ("none", "moderate", and "substantial", based on SF-36 physical functioning subscale scores) (28) and menopausal status was self-reported according to the SWAN criteria. This study had a median follow-up time of 9.7 years, and data was collected an average of 4.3 times per person. The study also assessed 24-hour fasting hormone levels, including serum testosterone (T), E2, and serum hormone-binding globulin (SHBG). Analyses were controlled for age, race, research site, economic status, comorbid conditions, final BMI, final physical activity level, and changes in BMI and physical activity. The odds of having a substantial functional limitation compared to having no or some limitation were significantly higher in late perimenopausal women, naturally postmenopausal women, surgically postmenopausal women, and hormoneusing/status unknown women compared to premenopausal and early perimenopausal women (all $\mathrm{p}<0.05)$. Further, lower E2 at visit 4 and less reduction in E2 and T from visit 4 to visit 12 were significantly associated with lower odds of reporting any functional limitations $(\mathrm{p}<0.05)$. Finally, a greater increase in SHBG from visit 4 to visit 12 was associated with greater odds of any functional limitations $(p<0.05)$.

Based on this evidence $(28,29)$, there seems to be a significant association between the SF-36 physical functioning subscale and menopausal status, with postmenopausal women self-reporting worse and more functional limitations compared to premenopausal and perimenopausal women, regardless of whether menopause was natural or surgical. However, there is little research comparing both 
subjective and objective measurements of physical function in relationship to menopausal status, which is a gap in literature the present study addresses.

\section{Objectively Measured Physical Function Performance in Middle-Age:}

\section{Relationships with Age at Menopause}

Beyond being associated with menopausal status, it is possible that physical function is associated with age at menopause. It is important to understand this association, as it may influence the associations between menopausal status and physical function. There are few studies available examining the associations between the age at which menopause occurs and physical function performance (57-59). Velez and Rosendaal et al. (57) assessed the age at natural menopause (ANM) and physical function in 775 older women (ages 65 to 74) who underwent natural menopause in Albania, Colombia, Brazil and Canada. ANM was self-reported as the age of the final menstrual period (FMP) and divided into 5 categories: <40, 40-44, 45-49, 50-54, and $\geq 55$ years. Handgrip strength and physical function (3-meter or 4-meter gait speed) were measured. When adjusting for age, years of education, income, height, BMI, hormone replacement therapy, postmenopausal hysterectomy, smoking status, and childhood economic and social adversity, with ANM 50-54 as the reference group, those with $A N M \geq 55$ had a significantly higher gait speed $(p=0.005)$, but not a significantly different handgrip strength $(\mathrm{p}=0.493)$. Additionally, those with ANM <40 had a significantly worse handgrip strength than those with ANM 50-54 ( $\mathrm{p}=0.001)$.

Velez and Alvarado et. al (58) similarly studied ANM and physical function in 9,920 naturally postmenopausal women aged 45-85 at baseline, using the Canadian Longitudinal Study on Aging. Handgrip strength and 4-meter walk velocity were 
assessed, and analyses controlled for education, BMI, hormone replacement, smoking status, age, and study site. With ANM 50-54 as a reference, women with ANM <40 had a significantly slower gait speed $(\mathrm{p}<0.001)$ and lower grip strength $(\mathrm{p}=0.042)$, while women with $A N M \geq 55$ had a significantly faster gait speed $(p=0.001)$ and a significantly higher grip strength $(\mathrm{p}<0.001)$.

Finally, Tom et al. (59) assessed 1,765 women from the United States aged $\geq 60$ using cross-sectional data from National Health and Nutrition Examination Survey (NHANES) III (59). ANM was again self-reported as the age of the FMP, and divided into 4 categories: $<45,45-49,50-54$, and $\geq 55$. Objective physical function measures included walking speed at a natural pace over 8 feet and time to complete 5 chair stands. Subjective physical function limitation was defined as having selfreported difficulties in three or more of the following: walking a quarter mile; walking up 10 steps; stooping, crouching, or kneeling; lifting and carrying up to 10 pounds; and standing up from an armless chair. After controlling for age, race/ethnicity, height, weight, education, smoking status, number of children, and use of estrogen therapy, higher ANM was associated with higher walking speed $(\mathrm{p}<0.01)$, while there were no significant associations between ANM and chair rise time $(\mathrm{p}=0.79)$ or ANM and selfreported functional limitation $(\mathrm{p}=0.06)$. While the latter was not statistically significant, these results suggest that later ANM is associated with lower chances of self-reported functional limitation.

Considering these studies together, some evidence supports a significant association between age at menopausal onset and objective measures of physical function performance (with lower age of onset being associated to poorer physical 
function performance in a variety of measures, most often gait speed) (57-59).

However, this association that has not been thoroughly explored, and it would benefit from further analysis.

\section{Physical Activity: Relationships with Age}

Physical activity (PA) can be defined as any movement produced by the body that results in a significant increase in caloric expenditure above resting levels (60). It is clear that with age, including across middle-age, physical activity tends to decline (21) and sedentary time tends to increase (10). This has negative implications for physical functioning, as it is well established that, in middle-aged and older women, worse physical function performance is associated with lower physical activity levels $(8,10,11,16,20,22,27,61-63)$ and increased sedentary time (10).

\section{Physical Activity: Relationships with Menopausal Status}

Since physical function performance is associated with physical activity level in middle-aged women $(10,61)$, it is important to discuss how physical activity levels might change during the menopausal transition. However, independent of age, the association between menopausal status and physical activity is poorly established $(16,26,34)$. Bondarev et al. (16) explored this relationship in 903 Finnish women ages 47-55, with menopausal status determined by combination of hormonal levels and the self-reported STRAW criteria. A self-report 7-point physical activity scale was subdivided into "low", "moderate", and "high" scores. This study found no significant association between physical activity level and menopausal status $(\mathrm{p}=0.227)$. However, a limitation of this study was that no confounding variables were identified and controlled for in the analysis. 
Da Câmara et al. (26) also found no significant relationship between menopausal status and physical activity level in 389 middle-aged Brazilian women (40-65). Menopausal status was self-reported according to the STRAW criteria. Physical activity level was self-reported as the total time per week subjects walked for at least 10 minutes without stopping, with results dichotomized as being $<90$ minutes per week and $\geq 90$ minutes per week. Sedentary time was assessed as self-reported time sitting per day and dichotomized into $<4$ hours per day and $\geq 4$ hours per day. No significant associations were found between menopausal status and sedentary time $(\mathrm{p}=0.642)$ or physical activity $(\mathrm{p}=0.305)$.

In contrast, Duval et al. (34) found a significant association between menopausal status and certain measures of physical activity when examining 102 premenopausal middle-aged women followed for 5 years. Menopausal status was selfreported and verified with FSH levels. Categories were defined as "premenopausal" (no changes in the menstrual cycle frequency), "menstrual transition" (irregular cycles with variable cycle length $>7$ days different from normal and/or 2 skipped cycles and an interval of 60 days of amenorrhea), or "postmenopausal" (FMP over 12 months ago, with FSH levels >30 IU/L). All subjects were verified to be premenopausal at baseline, and menopausal status was re-assessed at the 5-year follow-up. Physical activity level was assessed via accelerometer, which recorded daily energy expenditure from PA and time spent in sedentary and moderate PA. They found that time spent in moderate physical activity decreased over the menopausal transition until the onset of menopause, with the only significant year-to-year difference being that women 2 years prior to their FMP had a significantly higher level of moderate PA per 
week than women at the year of their FMP $(\mathrm{p}<0.05)$. Additionally, time spent in sedentary physical activity increased across the menopausal transition throughout postmenopause, with the year before the FMP having significantly lower sedentary time than the year of the FMP, and the year after the FMP having significantly higher sedentary time than the year of the FMP (all p<0.05). No significant associations were found between menopausal status and daily energy expenditure from PA. The results found by Duval (34) contrast those found by Bondarev (16) and Da Câmara (26), possibly because the latter two studies did not control for covariates that may have muted any associations between menopausal status and physical activity.

A major problem with research in this area is that physical activity levels are self-reported in two of the three studies $(16,26)$, which may lead to errors, as adults tend to overreport both time and intensity of exercise, with women providing a larger overestimation of their physical activity compared to men $(64,65)$. Additional research is needed to support the accuracy of the one study relating menopausal status to accelerometer-measured physical activity (34), which the present study seeks to address.

\section{Body Composition: Relationships with Age and Menopausal Status}

Body composition has an impact on many areas of health, including physical function performance, and aging is associated with changes in body composition (66). Increases in subcutaneous fat and visceral abdominal fat are seen with increased age in middle-aged women (22) and in women throughout the lifespan (23), while lean mass has been shown to decrease with age in middle-aged women (35). 
Poorer performance on physical function measures in middle-aged and older women is associated with higher adiposity (20), lower lean mass (20), lower leg mineral-free lean mass (MFLM) (67), higher body weight to MFLM ratio (67), higher visceral fat (22), poorer muscle quality (62), and increased relative adiposity (62). Thus, it is important to understand changes in body composition with menopausal status. Unlike physical activity and physical function, there is a large volume of research describing differences in body composition between menopausal status groups $(31,42,43)$, although there is little agreement between studies. In the past 5 years, two review articles have compiled the literature regarding this association $(42,43)$.

The first review article by Al-Safi et al. (42) described the associations between menopausal status and body composition and found that the associations between body mass and FMP are inconsistent. A number of studies reported that indirect estimates of poorer body composition such as higher BMI/weight gain were associated with later age at natural menopause (68), while other studies reported no significant associations (69). Furthermore, Al-Safi found that menopausal status is significantly associated with weight gain in four studies $(32,33,36,37)$, but only two of these studies found this association to be significantly independent of age $(33,37)$. When examining body composition with a highly valid direct measure (computed tomography, or CT), visceral and total body fat increased only throughout postmenopause, while subcutaneous adipose increased with age across menopausal stages, indicating that possible differences in fat distribution may occur along the menopausal spectrum (22). Al-Safi et al.'s review (42) also found that many studies 
were able to attribute a large amount of the weight gain across the menopausal transition to a reduction in energy expenditure seen during menopause, which is attributed to a combination of decreased physical activity and hormonal change associated with the menopausal transition (22). This underscores the importance of acknowledging the interactive relationships between body composition and lifestyle behaviors, including physical activity.

Karvonen-Gutierrez et al. (43) provided a second review assessing the associations between menopausal status and body composition. This review also found evidence linking obesity to a later age at FMP, specifically when looking at studies using indirect measures of body composition. The majority of the cross-sectional studies analyzed found strong evidence for the association between a later FMP and better body composition via indirect measures such as BMI and weight (38). Conversely, most longitudinal studies found weak (39) to no (41) association using such measures; this may be due to inaccuracies in recalling BMI in longitudinal designs, or may suggest that this relationship is not strong. This review also provides more information looking at direct measurements of body composition, providing multiple studies using DXA (22,30), CT (30), and magnetic resonance imaging (MRI) (30) to reinforce the fact that women have relatively more subcutaneous abdominal fat prior to the FMP and relatively more visceral abdominal fat after the FMP, reflecting increased central body fat distribution. Further, this review reports multiple studies finding a significant association between later menopausal phase and decreased lean muscle mass using DXA (40) and bioelectrical impedance analysis (BIA) (35). 
Greendale et al. (31) builds on these findings with a longitudinal assessment of 1,246 premenopausal SWAN study participants with mean age 46.66 at baseline. Data was collected annually, with a mean of 10 visits and a maximum of 13 . Menopausal status was self-reported according to the SWAN criteria, FMP was self-reported, weight was measured via scale, and body composition was measured via DXA (specifically reporting total fat mass and total lean mass). Fat mass and lean mass were found to both increase significantly prior to the start of menopause (1.0\% per year with $\mathrm{p}<0.0001$, and $0.2 \%$ per year with $\mathrm{p}=0.0002$, respectively). At the start of menopause (approximately 2 years prior to the FMP), rate of fat gain doubled and significant lean mass loss occurred, with both of these trends decelerating approximately 1.5 years after the FMP but still continuing until 2 years after the FMP. Overall values for change during the menopausal transition are a $1.7 \%$ increase in total fat mass per year $(\mathrm{p}<0.0001)$ and a $0.2 \%$ loss in total lean pass per year $(\mathrm{p}=0.007)$. After the FMP, both fat mass gain and lean mass loss decelerated to a zero slope (i.e. no changes over time) ( $\mathrm{p} \geq 0.1$ for both). Contrastingly, weight and BMI increased linearly prior to and throughout the menopausal transition $(0.3 \%$ and $0.4 \%$ per year respectively, both with $\mathrm{p}<0.0001$ ), with accelerations approximately 1 year before the FMP, decelerations approximately 3 years after the FMP, and stability after menopause. This study underscores the potential oversimplification of using indirect measurements of body composition (such as weight or BMI) to assess changes during menopause and may provide some explanation of the conflicting results seen with the studies using these measures in the previously mentioned review articles. 
Despite there being a large volume of research on the relationship between menopausal status and body composition, it is still difficult to decipher to what degree the changes in body composition seen in middle-age women are primarily driven by menopause, aging, or other related lifestyle/behavioral factors. Based on present evidence, it seems that increases in weight (i.e. increases in BMI) seen during menopause may be more strongly associated with age than menopausal status, since BMI is associated with menopausal status (36), but rarely when age is controlled for (37). On the other hand, changes in fat distribution and lean mass (observed with direct measurements like DXA, CT, and MRI) may be more strongly associated with menopause, as increased visceral abdominal fat $(22,30,31)$ and decreased lean mass $(28,58,69)$ have been shown with advancing menopausal phase, even when controlling for age. A major limitation of the current research in this area is that the most common methods of describing body composition are indirect estimates (such as BMI and waist-to-hip-ratio) and not direct measurement techniques (such as DXA), which would likely produce more accurate and descriptive results and may change the observed trends.

\section{Conclusion:}

Middle-aged women are understudied in general, and there is especially little agreement on the associations between menopausal status and physical function,

physical activity, and body composition. From existing literature, there is preliminary evidence associating more advanced menopausal status with poorer physical function (16,24-29), lower physical activity (34), and poorer body composition $(22,30,31,35,40)$ in middle-aged women. 
However, it is difficult to make conclusions about these associations because there is little commonality in measurement techniques in existing literature. Each variable has a number of options for measurement: menopausal status can be selfreported by the SWAN, STRAW, or PENN-5 criteria, or measured with blood levels of hormones such as through the WISE criteria; physical function can use self-report measures like the SF-36 physical functioning subscale or objective tasks such as the 6minute walk test; physical activity can be self-reported with questionnaires or objectively measured via accelerometry; body composition can be estimated with indirect measurements such as BMI or directly measured with tools like DXA. Thus, it is possible that only certain measures of physical function, physical activity, and body composition are sensitive enough to detect significant differences between menopausal status groups, whereas others are not.

Despite these difficulties, it is important to further investigate differences in physical function, physical activity, and body composition between menopausal status groups in order to better understand the health of women at all stages of the menopausal transition. Middle-age may offer an important time frame to improve or slow the progression of any negative changes in physical function, physical activity, and body composition before they tend to decline at a more rapid rate in older adulthood (6). Thus, a better understanding of any negative changes during middle-age may help to optimize prevention and treatment during this period of life, ideally leading to improved health in middle-age that continues into older adulthood.

The present study clarifies and adds to existing literature by incorporating physical function tasks that have been previously unstudied in association with 
menopausal status (transfer task, 8-foot up-and-go, 30-second chair stand, and lift-andcarry), as well as incorporating physical function measures that have been studied in association with menopausal status (6-minute walk test, handgrip strength, and the SF36 physical functioning subscale) to allow for comparison with existing literature.

Further, it adds to the understanding of associations between menopausal status and accelerometer-measured physical activity and adds to the equivocal evidence base examining menopausal status and its association with fat mass and lean mass. 


\section{CHAPTER 3}

\section{METHODOLOGY}

\section{Participants}

A convenience sample was recruited on a rolling basis from 2016 to 2019 via flyers posted at the University of Rhode Island and in the local community, social media posts, and word of mouth. Eligibility criteria required participants to be middleaged (40-64 yr), English-speaking women living independently, with BMI values below $45.0 \mathrm{~kg} / \mathrm{m}^{2}$ (the capacity of the DXA scanner in this study). Subjects were excluded if they were currently smoking (or quit in the past 6 months), were pregnant, had any diseases or conditions preventing safe study participation, or experienced weight change of over five pounds in the past three months. Participants also had to be willing to wear an accelerometer for a seven to ten- day period and participate in a DXA scan. All study procedures were approved by the University's Institutional Review Board (IRB) in October 2016 (board reference number HU1516-206) and all participants signed an IRB approved informed consent form prior to enrollment in the study.

\section{Procedures}

Interested participants completed an online eligibility survey to determine if they met basic inclusion criteria. If inclusion criteria were met, these individuals were contacted via email to schedule two visits to the Human Performance Laboratory at the University of Rhode Island's Independence Square building. Visits were separated 
by seven to ten days. During the first visit, participants provided written informed consent, and completed the Physical Activity Readiness Questionnaire (PAR-Q) and the Mini-Mental State Exam. Additionally, self-reported menopausal status, chronological age, and muscular strength and physical function measures were assessed during visit 1. Participants were then provided with an accelerometer to wear for seven to ten days and were given a physical activity log.

Visit 2 was conducted seven to ten days after visit 1 , to allow for the collection of objectively measured physical activity data via accelerometry, medical history, and quality of life. During visit 2, accelerometers were returned, and physical activity logs were reviewed with participants for any necessary clarification. Further, DXA scans and measures of muscular capacity assessments were performed during visit 2.

\section{Menopausal Status Assessment}

Menopausal status was self-reported utilizing the SWAN criteria but combined postmenopausal stages (stages 3 and 4), as is the norm in much of present literature (5). The SWAN criteria is as follows: stage 1) pre-menopausal was defined as no change in menstrual bleeding patterns; stage 2) early transition/peri-menopause was defined as a change in length of bleeding or the interbleed interval; stage 3) late transition/peri-menopause was defined as no menstrual bleeding (amenorrhea) in the last 3-11 months; and stage 4) post-menopause, which was divided into natural postmenopause, defined as no bleeding in the past 12 months not due to hysterectomy (surgical removal of the uterus), and surgical post-menopause, defined as a bilateral oophorectomy (surgical removal of the ovary) with or without hysterectomy (5). 


\section{Chronological Age Assessment}

Birth date was self-reported and used to determine chronological age.

\section{Body Composition Assessment}

Weight in kg was obtained via a calibrated digital scale (Tanita WB-100,

Arlington Heights, IL) and standing height in $\mathrm{cm}$ was obtained via a stadiometer (Seca 213, Chino, CA). BMI was computed with the formula BMI = (weight in $\mathrm{kg}) /($ height in $\mathrm{m}^{2}$ ). DXA scans were performed by a trained professional using a GE Lunar iDXA (Waukesha, WI). Fat mass (FM) and mineral-free lean mass (MFLM) were obtained according to manufacturer's guidelines and converted into percentages.

\section{Physical Activity Assessment}

Physical activity level was measured via ActiGraph accelerometers (Actigraph GT9XLink, Pensacola, FL) between visits 1 and 2 (seven to ten days). Physical activity was quantified by average steps per day (steps/day), average minutes spent in moderate and vigorous physical activity per day (MVPA/day), and average minutes spent in low, moderate and vigorous activity per day (LMVPA/day). Physical activity logs were also completed by participants on the days they wore the accelerometer and compared to accelerometer data to ensure accuracy. To be included in the final data analysis, participants needed at least 4 valid wear days (a day with at least ten hours of confirmed wear). This data was analyzed via the accompanying ActiLife software.

\section{Objective Measures of Physical Function}

All objective physical function measures were performed by trained personnel following standardized scripts and using standardized equipment. At least two minutes of rest were provided between each task. Further, participants were permitted to 
complete a second trial of any functional tasks they chose if they thought they could improve upon their first trial.

- Transfer task (TRANSFER): The participant began in a standing position on a mat. On the command "go", the participant sat down on the mat and returned to a standing position in whatever manner they chose as quickly as possible. Total time was recorded (70).

- 8-foot up-and-go (UPGO): The participant began seated in an armless chair with its back placed against a stable surface such as a wall. On the command "go", the participant stood up and walked around a small plastic cone placed 8feet from the chair and returned to a seated position in the chair as quickly as possible. Total time was recorded (71).

- 30-second chair stands (STAND): The participant began seated in an armless chair with its back placed against a stable surface such as a wall. On the command "go", the participant rose to a standing position using only the legs, keeping her arms crossed across her chest. The participant proceeded to return to a fully seated (i.e. buttocks contacting the chair) position and then fully standing position as many times as possible in 30 seconds. Total number of full touches between buttock and chair was recorded (72).

- 6-minute walk test (6MWT): The participant began in a standing position at the end of a preset course a known distance apart (30 feet). On the command "go", the participant walked as quickly as possible, performing laps back and forth over the preset course in order to cover as much distance as possible in 6 minutes. The participant was instructed to pace herself in order to be able to 
continue walking the entire time, but termination and/or rest breaks were allowed at any point. The total distance covered (the distance of each pass $\mathrm{x}$ the total number of passes + the distance of the final partial pass) was recorded (73).

- Lift and carry (LIFT): The participant began in a standing position at the end of a preset 20-foot course. A milk crate was placed next to the participant containing $10 \mathrm{lbs}$. At the other end of the course, a shelf of standard height (51.5 inches tall) was placed against a wall. On the command "go", the participant lifted the crate using proper lifting technique, walked over the shelf, placed the crate on the shelf, fully released her grip on it, picked the crate back up, returned to the starting position, put the crate down, and fully released her grip on it. The participant completed 5 repetitions of this sequence. Total time was recorded.

- Lower extremity physical function composite score (LEPF-CS): Z scores for the four lower extremity physical function tasks (transfer task, 8-foot up-andgo, 30-second chair stands, and 6-minute walk test) were computed using SPSS statistical analysis software. Z scores in which a lower score reflected better physical function (transfer task and 8-foot up-and-go) were reverse scored by taking the inverse of the $\mathrm{Z}$ score. Then, all four $\mathrm{Z}$ scores were totaled to form the lower extremity physical function composite score.

\section{Subjective Measure of Physical Function}

The RAND 36-Item Short Form Survey (SF-36) was used to measure healthrelated quality of life and perceived physical function was assessed using the physical 
functioning subscale of the SF-36 (SF-36 PF). This subscale contains ten items that assess an individual's perception of their ability to be physically active and complete activities of daily living on a 3-point Likert scale (yes, limited a lot; yes, limited a little; and no, not limited at all) $(74,75)$. Previous literature has consistently found an association between menopausal status and this subscale $(24,28,29)$, and thus it was included to compare the results of this study with previous literature on the topic.

\section{Muscular Strength Assessment}

Muscular strength was estimated via hand grip dynamometry (Jamar Technologies Hydraulic Hand Dynamometer, Bolingbrook, IL). Maximal handgrip strength was tested twice bilaterally according to manufacturer instructions. The average value for the right and left hands were computed and summed for an overall handgrip score (HGS).

\section{Statistical Analysis}

SPSS statistical software version 26.0 for Windows (IBM Corp, Armonk, NY) was utilized to perform all data analysis. All data was assessed for normal distribution; outliers in outcome variables (defined as data points falling outside of 3 standard deviations from the mean) were excluded from the study. Next, descriptive statistics were calculated for the total sample as well as for each menopausal group. A multivariate analysis of covariance (MANCOVA) and subsequent post hoc analysis were used to analyze differences among these groups, with age and total number of chronic medical conditions as control variables. Finally, linear multiple regression analysis examined chronological age as an independent predictor of body composition 
(\% fat), physical activity, and physical function, while controlling for total number of chronic medical conditions. 


\section{CHAPTER 4}

\section{FINDINGS}

180 middle-aged women were screened for participation in this study. Eleven were deemed ineligible for reasons including, being a smoker (2), not living independently (1), BMI too large or not weight stable (7), or severe musculoskeletal disorder (1). Thirty-eight did not respond to follow-up contact, leaving 131 eligible participants. Four declined participation, therefore 127 scheduled visit 1 . Four subjects chose not to attend and one did not complete visit 1 due to severe hypertension. Two declined scheduling visit 2 due to the time commitment, therefore 120 completed visit 2. Thirteen subjects were excluded from data analysis because of missing data (10) or representing outliers 3 or more standard deviations outside of the mean on measures of physical function (3). Thus, 107 participants were included in the final data analysis.

Table 1 shows participant characteristics for the entire sample $(n=107)$ and Table 2 shows participant characteristics by menopausal status group (premenopausal $n=22$, perimenopausal $n=24$, and postmenopausal $n=61$ ). The sample was $98.13 \%$ white. On average, participants had $3.04 \pm 2.50$ significant chronic conditions and regularly took $1.02 \pm 1.30$ prescription medications and $1.33 \pm 2.20$ over-the-counter medications. The sample was overweight (BMI of 25 to $<30 \mathrm{~kg} / \mathrm{m}^{2}$ ) (60) with a mean BMI of $26.31 \pm 5.11 \mathrm{~kg} / \mathrm{m}^{2}$. Mean percent fat was $38.04 \pm 8.06 \%$, which fell into the "very poor" classification of percent fat using the American College of Sports Medicine's recommendations for women of their age ( $\geq 33.4 \%$ for women $40-49$ and 
$\geq 34.9 \%$ for women 50-59) (60). However, the sample's percent fat was lower than United States population norms (39.2\% for women ages 40-49, $41.7 \%$ for women ages 50-59, and 42.4\% for women ages 60-69) (76).

When assessing physical activity levels, $78.5 \%$ of the sample met the required four complete wear days (10 hours or more) for the accelerometer. Average wear time was $6.18 \pm 1.06$ complete days per person. Only $25.23 \%$ of participants met the recommended 10,000 steps per day (77) and 42.99\% achieved an average of at least 30 minutes of moderate to vigorous activity per day.

Figures 2a-2h display MANCOVA findings examining differences in body composition, physical activity level, and physical function between menopausal status groups. Controlling for age and total number of chronic medical conditions, no statistically significant differences between menopausal status groups were found for any of the outcome variables. As there were no significant between-group differences found in the MANCOVA, post hoc analysis was not performed. ANOVA found that age was significantly different between each menopausal status group $(\mathrm{p} \leq 0.001$ for all comparisons).

Tables $3 \mathrm{a}$ and $3 \mathrm{~b}$ provide results from multiple linear regression analysis assessing the independent associations of age and menopausal status with body composition, physical activity level, and measures of physical function when controlling for total number of chronic medical conditions. Age was independently associated with TRANSFER ( $\mathrm{p}=0.015$ ), explaining $11.1 \%$ of the variability in TRANSFER when chronic medical conditions were held constant. The overall model using age and menopausal status as predictors of TRANSFER, while controlling for 
chronic medical conditions, was significant as well $(\mathrm{p}=0.001)$, although menopausal status was not independently associated with TRANSFER ( $\mathrm{p}=0.876$ ). Similarly, age was independent associated with HGS ( $\mathrm{p}=0.002$ ), explaining $14.7 \%$ of the variability in HGS when chronic medical conditions were held constant. The overall model was significant as well $(\mathrm{p}=0.001)$, although menopausal status was not a significant independent predictor of HGS ( $\mathrm{p}=0.500$ ). Menopausal status and age were not significant predictors of any other outcome variables, and no other models achieved overall significance $(\mathrm{p}<0.05)$.

Tables $4 \mathrm{a}-4 \mathrm{c}$ report correlations between study variables for premenopausal, perimenopausal, and postmenopausal women when controlling for age, BMI, and total number of chronic medical conditions. Correlations between study variables vary greatly when comparing menopausal status groups. For example, the correlations between measures of body composition and physical activity is stronger for premenopausal women (Table 4a) and postmenopausal women (Table 4c) compared to perimenopausal women (Table 4b). Specifically, the correlation $(r)$ between steps per day and fat mass $\%$ is -0.322 in premenopausal women, -0.121 in perimenopausal women, and -0.313 in postmenopausal women. Similarly, the correlation $(r)$ between MVPA per day and fat mass $\%$ is -0.359 in premenopausal women, -0.191 in perimenopausal women, and -0.299 in postmenopausal women. Also of note is that the correlation between the lower extremity physical function composite score and body composition (percent fat) is stronger in premenopausal women $(r=-0.351)$ and postmenopausal women ( $r=-0.265)$ compared to perimenopausal women $(r=0.039)$, although correlations with individual functional tasks is more variable. 
Interestingly, which measure of physical activity is most strongly associated with the lower extremity physical function composite score varies by menopausal status; in premenopausal and postmenopausal women it is MVPA/day ( $r=0.421$ and 0.361 , respectively), while in perimenopausal women it is LMVPA/day (i.e. total PA per day; $r=0.628)$. Relationships between individual measures of physical function and physical activity is also highly variable between menopausal status groups, with mean correlations between all measures of physical activity (steps/day, MVPA/day, and LMVPA/day) and all measures of physical function (transfer task time, 8-foot up-andgo time, 30-second chair stand repetitions, 6-minute walk test distance, lower extremity physical function composite score, SF-36 physical functioning subscale, and handgrip strength) being close to 0 for all groups ( $r=0.108$ for premenopausal, 0.042 for perimenopausal, and -0.004 for postmenopausal). High variability in these results indicate that the associations between study variables vary with different phases of the menopausal transition, with perimenopausal women often exhibiting weaker associations compared to premenopausal and postmenopausal women. 


\section{CHAPTER 5}

\section{CONCLUSION}

The present study explores: (1) the differences in age, physical function performance, and physical activity among menopausal status groups, and (2) the strength of the associations between age, menopausal status, physical function

performance, physical activity, and body composition in middle-aged women. Middleaged women are often underrepresented in research for a variety of reasons including hormonal fluctuations $(5,16)$ and pregnancy $(18,19)$. Therefore, this study builds on the understanding of these associations in an understudied population using both standard measures in the existing literature and measures of physical function that have not been previously tested in association with menopausal status. Further, this study seeks to describe differences in correlates of physical function between menopausal status groups that have been rarely (physical activity) or inconsistently (body composition) reported using the sophisticated measurement techniques of accelerometry and DXA

The results of this study refute the primary hypothesis that there would be significant differences in physical function, physical activity, and body composition between menopausal status groups, as the only significant difference found between menopausal status groups was age. Similarly, the results of this study refute the secondary hypothesis. Overall, in contrast to what has been seen in previous studies $(16,26,27), \mathrm{R}^{2}$ and $\beta$ values were low, indicating that, in this sample, total number of 
chronic medical conditions, age, and menopausal status were generally poor predictors of physical function, physical activity, and body composition. Specifically, menopausal status was not significantly and independently associated with any measures of physical function, physical activity, or body composition when controlling for total number of chronic medical conditions. With the same control variables, age was significantly and independently associated with transfer task and handgrip strength performance.

The null findings in this study may be a result of the fact that the study participants exhibited somewhat higher physical function, higher physical activity, and more optimal body composition compared to population norms and results from similar studies. Specifically, the present study's participants reported higher mean SF36 physical functioning subscale scores (94.71) compared to a mean score of 85.3 found in a study of 506 middle-aged women (24). Additionally, a study of 1,862 middle-aged adults found a mean of 6,801 steps per day (78) compared to a mean of 8,256 steps per day in this study and a study of 962 middle-aged women found a mean of 29.2 minutes of MVPA per day (79) compared to 32.2 minutes of MVPA per day in the present investigation. Furthermore, $\%$ fat was lower in this study (37.8\%) compared to population norms for women in United States (39.2\% for ages 40-49, $41.7 \%$ for ages $50-59$, and $42.4 \%$ for ages $60-69$ ) (76). Thus, the present sample appears healthier in these variables compared to the general population of middle-aged women in the US, which may account for why the study results overall disagreed with existing research in this area. 
This study's findings that there are no associations between menopausal status and physical function conflict with much of the existing body of literature. Sowers and Tomey et al. (24) demonstrated that, when controlling for age, BMI, and smoking behavior, self-reported menopausal status was associated with the objective physical function measures of 3-stair ascent time, sit-to-stand time, and maximal gait velocity, as well as self-report perceived physical functioning using the SF-36. A possible reason why the present study's findings conflict with those of Sowers and Tomey et al. (28) is that the two investigations used different measures of objective physical functioning; it is possible that some measures of objective physical functioning may be more sensitive to change during the menopausal transition. Furthermore, the study by Sowers and Tomey et al. (24) followed a 5-year longitudinal design and it is feasible that longitudinal designs are optimal for identifying changes across the menopausal transition, compared to a cross-sectional approach. Importantly, Sowers and Tomey et al. (24) also used their own definition of menopausal status stages, as opposed to the more established SWAN criteria, which may also impact their results.

Also in contrast with the present findings, a cross-sectional study by Tseng et al. (28) and a longitudinal study by El Khoudary et al. (29) found significant associations between menopausal status and the SF-36 physical functioning subscale when controlling for age, with poorer self-perceived function in those who were further along in the menopausal transition. While these studies used the SWAN criteria for defining menopausal status, they both had a much larger sample size $(n=2236$ and $n=2495$, respectively) than the current investigation $(n=107)(28,29)$. 
Larger sample sizes may help ensure the sample is more representative of the selected population.

Previous work done in London and Brazil $(25,26)$ found significant associations between menopausal status and the strength outcome of handgrip strength when controlling for age. Therefore, findings related to our outcomes of interest may be region/location specific and may only be generalizable to middle-aged women from these areas. Both of these studies also used alternative measurements of menopausal status to the SWAN criteria $(25,26)$, which may have contributed to differences in results. Kurina et al. (27) also found that associations between menopausal status and grip strength in women in the United States were present but non-significant. This study used the SWAN criteria, although it was longitudinal, which may account for differences in results compared to the present study.

While the majority of pre-existing literature shows association between menopausal status and physical function when controlling for age $(24-27,29)$, several available studies agree with the results of the present investigation and have found no significant associations between these outcomes $(25,26,28)$. For example, Tseng et al. (28) found that natural gait velocity was not significantly associated with menopausal status when controlling for age in women in the United States. Cooper et al. (25) found that 30-second single-leg stand time and repeated chair stand performance were not significantly associated with menopausal status when controlling for age. Additionally, Da Câmara et al. (26) found that natural gait velocity and repeated chair stands were not associated with menopausal status when controlling for age, in a cross-sectional study that used a chair stand task similar to the present study's 30- 
second chair stand task. It is possible that there are no significant differences in physical function among menopausal status groups, but it is also possible that the objective measures of physical function utilized in these studies $(25,26)$ and the present study are not sensitive enough to detect smaller differences in physical function that may exist between menopausal status groups. In regards to physical activity, the present results align with cross-sectional studies using self-report physical activity $(16,26)$, but contrast with a longitudinal study using accelerometer-measured physical activity (34). It is possible that study design accounts for these conflicting results, as cross-sectional studies may be less representative of individuals' true physical activity behaviors over time compared to longitudinal studies. The crosssectional nature of the present study may also be a limitation in that we are unable to make any conclusions about causality.

The present study's findings that there are no associations between menopausal status and body composition when controlling for age agree with existing literature on BMI $(33,37,42,43)$, but disagree with previous work examining body fat and lean mass $(22,30,31,35,40)$. The majority existing studies support that weight gain (i.e. increased BMI) is not associated with menopausal status when controlling for age $(33,37)$. In contrast, negative changes in body fat distribution (i.e. increases in visceral abdominal fat) $(22,30,31)$ and decreased lean mass $(31,35,40)$ have been consistently associated with menopausal status when controlling for age. In three studies assessing US women with the SWAN criteria, DXA measurements, and longitudinal designs, the menopausal transition was associated with increased visceral abdominal fat $(22,31)$, increased subcutaneous fat (22), increased total fat (35), decreased lean mass 
(49), and decreased skeletal muscle mass (35), when controlling for age. Two cross sectional studies using alternative methods to define menopausal status similarly found the menopausal transition to be associated with increased visceral abdominal fat (30) and decreased lean mass (40) when controlling for age.

The present study did not demonstrate a between-group difference in physical activity, unlike a prior study (34). As physical activity has been shown to be associated with improved physical function and body composition in middle-aged women (11), it is possible that elevated physical activity levels in the present sample are responsible for combatting any adverse effects of age or menopausal status on physical function and body composition in the current cohort. Furthermore, the strength of the association between physical activity and other study variables, including percent fat and physical function outcomes, vary greatly between menopausal status groups, indicating that these relationships may vary in strength across the menopausal transition. Specifically, it appears that physical function measures are least associated with body composition and physical activity measures in perimenopausal women and most strongly associated with body composition and physical activity in premenopausal women, indicating that perhaps an unconsidered variable is responsible for variability in physical function in these groups.

All studies have limitations. First, many of the variables in the present study are highly associated with each other. For example, in middle-aged women, physical function is associated with both physical activity and body composition (11), and body composition and physical activity are associated with each other $(20,22,62,67)$. Age and menopausal status were also highly positively correlated in this study $(\mathrm{r}=0.78$, 
$\mathrm{p} \leq 0.001)$. Due to these interrelations, it is difficult to differentiate individual relationships. Furthermore, this study might be limited by the fact that it uses selfreport menopausal status as opposed to blood-draw hormonal determinants. Adding blood-draw hormonal levels would provide a method of validating self-report menopausal status and may also provide an explanation for mechanisms of any observed changes in physical function, physical activity, and body composition over the menopausal transition (5). Additionally, as with all studies, results of the present study are only generalizable to populations similar to the study sample: communitydwelling, non-smoking women ages 40-64 who were free of orthopedic or other health conditions preventing safe study participation. Notably, 98.13 percent of this sample was Caucasian. It is also possible that the sample selected is not representative of the true population it was attempting to represent. This study was advertised as an opportunity for middle-aged women to learn more about their present physical activity levels, physical function, and body composition; it is therefore possible that women less interested in their physical health self-selected out of this study, whereas more active women were more interested in learning about these characteristics. A final potential limitation of this study is its relatively small sample size. Larger sample sizes may be more representative of the actual population of non-smoking middle-aged women, which might provide a more accurate picture of physical function and its correlates in this population.

In conclusion, more research is still needed to help clarify the associations between age, menopausal status, physical function, physical activity, and body composition in middle-aged women. The present study supports that there are 
significant associations between age and two outcome measures: transfer task time and handgrip strength. It is possible that the true associations between age and menopausal status and the outcome measures of physical function, physical activity, and body composition are weak to nonexistent, and that other factors are responsible for variability in these outcome measures. However, it is also possible that the limitations in this study have prevented the observation of significant associations. Future studies would optimally be longitudinal in nature in order to monitor these variables over the menopausal transition. Other measures of physical function such as maximal gait velocity and 3-stair ascent time (24) should also be incorporated, as it is possible that some measures of physical function are more sensitive to change and therefore, more strongly associated with menopausal status than others. This research will help us better understand the causes and correlates of physical function in middle aged women. In turn, this understanding will help guide interventions to improve the physical function limitations observed in approximately one fifth of middle aged women $(2,3)$, and could prevent the decline in physical functioning that accelerates during older adulthood (9). 


\section{TABLES}

Table 1. Participant demographics $(\mathrm{n}=107)$

\begin{tabular}{lll}
\hline Variable & Mean \pm SD & Range \\
\hline Age $(\mathrm{y})$ & $53.31 \pm 6.14$ & $40-64$ \\
Height $(\mathrm{cm})$ & $163.35 \pm 5.51$ & $150.60-177.60$ \\
Weight $(\mathrm{kg})$ & $69.71 \pm 14.48$ & $44.30-118.30$ \\
BMI $\left(\mathrm{kg} / \mathrm{m}^{2}\right)$ & $26.09 \pm 5.11$ & $17.63-42.93$ \\
FM $(\%)$ & $37.77 \pm 8.06$ & $18.99-55.84$ \\
MFLM $(\%)$ & $62.23 \pm 8.06$ & $44.16-81.01$ \\
Steps/day & $8256.65 \pm 3321.90$ & $3275.40-20301.83$ \\
MVPA/day (min) & $32.16 \pm 24.49$ & $2.00-113.14$ \\
LMVPA/day (min) & $329.37 \pm 75.65$ & $170.00-609.00$ \\
TRANSFER time (s) & $3.81 \pm 0.99$ & $1.53-6.75$ \\
UPGO time (s) & $5.24 \pm 0.85$ & $2.38-7.37$ \\
STAND repetitions (reps) & $20.23 \pm 5.35$ & $10.00-38.00$ \\
6MWT distance (m) & $576.03 \pm 67.49$ & $429.30-734.31$ \\
LIFT time (s) & $57.99 \pm 9.48$ & $38.84-80.66$ \\
LEPF-CS & $0.10 \pm 2.92$ & $-5.99-8.34$ \\
SF-36 PF & $94.71 \pm 7.66$ & $65.00-100.00$ \\
HGS (kg) & $53.31 \pm 12.53$ & $18.00-90.00$
\end{tabular}

BMI = body mass index; FM = fat mass; MFLM = mineral-free lean mass; Steps/day $=$ average number of steps per day; MVPA/day $=$ average minutes of moderate + vigorous physical activity per day; LMVPA/day $=$ average minutes of light + moderate + vigorous physical activity; TRANSFER $=$ transfer task; UPGO $=8$-foot up-and-go; STAND = 30-second chair stands; $6 \mathrm{MWT}=6$-minute walk test; LIFT = lift and carry; LEPF-CS = lower extremity physical function composite score; SF-36 $\mathrm{PF}=$ Short Form 36 physical functioning subscale; HGS = average right + average left handgrip strength 


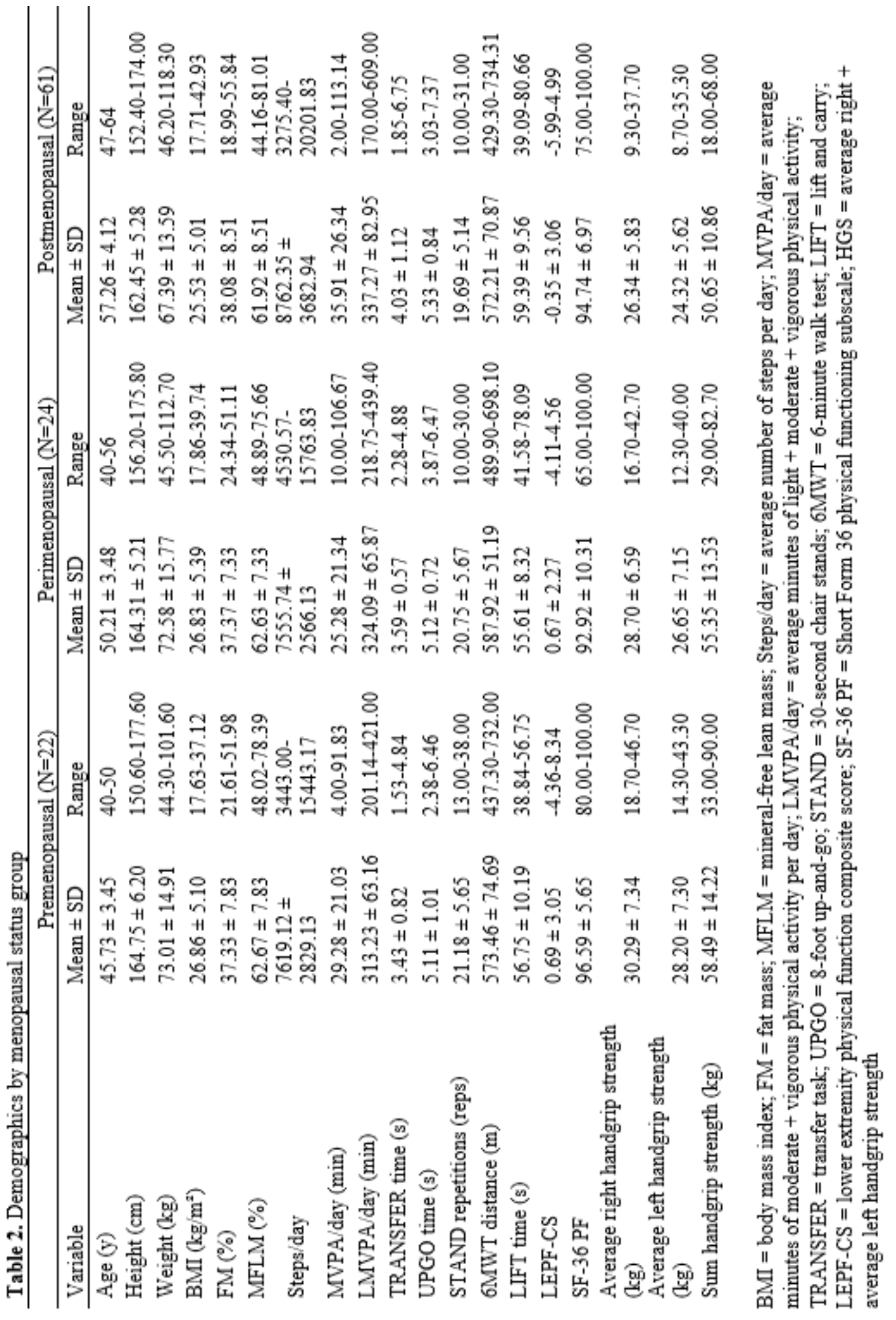


Table 3a. Multiple regression for body composition and physical activity

\begin{tabular}{lcccccc}
\hline \multicolumn{1}{c}{ Variables } & $\mathrm{B}$ & $\mathrm{SEB}$ & $\mathrm{p}$ & $\beta$ & $95 \% \mathrm{CI}$ & $\mathrm{R}^{2}$ \\
\hline Medical Conditions & 0.03 & 0.02 & 0.147 & 0.14 & {$[-.01,0.8]$} & $0.019^{\mathrm{a}}$ \\
Age & -0.02 & 0.01 & 0.139 & -0.23 & {$[-0.05,0.01]$} & $0.043^{\mathrm{b}}$ \\
Menopausal Status & 0.07 & 0.11 & 0.542 & 0.09 & {$[-0.15,0.28]$} & $0.047^{\mathrm{c}}$ \\
\hline \multicolumn{7}{c}{ (b) Fat mass $\left(\mathrm{R}^{2}=0.011, \mathrm{p}=0.757\right)$} \\
Medical Conditions & 0.25 & 0.32 & 0.430 & 0.08 & {$[-0.38,0.88]$} & $0.006^{\mathrm{a}}$ \\
Age & -0.13 & 0.21 & 0.543 & -0.10 & {$[-0.53,0.28]$} & $0.006^{\mathrm{b}}$ \\
Menopausal Status & 1.15 & 1.56 & 0.465 & 0.11 & {$[-1.95,4.24]$} & $0.011^{\mathrm{c}}$ \\
\hline
\end{tabular}

(c) Mineral-free lean mass $\left(\mathrm{R}^{2}=0.011, \mathrm{p}=0.757\right)$

\begin{tabular}{lcccccc}
\hline Medical Conditions & -0.25 & 0.32 & 0.430 & -0.08 & {$[-0.88,0.38]$} & $0.006^{\mathrm{a}}$ \\
Age & 0.13 & 0.21 & 0.543 & 0.10 & {$[-0.28,0.53]$} & $0.006^{\mathrm{b}}$ \\
Menopausal Status & -1.15 & 1.56 & 0.465 & -0.11 & {$[-4.24,1.95]$} & $0.022^{\mathrm{c}}$ \\
\hline
\end{tabular}

(d) Total steps per day $\left(\mathrm{R}^{2}=0.033, \mathrm{p}=0.322\right)$

\begin{tabular}{lcccccc}
\hline Medical Conditions & -117.81 & 129.03 & 0.363 & -0.09 & {$[-373.70,138.09]$} & $0.007^{\mathrm{a}}$ \\
Age & 14.15 & 83.49 & 0.866 & 0.03 & {$[-151.44,179.74]$} & $0.025^{\mathrm{b}}$ \\
Menopausal Status & 576.22 & 636.36 & 0.367 & 0.14 & {$[-685.85,1838.29]$} & $0.033^{\mathrm{c}}$ \\
\hline
\end{tabular}

(e) Moderate and vigorous PA per day $\left(\mathrm{R}^{2}=0.049, \mathrm{p}=0.157\right)$

\begin{tabular}{lcccccc}
\hline Medical Conditions & -1.67 & 0.94 & 0.079 & -0.17 & {$[-3.55,0.20]$} & $0.019^{\mathrm{a}}$ \\
Age & -0.14 & 0.61 & 0.819 & -0.04 & {$[-1.35,1.07]$} & $0.019^{\mathrm{b}}$ \\
Menopausal Status & 5.19 & 4.65 & 0.268 & 0.17 & {$[-4.04,14.41]$} & $0.021^{\mathrm{c}}$ \\
\hline \multicolumn{6}{c}{ (f) Light, moderate, and vigorous PA per day $\left(\mathrm{R}^{2}=0.017, \mathrm{p}=0.614\right)$} \\
\hline Medical Conditions & -0.08 & 2.96 & 0.978 & 0.00 & {$[-5.96,5.79]$} & $0.000^{\mathrm{a}}$ \\
Age & 0.42 & 1.92 & 0.826 & 0.03 & {$[-3.38,4.23]$} & $0.013^{\mathrm{b}}$ \\
Menopausal Status & 9.66 & 14.61 & 0.510 & 0.10 & {$[-19.31,38.64]$} & $0.017^{\mathrm{c}}$ \\
\hline
\end{tabular}

$\mathrm{B}=$ unstandardized regression coefficient SEB $=$ coefficients standard error; $\beta=$ standardized regression coefficient

$* \mathrm{p} \leq 0.05$

$* * \mathrm{p} \leq 0.001$

${ }^{a}$ value for a model using chronic medical conditions as an independent variable

${ }^{\mathrm{b}}$ value for a model using chronic medical conditions and age as independent variables

${ }^{c}$ value for a model using chronic medical conditions, age, and menopausal status as independent variables 
Table 3b. Multiple regression for physical function and strength

\begin{tabular}{lcccccc}
\hline \multicolumn{1}{c}{ Variables } & $\mathrm{B}$ & $\mathrm{SEB}$ & $\mathrm{p}$ & $\beta$ & $95 \% \mathrm{CI}$ & $\mathrm{R}^{2}$ \\
\hline & $\mathrm{g})$ & Transfer task time $\left(\mathrm{R}^{2}=0.14, \mathrm{p}=0.001^{* *}\right)$ & & \\
\hline Medical Conditions & 0.06 & 0.04 & 0.126 & 0.14 & {$[-0.02,0.13]$} & $0.012^{\mathrm{a}}$ \\
Age & 0.06 & 0.02 & $0.015^{*}$ & 0.36 & {$[0.01,0.10]$} & $0.123^{\mathrm{b}}$ \\
Menopausal Status & -0.03 & 0.18 & 0.876 & -0.02 & {$[-0.38,0.33]$} & $0.115^{\mathrm{c}}$ \\
\hline
\end{tabular}

\begin{tabular}{lcccccc}
\multicolumn{7}{c}{ (h) 8-foot up-and-go time $\left(\mathrm{R}^{2}=0.040, \mathrm{p}=0.235\right)$} \\
\hline Medical Conditions & 0.05 & 0.03 & 0.141 & 0.14 & {$[-0.02,0.11]$} & $0.012^{\mathrm{a}}$ \\
Age & 0.02 & 0.02 & 0.415 & 0.13 & {$[-0.03,0.06]$} & $0.022^{\mathrm{b}}$ \\
Menopausal Status & 0.02 & 0.16 & 0.919 & 0.02 & {$[-0.31,0.34]$} & $0.012^{\mathrm{c}}$ \\
\hline
\end{tabular}

\begin{tabular}{lcccccc}
\hline \multicolumn{7}{c}{ (i) 30 -second chair stands $\left(\mathrm{R}^{2}=0.030, \mathrm{p}=0.363\right)$} \\
\hline Medical Conditions & -0.17 & 0.21 & 0.422 & -0.08 & {$[[-0.58,0.25]$} & $0.006^{\mathrm{a}}$ \\
Age & -0.14 & 0.14 & 0.298 & -0.16 & {$[-0.41,0.13]$} & $0.03^{\mathrm{b}}$ \\
Menopausal Status & 0.06 & 1.03 & 0.953 & 0.01 & {$[-1.98,2.10]$} & $0.03^{\mathrm{c}}$ \\
\hline \multicolumn{7}{c}{ (j) 6-minute walk test distance $\left(\mathrm{R}^{2}=0.022, \mathrm{p}=0.512\right)$} \\
\hline Medical Conditions & -3.91 & 2.64 & 0.141 & -0.15 & {$[-9.14,1.32]$} & $0.21^{\mathrm{a}}$ \\
Age & -0.23 & 1.71 & 0.893 & -0.02 & {$[-3.61,3.15]$} & $0.022^{\mathrm{b}}$ \\
Menopausal Status & -0.90 & 13.02 & 0.945 & -0.01 & {$[-26.72,24.92]$} & $0.022^{\mathrm{c}}$ \\
\hline \multicolumn{7}{c}{ (k) Lift and carry time $\left(\mathrm{R}^{2}=0.059, \mathrm{p}=0.099\right)$} \\
\hline Medical Conditions & 0.44 & 0.36 & 0.232 & 0.12 & {$[-0.28,1.16]$} & $0.014^{\mathrm{a}}$ \\
Age & 0.40 & 0.24 & 0.091 & 0.26 & {$[-0.07,0.87]$} & $0.058^{\mathrm{b}}$ \\
Menopausal Status & -0.79 & 1.80 & 0.662 & -0.07 & {$[-4.35,2.78]$} & $0.059^{\mathrm{c}}$ \\
\hline \multicolumn{7}{c}{ (1) Lower extremity physical function composite score $\left(\mathrm{R}^{2}=0.069, \mathrm{p}=0.063\right)$} \\
\hline Medical Conditions & -0.18 & 0.11 & 0.112 & -0.15 & {$[-0.40,0.04]$} & $0.015^{\mathrm{a}}$ \\
Age & -0.11 & 0.07 & 0.150 & -0.22 & {$[-0.25,0.04]$} & $0.051^{\mathrm{b}}$ \\
Menopausal Status & 0.05 & 0.55 & 0.932 & 0.01 & {$[-1.05,1.14]$} & $0.042^{\mathrm{c}}$ \\
\hline
\end{tabular}

(m) SF-36 physical functioning subscale $\left(\mathrm{R}^{2}=0.035, \mathrm{p}=0.311\right)$

\begin{tabular}{lllllll}
\hline Medical Conditions & -0.56 & 0.31 & 0.076 & -0.18 & {$[-1.17,0.06]$} & $0.031^{\mathrm{a}}$ \\
Age & -0.02 & 0.19 & 0.912 & -0.02 & {$[-0.41,0.36]$} & $0.034^{\mathrm{b}}$ \\
Menopausal Status & -0.47 & 1.47 & 0.749 & -0.05 & {$[-3.38,2.44]$} & $0.035^{\mathrm{c}}$ \\
\hline
\end{tabular}

\begin{tabular}{lcccccc}
\hline \multicolumn{7}{c}{ (n) Handgrip strength $\left(\mathrm{R}^{2}=0.157, \mathrm{p}=0.001^{* *}\right)$} \\
\hline Medical Conditions & 0.41 & 0.45 & 0.368 & 0.08 & {$[-0.49,1.31]$} & $0.006^{\mathrm{a}}$ \\
Age & -0.94 & 0.29 & $0.002^{*}$ & -0.46 & {$[-1.52,-0.36]$} & $0.153^{\mathrm{b}}$ \\
Menopausal Status & 1.52 & 2.24 & 0.500 & 0.10 & {$[-2.93,5.96]$} & $0.157^{\mathrm{c}}$ \\
\hline
\end{tabular}

$\mathrm{B}=$ unstandardized regression coefficient SEB $=$ coefficients standard error; $\beta=$ standardized regression coefficient

$* \mathrm{p} \leq 0.05$

$* * p \leq 0.001$

${ }^{a}$ value for a model using chronic medical conditions as an independent variable

${ }^{\mathrm{b}}$ value for a model using chronic medical conditions and age as independent variables

${ }^{\mathrm{c}}$ value for a model using chronic medical conditions, age, and menopausal status as independent variables 


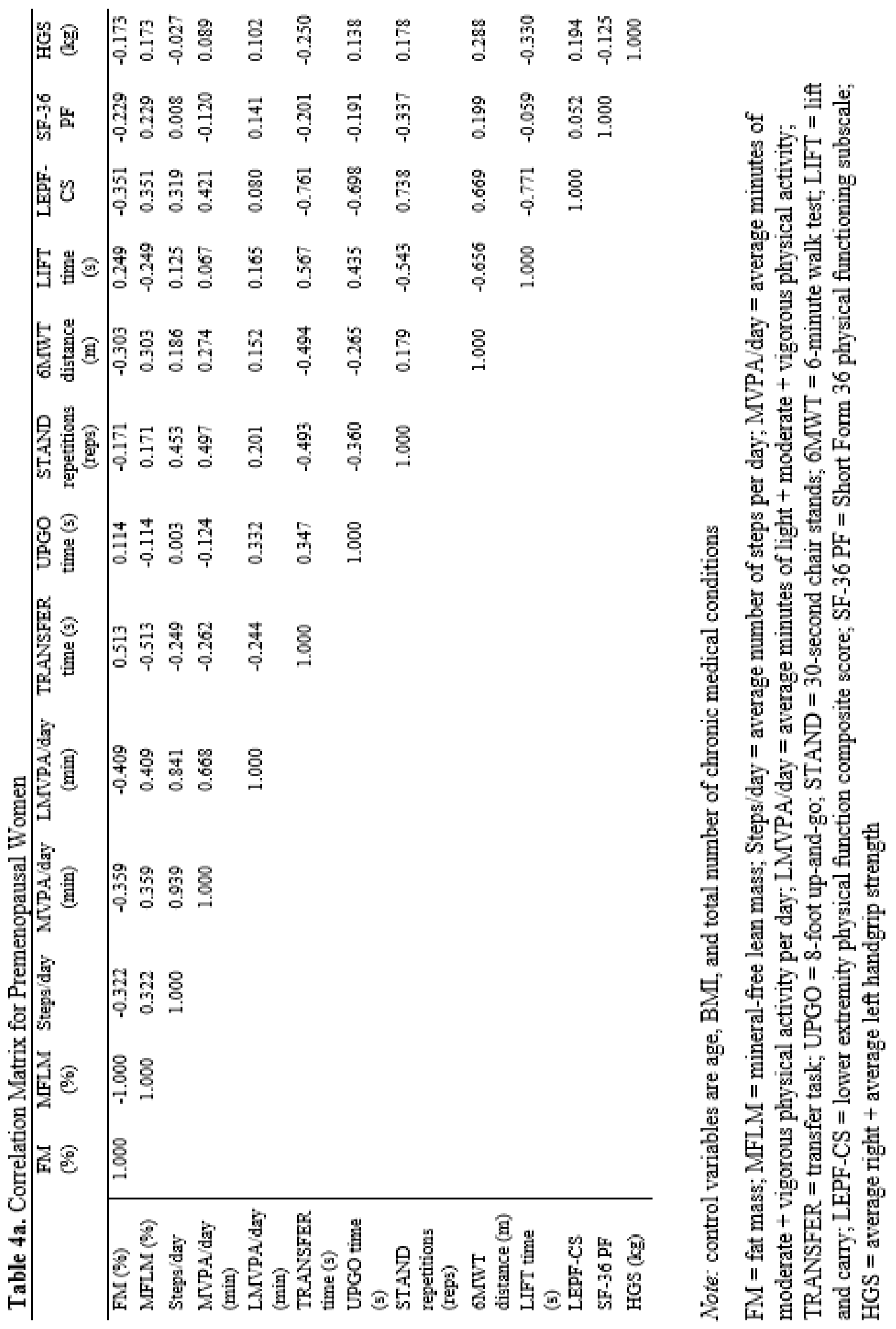




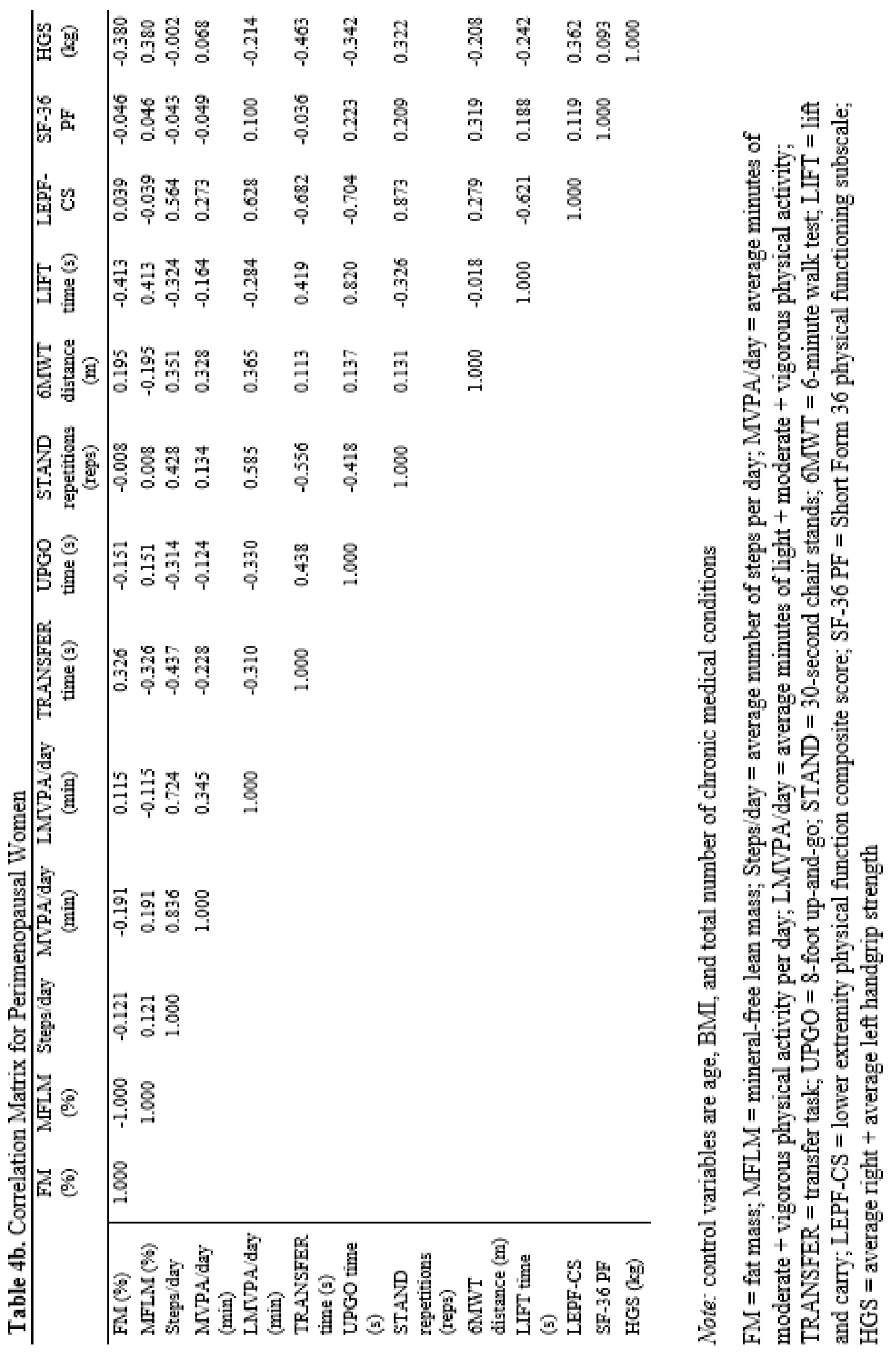




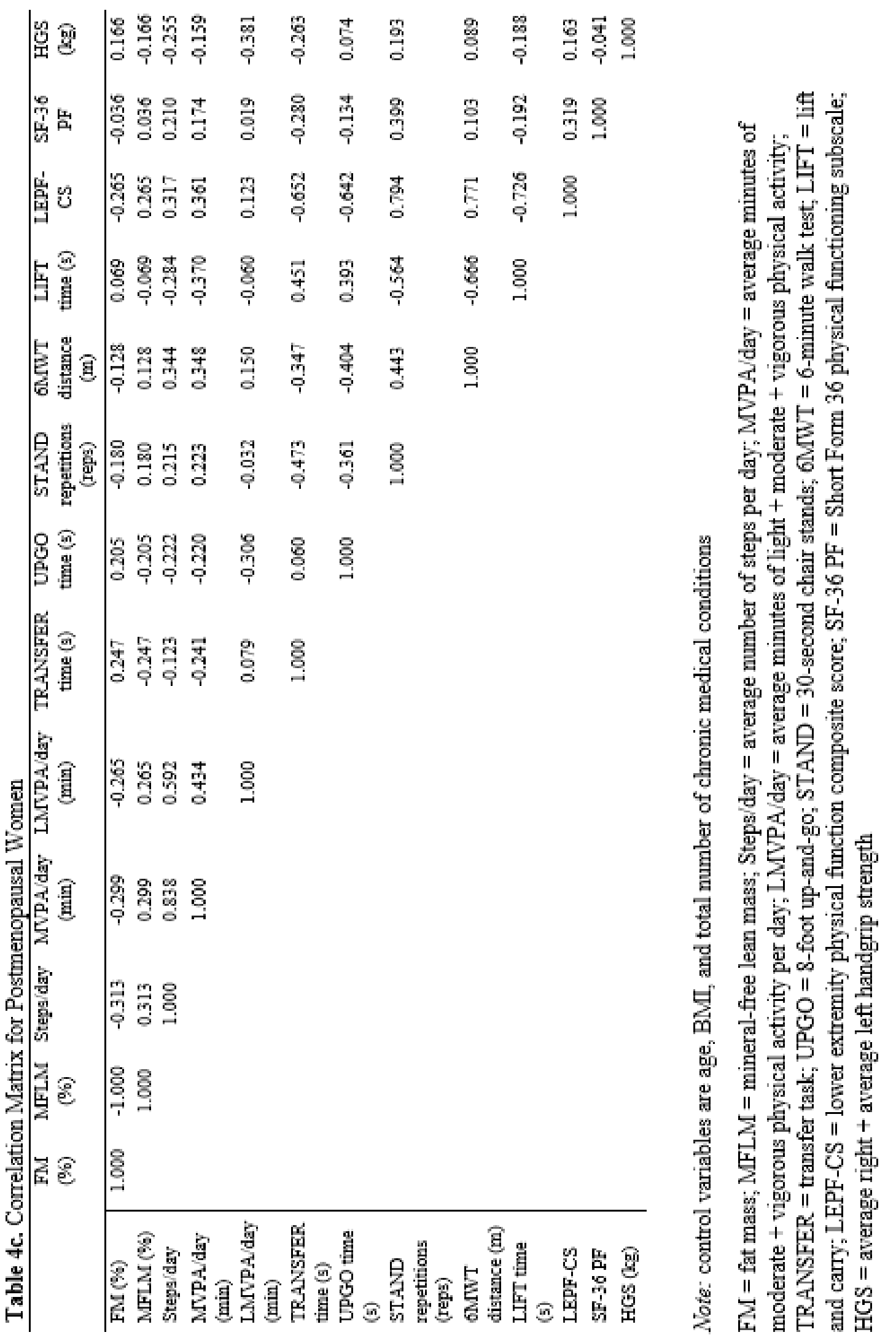




\section{FIGURES}

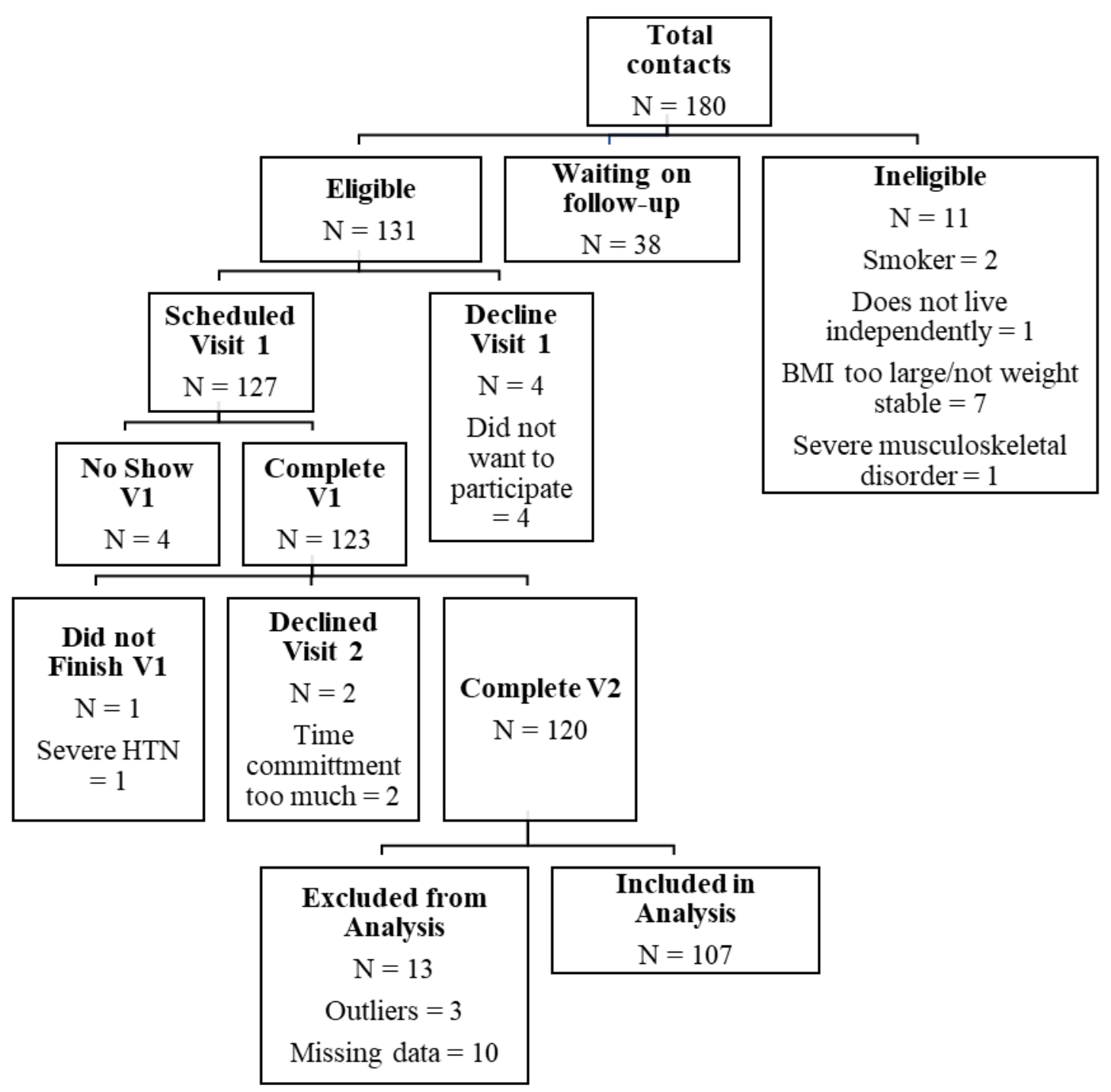

Figure 1. Study flow chart 


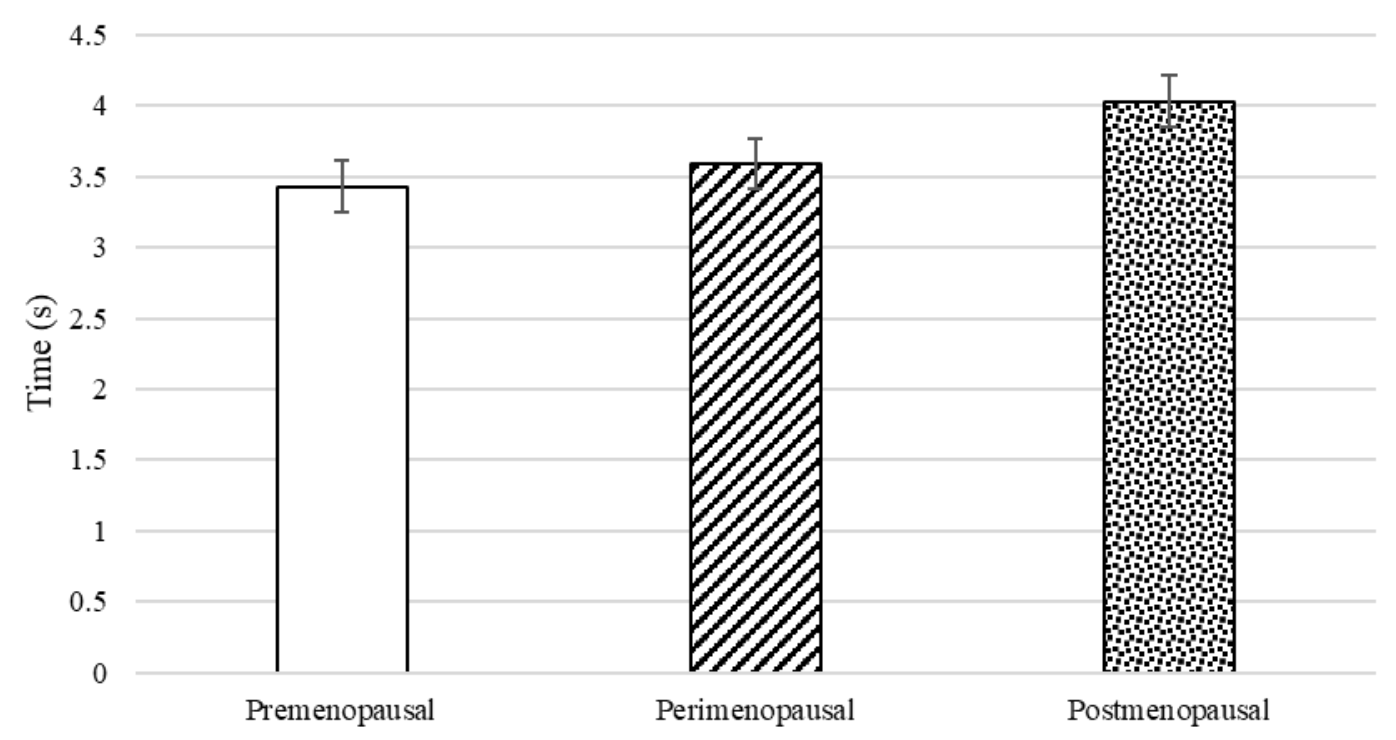

Figure 2a. Transfer task performance by menopausal status

Data shown as mean $\pm \mathrm{SE}$ 


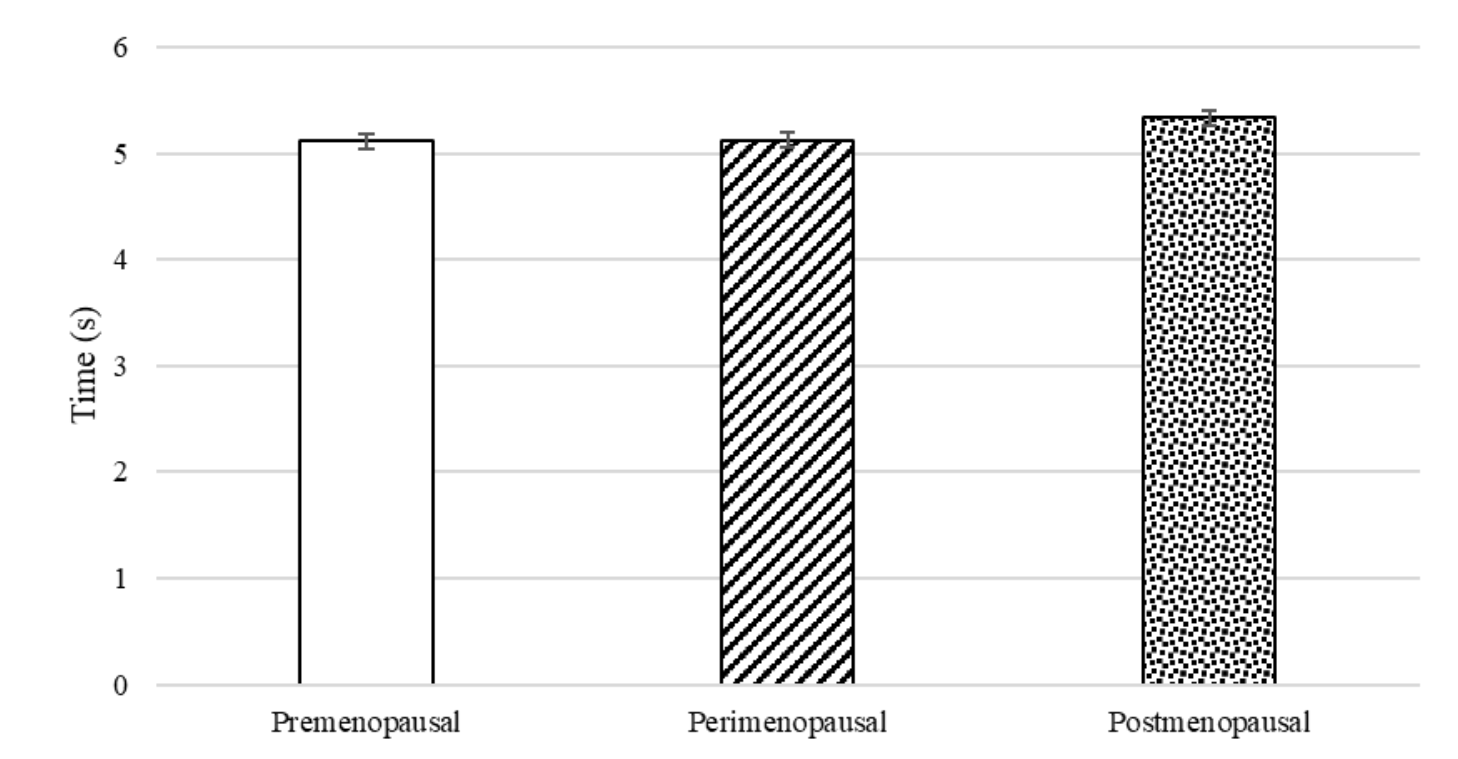

Figure 2b. 8-foot up-and-go performance by menopausal status

Data shown as mean $\pm \mathrm{SE}$ 


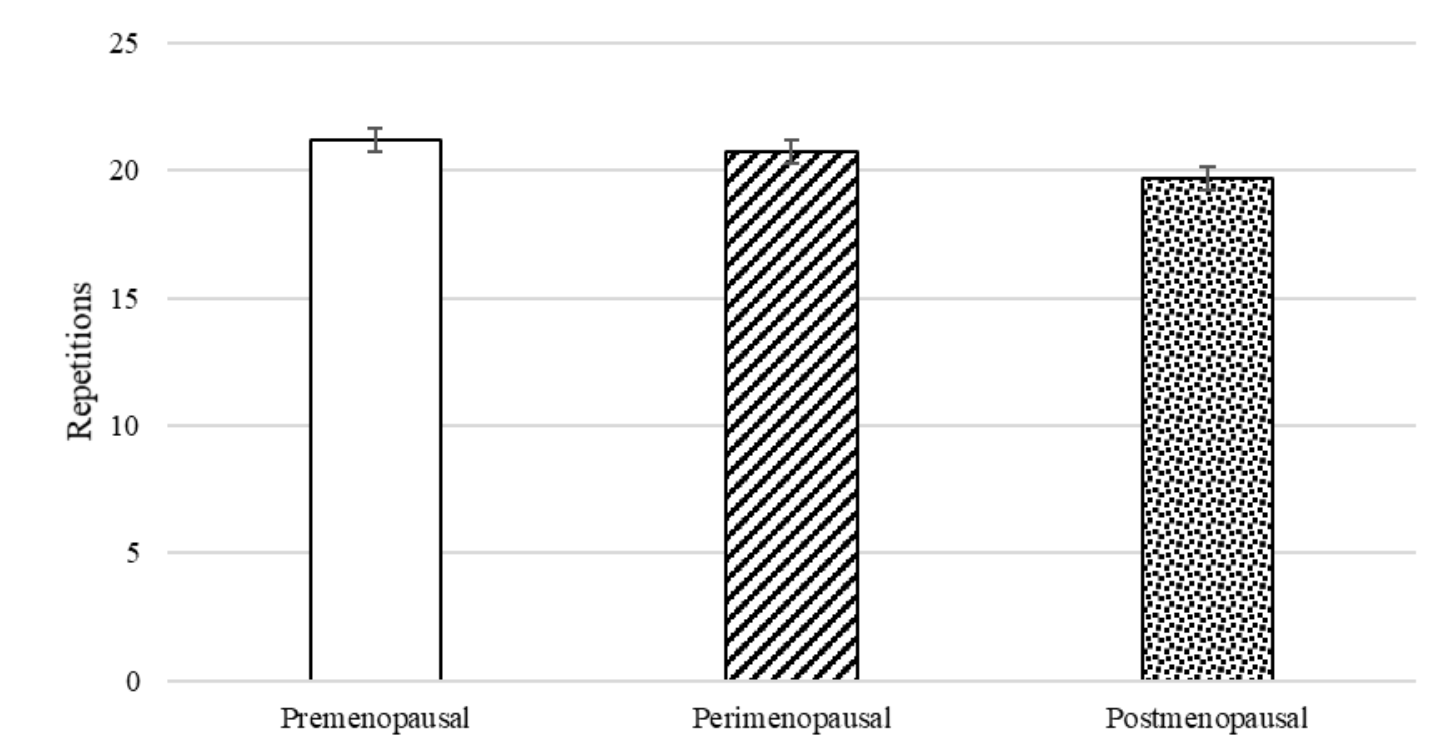

Figure 2c. 30-second chair stands performance by menopausal status Data shown as mean $\pm \mathrm{SE}$ 


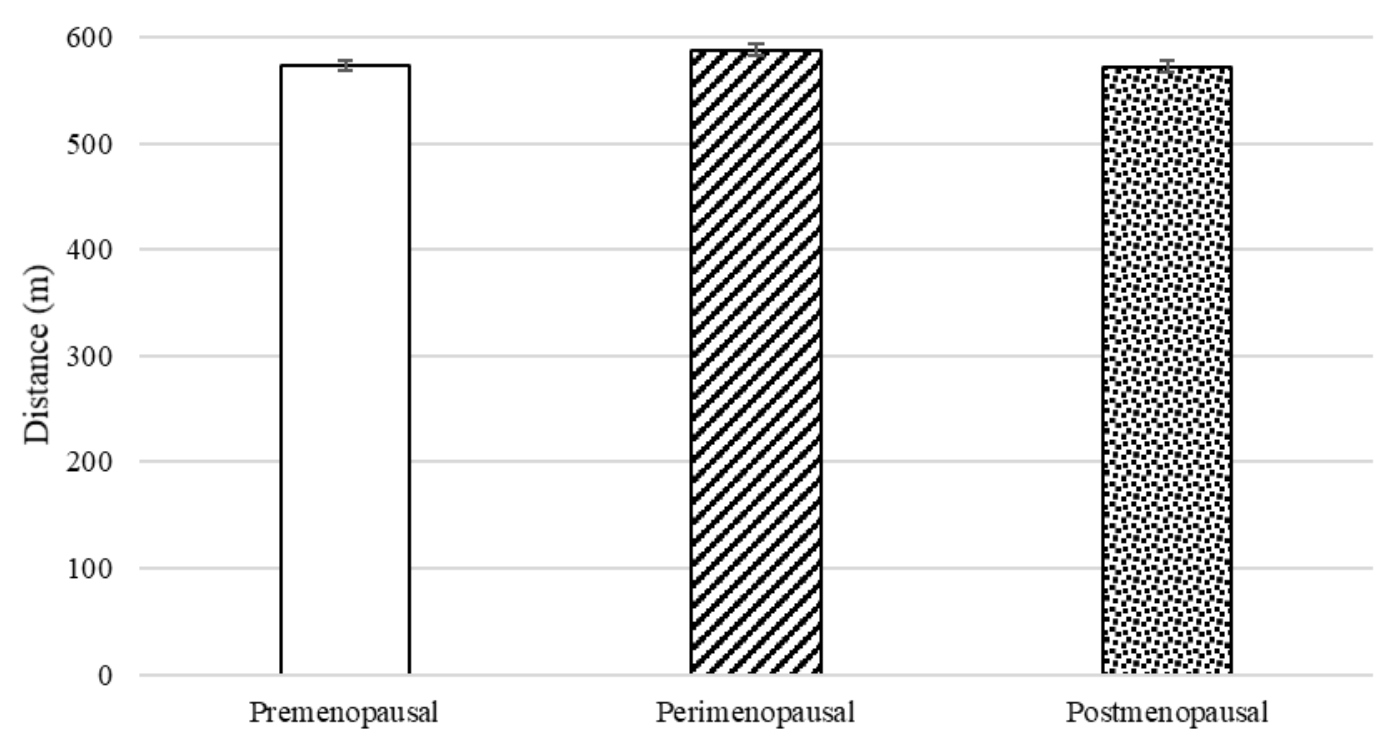

Figure 2d. 6-minute walk test performance by menopausal status Data shown as mean $\pm \mathrm{SE}$ 


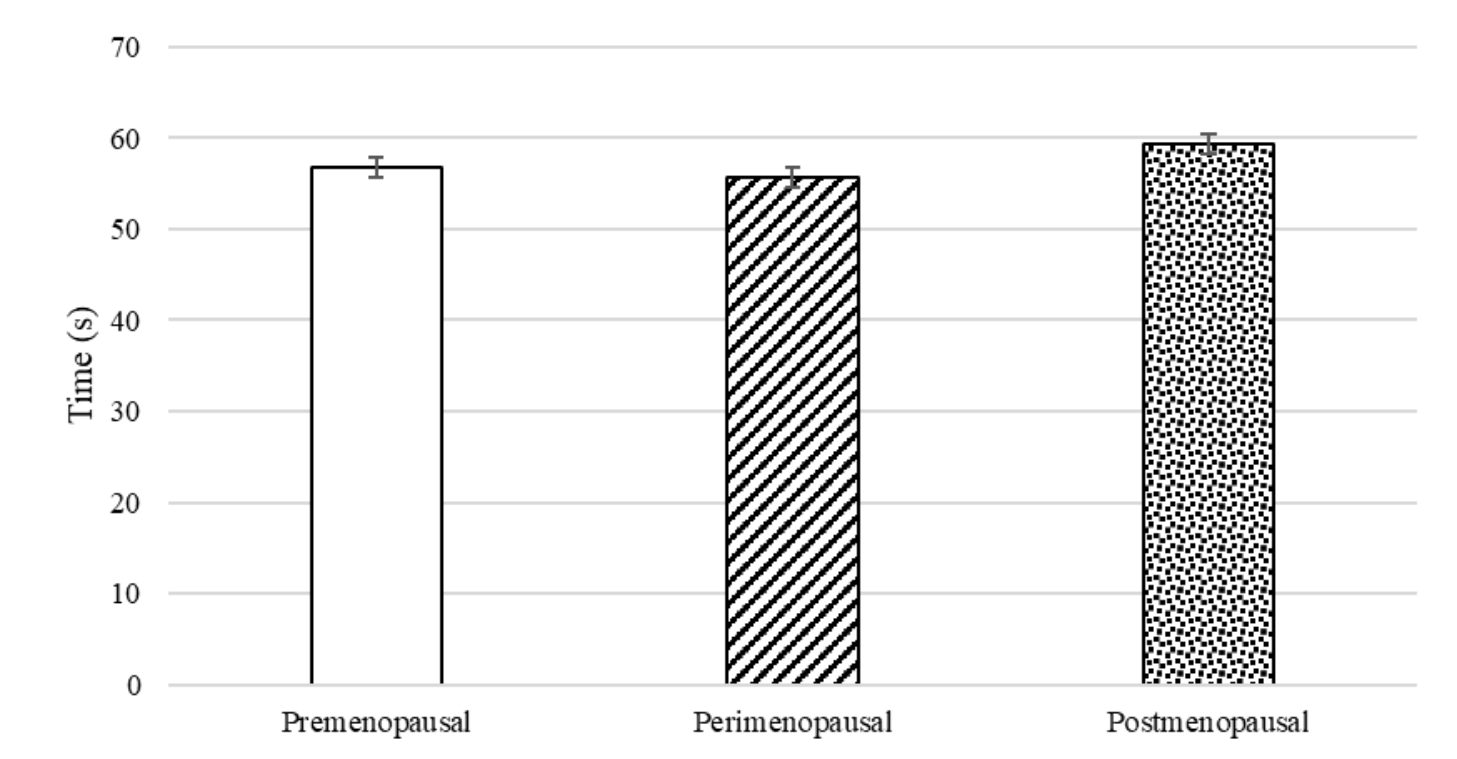

Figure 2e. Lift and carry performance by menopausal status

Data shown as mean $\pm \mathrm{SE}$ 


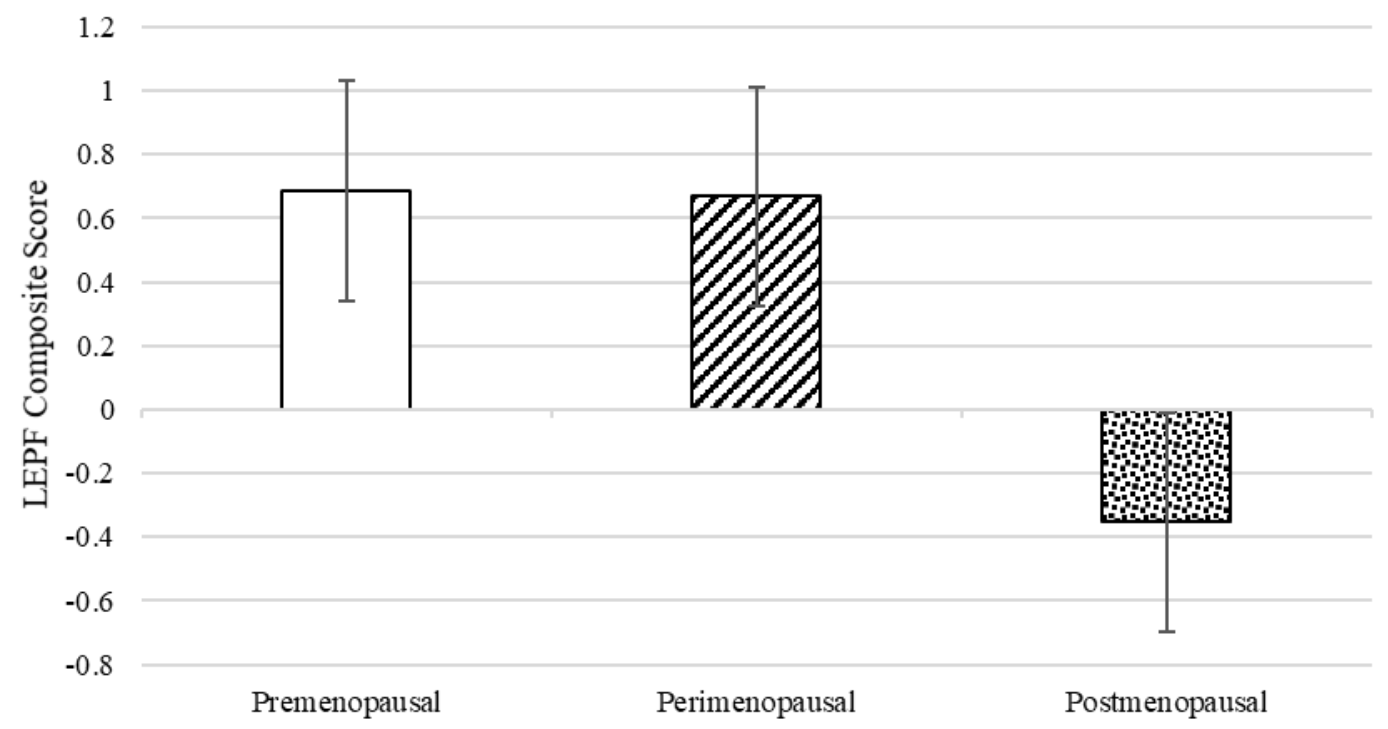

Figure 2f. Lower extremity physical function composite score by menopausal status Data shown as mean $\pm \mathrm{SE}$ 


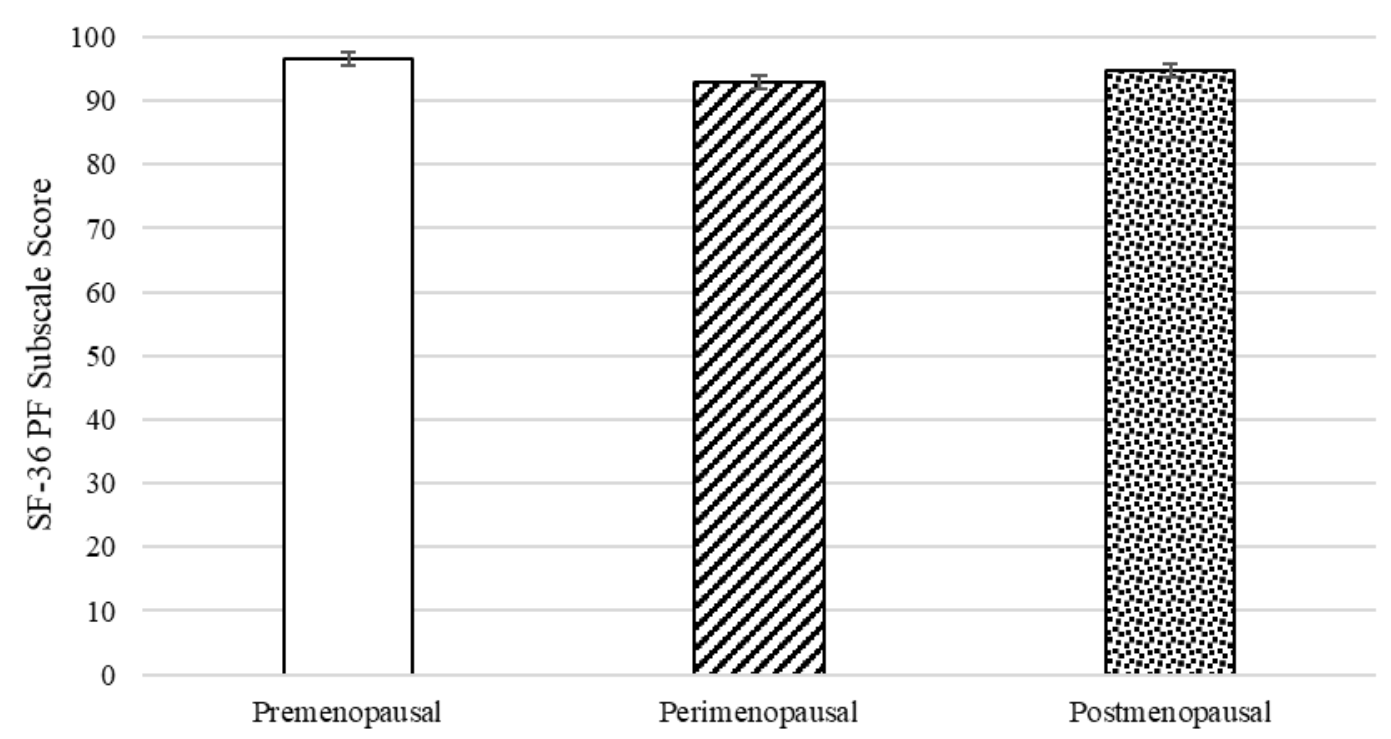

Figure 2g. SF-36 physical functioning subscores by menopausal status Data shown as mean $\pm \mathrm{SE}$ 


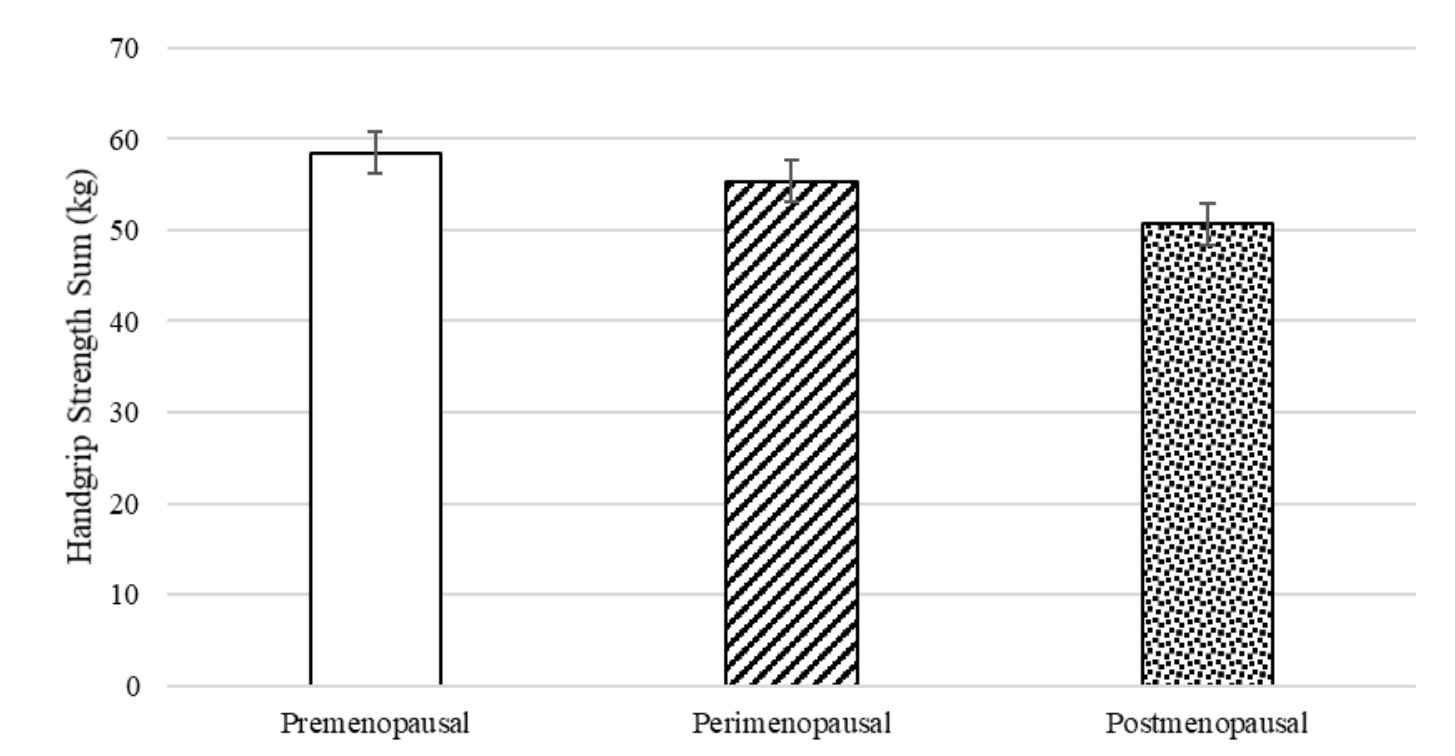

Figure 2h. Handgrip strength sums by menopausal status

Data shown as mean $\pm \mathrm{SE}$ 


\section{APPENDICES}

\section{Appendix A. Women's Health Improvement Initiative screening questionnaire}

Thank you for your interest in our research study.

The purpose of this research study is to assess markers of physical and mental health and quality of life among middle-aged women. We are asking eligible participants to come to the Department of Kinesiology at the University of Rhode Island for two measurement visits that will be completed 7-10 days apart. If you participate in the study, we will measure your body composition, ask you questions about yourself, such as questions about your body perceptions, personality, and well-being, assess your physical function, muscular strength, and assess your levels of physical activity and levels of stress. We will also ask you to wear a physical activity monitor clipped to your waist during all waking hours for 7 days, provide us with saliva samples and answer some questionnaires at home during the time between your visits.

Do you think you might be interested in participating in this study?

Yes

No

Before enrolling you in our study, we need to ask you some questions to determine if you are eligible. Please answer the following questions about yourself and your health history. This should only take about 15 minutes of your time. Some of these questions pertain to sensitive topics and therefore there is a possibility that some of these questions may make you uncomfortable. If so, you can skip any questions you do not choose to answer.

All information that you share in this screening process, including your name and any other information that can possibly identify you, will be strictly confidential and will be kept under lock and key. If after completion of this screening process it is determined that you are not eligible for the study then, if you grant us permission, we will keep your screening information in a password protected computer file in the event our eligibility criteria change and you then become eligible for participation in the current study.

If you do not want us to keep your information on file, we will record the reason for your ineligibility, without any of your identifying information and then destroy your screening information. If you are eligible for the study and you decide to participate, your information will be coded with an identifying number and we will contact you to schedule your first visit. Remember, your participation is voluntary; you can refuse to answer any questions or stop the screening process at any time without penalty or loss of benefits to which you are otherwise entitled.

Do we have your permission to ask you these questions?

$$
\begin{aligned}
& \text { Yes } \\
& \text { No }
\end{aligned}
$$


This study includes the administration of bone and body composition scan, using Dual Energy

X-ray Absorptiometry, commonly referred to as a DXA scan or a bone scan. This scan uses a small amount of radiation to assess your body composition including your fat mass, muscle mass and bone density. The three scans that we are administering together amount to approximately $1 / 6$ of the amount of radiation used during one traditional $x$-ray.

Are you willing to undergo a DXA scan?

$\mathrm{O}$ Yes

N No

Are you between the ages of 40 and 64 years?
$\bigcirc$ Yes
No

What is your date of birth?

\begin{tabular}{l|l|} 
& Please enter below \\
\hline Month & \\
Date & \\
Year &
\end{tabular}

What is your current age in years? 
Do you understand spoken and written English?
$\mathrm{O}$ Yes
No

What is your current height in feet and inches?

Feet

Inches

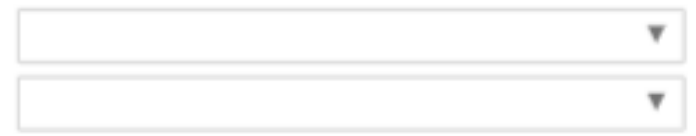

What is your current weight in pounds?

What is your highest weight in the past 3 months in pounds?

What is your lowest weight in the past 3 months in pounds?

Do you live independently?
Yes
$\mathrm{O}$ No 
Are you able to transport yourself or obtain transportation to the URI Kingston campus for 2

measurement visits?
$\bigcirc$ Yes
No

Do you currently smoke or have you smoked within the past 6 months?
Yes
No

Have you recently experienced a cardiovascular disease event (e.g. recent myocardial

infarction, stent placement) or do you have unstable cardiovascular disease (e.g.

unstable angina)?

Yes

No

Do you have a history of COPD (e.g. chronic bronchitis, emphysema) or severe asthma?
$\mathrm{O}$ Yes
$\mathrm{O}$ No

Do you have a history of severe orthopedic/musculoskeletal or neuromuscular

impairments that would contraindicate exercise (including severe arthritis)?
$\bigcirc$ Yes
No 
If you answered yes above, please provide us with some information about these conditions:

Have you been diagnosed with Type 1 or Type 2 Diabetes mellitus?
Yes
No

Have you been diagnosed with Type 1 or Type 2 Diabetes mellitus?
Type 1
Type 2

Is your medication stabilized?

Have you been diagnosed with HIV?
Yes
No

Do you have a history of dizziness or balance disorders?

Yes

No 
Have you ever been diagnosed with mental illness, clinical depression or dementia?

$\mathrm{O}$ Yes

No

If yes, can you tell us more about your diagnosis and treatment plan:

Do you use an assistive device to help you walk (e.g. canes, crutches, walkers, braces)?
$\mathrm{O}$ Yes
No 


\begin{tabular}{|c|c|c|}
\hline & Yes & No \\
\hline \multicolumn{3}{|l|}{ High blood pressure (hypertension)? } \\
\hline \multicolumn{3}{|l|}{ High blood cholesterol? } \\
\hline $\begin{array}{l}\text { Cardiovascular disease (such as heart disease; heart } \\
\text { attack, myocardial infarction), congestive heart failure } \\
\text { (CHF), heart rhythm disorders (arrhythmias), heart } \\
\text { murmur, chest pain (angina)? }\end{array}$ & & \\
\hline $\begin{array}{l}\text { Cerebrovascular disease (such as a stroke, transient } \\
\text { ischemic attack (TIA))? }\end{array}$ & & \\
\hline Peripheral Vascular Disease (PVD)? & $\bigcirc$ & \\
\hline $\begin{array}{l}\text { Chronic Obstructive Pulmonary Disease (such as } \\
\text { emphysema, chronic bronchitis)? }\end{array}$ & & \\
\hline Asthma? & $\mathrm{O}$ & \\
\hline $\begin{array}{l}\text { Arthritis (such as osteo-arthritis, degenerative joint } \\
\text { disease, rheumatoid arthritis)? }\end{array}$ & & \\
\hline $\begin{array}{l}\text { Upper gastrointestinal disease (such as an ulcer, hiatal } \\
\text { hernia, gastroesophageal reflux disease (GERD)? }\end{array}$ & C & \\
\hline $\begin{array}{l}\text { Chronic liver disease (such as chronic or persistent } \\
\text { hepatitis, cirrhosis)? }\end{array}$ & & \\
\hline Cancer? & $\bigcirc$ & ○ \\
\hline a) If yes, please specify type: & & \\
\hline b) If yes, please specify date of diagnosis: & & \\
\hline $\begin{array}{l}\text { Anorexia nervosa (not eating and losing extreme } \\
\text { amounts of weight)? }\end{array}$ & C & \\
\hline $\begin{array}{l}\text { Bulimia (eating, sometimes large amounts of food and } \\
\text { then vomiting)? }\end{array}$ & $\mathrm{O}$ & \\
\hline Degenerative disc disease? & $\bigcirc$ & \\
\hline Depression? & C & \\
\hline Anxiety? & $\bigcirc$ & \\
\hline $\begin{array}{l}\text { Visual impairment (such as cataracts, glaucoma, } \\
\text { macular degeneration)? }\end{array}$ & $\bigcirc$ & \\
\hline
\end{tabular}




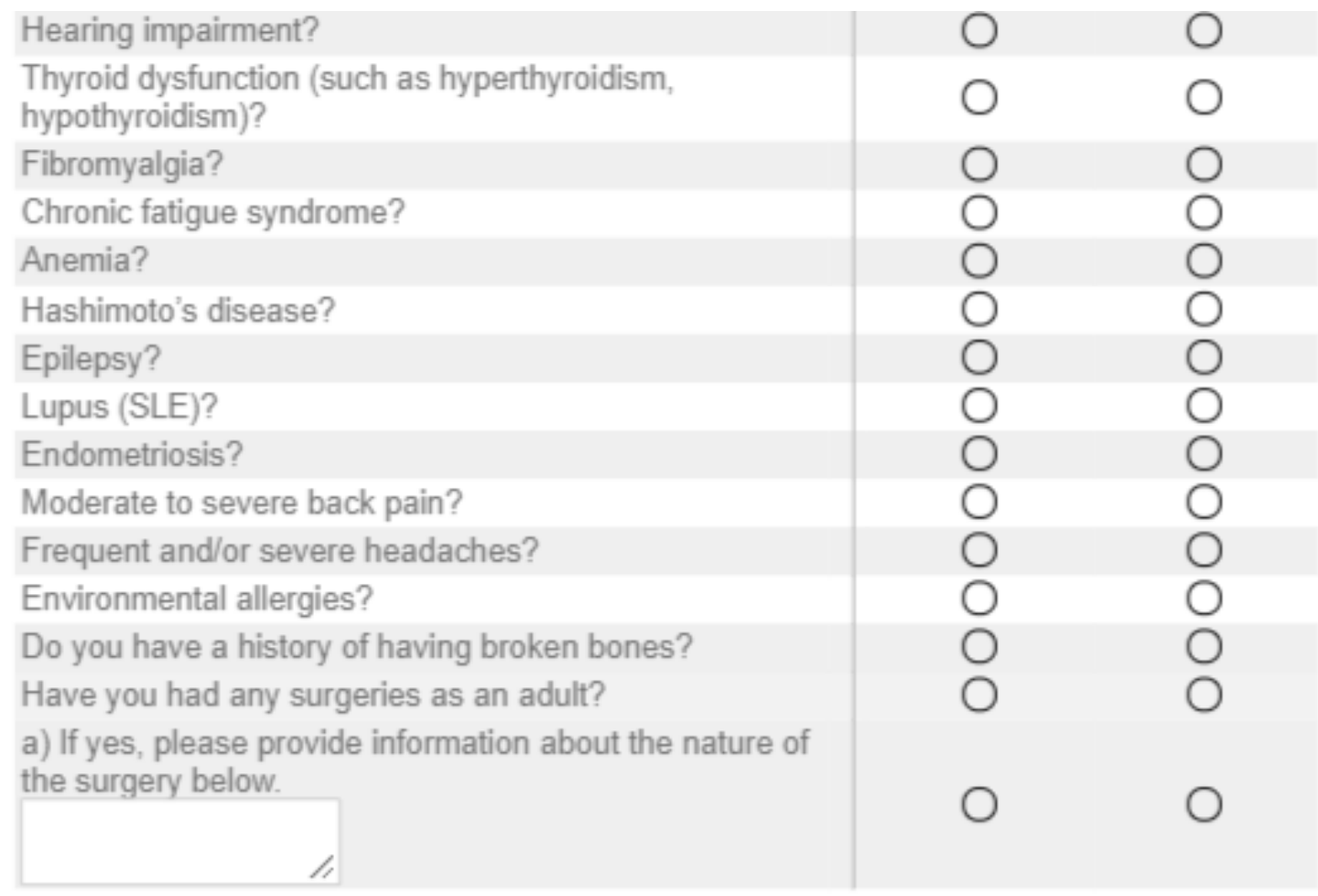

Do you have any other health issues you would like to disclose?
$\mathrm{O}$ Yes
$\bigcirc$ No 
Do you take any medications or supplements?
$\mathrm{O}$ Yes
$\mathrm{ONo}$

If yes, please list these in the space below, and indicate the dose (amount) you take, what

you take the medication to treat, and the frequency with which you take this

medication.

Which of the following racial or ethnic groups best describes you? (Please select all

categories that apply.)

$\square$ Asian/Pacific

$\square$ Black

Hispanic

Indian/Alaskan

White

$\square$ Other: Please describe 
How many alcoholic beverages do you drink (includes wine, beer and hard liquor)?
None
$\mathrm{O}$ Less than once a week
1-3 drinks per week
4-6 drinks per week
O drink daily
O 2 drinks daily
3 drinks daily
More than 3 drinks daily

How many caffeinated beverages do you drink (includes coffee, soda, energy drinks)?
None
$\mathrm{O}$ Less than once a week
1-3 drinks per week
4-6 drinks per week
1 drink daily
2 drinks daily
3 drinks daily
More than 3 drinks daily

On average, how many meals do you consume each day? 
Do you try to eat a special diet?
$\bigcirc$ Low fat
Low carbohydrate
High protein
Vegetarian
Other:

How many servings of dairy do you consume each day?

How many servings of fruits do you consume each day?

How many servings of vegetables do you consume each day?

$\mathbf{v}$

How many servings of fish do you consume each week?

Please describe your current employment. 
Would you describe your current employment as:
$\bigcirc$ Full time - working at least 35 hours/week
$\bigcirc$ Part time - working less than 35 hours/week
Laid-off or unemployed, but looking for work
$\bigcirc$ Laid-off or unemployed, but not looking for work
Retired, not working at all
$\bigcirc$ Retired, working part-time
Disabled
Full time homemaker
Other, please specify:

Please tell us about your highest level of education:
Less than a high school diploma
$\bigcirc$ High school diploma or equivalent
Some College
$\bigcirc$ Graduated from college
$\bigcirc$ Graduate or professional degree

Have you ever been married or lived with a partner?
Yes
No 
Have you ever been divorced or had a live-in relationship end?

$\bigcirc$ Yes

No

Have you ever been widowed or had a live-in partner die?

Yes

No

Do you now live with a partner or spouse?

$\bigcirc$ Yes

No

If you currently live with a partner or spouse, what is your partner's highest level of education (last grade completed or degree(s) received):

Less than a high school diploma

High school diploma or equivalent

Some college

$\mathrm{O}$ Graduated from college

Graduate or professional degree 
Your total yearly household income (includes income from all sources):

○ $\$ 0-14,999$

O $\$ 15,000-29,999$

O $\$ 30,000-44,999$

O $\$ 45,000-59,999$

O $\$ 60,000-74,999$

O $\$ 75,000-99,999$

O $\$ 100,000-149,999$

O $\$ 150,000-199,999$

O $\$ 200,000-249,999$

O \$Over 250,000

Other than yourself, how many people live in your household?

Do you have children (biological, adopted or extended family)?
$\mathrm{O}$ Yes
$\bigcirc$ No

If yes, how many?

$\square$

How many (if any) currently live with you? 
What are the current major stressors or life changes in your life?

Please provide an explanation here:

Any major changes in family health during the past year?

If yes, please explain:

How would you describe your sexual orientation?

Heterosexual

$\mathrm{O}$ Lesbian

Bisexual

Other (please specify:)

How would you describe your current menstrual status?

Premenopause (before menopause; having regular periods)

Perimenopause/menopause transition (changes in periods, but have not gone 12 months in a row without a period)

Postmenopause (after menopause) 
If you are post menopausal, was your menopause:

Spontaneous (natural)

O Surgical (removal of both ovaries)

Due to chemotherapy or radiation therapy

Other, please explain:

O Not applicable

If you are no longer having periods, what was your age when you had your last period?

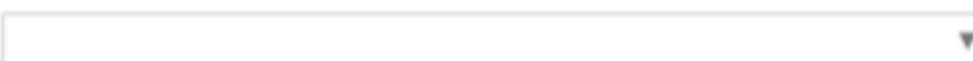

If you are still having periods, how often do they occur?

On average, how many days does your period last?

Are your periods painful?

$\bigcirc$ Yes

$\mathrm{ONo}$

Not applicable 
If yes, how painful?

Mild

Moderate

$\mathrm{O}$ Severe

Not applicable

Do you have any problems with PMS?

Yes

No

How would you rate your knowledge about menopause?

Very good

Moderately good

Fair

$\bigcirc$ Little Knowledge

Where do you get your information about menopause (mark all that apply)

$\square$ Books

$\square$ Internet

$\square$ Magazines

$\square$ Friends

$\square$ TV

$\square$ Health care providers

$\square$ Other 
How do you view menopause?

Positively. For example, menopause means no more periods and no more worry about contraception.

Neutral.

Negatively. For example, menopause means a loss of fertility and loss of youth.

Other:

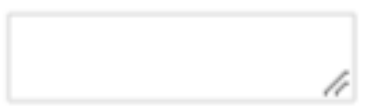

What concerns you about menopause? Please provide any of your thoughts in the space provided.

What are your current views regarding hormone therapy for menopause?

Positive. Hormone therapy is appropriate for some women.

Neutral.

Negative. I don't support the use of hormone therapy.

What concerns you most about hormone replacement therapy? Please provide any of your thoughts in the space provided. 
Please mark the appropriate box with to record your response to the following: How often do you engage in each of the following behaviors?

\begin{tabular}{|c|c|c|c|c|c|}
\hline & $\begin{array}{l}\text { Every } 6 \\
\text { months }\end{array}$ & Once a year & $\begin{array}{c}\text { Every } 2 \\
\text { years }\end{array}$ & $\begin{array}{l}\text { More than } \\
\text { every } 2 \\
\text { years }\end{array}$ & Never \\
\hline $\begin{array}{l}\text { See a health care } \\
\text { professional for a } \\
\text { general physical } \\
\text { exam? }\end{array}$ & & & & & \\
\hline $\begin{array}{l}\text { See a health care } \\
\text { professional for a } \\
\text { women's health } \\
\text { exam? }\end{array}$ & & & & & \\
\hline $\begin{array}{l}\text { See a dental } \\
\text { professional for a } \\
\text { dental } \\
\text { exam/cleaning? }\end{array}$ & & & & & \\
\hline $\begin{array}{l}\text { See a health care } \\
\text { professional for an } \\
\text { eye exam? }\end{array}$ & & & & 0 & \\
\hline
\end{tabular}

Please mark the appropriate box to record your response to the following: How often do you engage in each of the following behaviors?

\begin{tabular}{|c|c|c|c|c|c|c|}
\hline & $\begin{array}{l}\text { Every } \\
\text { month }\end{array}$ & $\begin{array}{l}\text { Every } 6 \\
\text { months }\end{array}$ & $\begin{array}{c}\text { Once a } \\
\text { year }\end{array}$ & $\begin{array}{c}\text { Every } 2 \\
\text { years }\end{array}$ & $\begin{array}{l}\text { More } \\
\text { than } \\
\text { every } 2 \\
\text { years }\end{array}$ & Never \\
\hline $\begin{array}{l}\text { How often do you } \\
\text { have a pap smear? }\end{array}$ & 0 & 0 & $\mathrm{O}$ & $\bigcirc$ & 0 & $\bigcirc$ \\
\hline $\begin{array}{l}\text { How often do you } \\
\text { have breast exams } \\
\text { by a doctor or } \\
\text { nurse? }\end{array}$ & 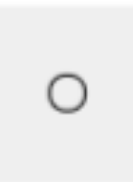 & $\cap$ & & & & ) \\
\hline $\begin{array}{l}\text { How often do you } \\
\text { have mammograms? }\end{array}$ & $\cap$ & $\cap$ & $\cap$ & $\Omega$ & $\Omega$ & 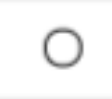 \\
\hline $\begin{array}{l}\text { How often do you } \\
\text { breast self-examine? }\end{array}$ & 0 & $\bigcirc$ & 0 & 0 & 0 & 0 \\
\hline
\end{tabular}


What is the best way to contact you?

Phone

$\bigcirc$ Email

Mail

Other

Please enter the following contact information:

Full Name

Please provide us with a phone number to reach you (including area code)

Phone Number

Please provide us with an email address (if you have one)

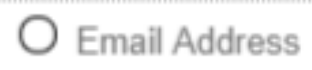

Please provide us with a mailing address, including Street, City/Town, Zip Code

Address

Thank you very much for your time. Based on the information you provided us in this questionnaire, we will determine your eligibility to participate in the study. We will be contacting you in the near future to schedule your first visit to the research lab at the University of Rhode Island. If you have any questions about this research project, please feel free to contact our Principal Investigator, Dr. Sabik by email at sabik@uri.edu or by phone at (401) 874-5439. You can contact Dr. Ward-Ritacco by email christieward@uri.edu or by phone at (401) 874-5638. 


\title{
Appendix B. Women's Health Improvement Initiative informed consent
}

\author{
THE \\ UNIVERSITY \\ OF RHODE ISLAND \\ COLLEGE OF \\ HEALTH SCIENCES \\ HEALTH STUDIES PROGRAM \\ 25 Independence Way, Sulte P, Kingston, RI 02881 USA p: 401.874.7499 t: 401.874.4215 web.uri.edu/health-studies

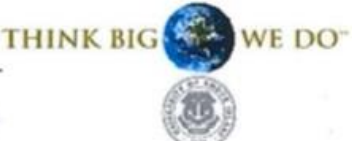

Project Title: Evaluating Physical Function and Self Perception in Middle-Aged Women

\section{CONSENT FORM FOR RESEARCH}

You have been invited to take part in the research project described below. A member of the research team will explain the project to you in detail. You should feel free to ask questions. If you have more questions later, Dr. Natalie Sabik and Dr. Christie Ward-Ritacco, the persons mainly responsible for this study, will be happy to talk with you about them. You can contact Dr. Sabik by email at sabik@uri.edu or by phone at (401) 874-5439. You can contact Dr. WardRitacco by email christieward@uri.edu or by phone at (401) 874-5638.

Inclusionary Criteria

To be a candidate for this study you must 1) be able to speak and read English, 2) be a woman, 3) be between 40 64 years of age, 4) have no recent changes in your body weight (within $\sim 5$ pounds for the past 3 months), 5) have a body mass index of $18.5-45.0 \mathrm{~kg} / \mathrm{m}^{2}, 6$ ) be a non-smoker, 7) not be pregnant, 8) be willing to have a dual energy Xray absorptiometry (DXA) scan, 9) be free of diseases or conditions that would prevent reasonably safe participation in study related testing, and 10 ) be living independently.

\section{Project Description}

The main purpose of this study is to assess how physical factors, such as exercise, body composition, and muscular strength, relate to well-being among middle-aged women. We want to learn about how these factors are related because physical changes during midlife place women at increased risk of poorer quality of life, including increased functional limitations and decreased psychological well-being. A growing number of middle-aged Americans are reporting decreases in their physical health, mental health, ability to perform activities of daily living, and ability to work. Examining the associations between these factors will help us to understand barriers to health and will allow us to design effective interventions to improve quality of life in middle-aged women.

Your participation will include coming to the URI Kingston campus for two testing visits and completing a series of tasks at home in between your visits. All of the testing will take place on the URI Kingston campus in Independence Square. You are responsible for your own transportation to all of the testing visits.

\section{Time Commitment}

Interested women will complete a short online screening questionnaire. Women who qualify to take part in the research study will be asked to come to the Department of Kinesiology at the University of Rhode Island for two visits that will occur 7-10 days apart. During the time between visits you will complete a series of questionnaires. The total time commitment for this study is 7 hours.

\begin{tabular}{|c|c|c|}
\hline stry & IRB NUMBER: & HU1516-206 \\
\hline & AL DATE: & October 23, 2017 \\
\hline (2) & IRB EXPIRATION DATE: & October 19,2018 \\
\hline
\end{tabular}


What Will I Do As a Participant in This Study?

If you choose to participate in the study you will be asked complete two in person visits and complete a series of tasks at home between the two visits.

Visit 1:

First we will check your interest and ability to take part in this study. Then we will review and sign this form. Next, we will complete a paper and pencil administered questionnaire making sure that you are able to engage in physical activity safely and one to examine your cognitive performance.

Next, a qualified member of the research team will collect 160 microliters (about a half a teaspoon) of your blood using a finger stick technique. Your blood sample will be analyzed for hemoglobin and hematocrit, to assess your risk for anemia.

After your blood sample is taken, we will measure your height and weight, your waist circumference, and take your heart rate and blood pressure. Then you will have a DXA scan in room 129 of the Independence Square building. A DXA scan is a body scan that tells us information about your body fat, your muscle mass, and your bone density. We will provide you with medical "scrubs" to wear during scanning if you are wearing clothing that would interfere with the scan. You will lie on a padded table that remains stationary as the scanning arm moves over your body. Total scanning time, complete with positioning, takes approximately 20 minutes. A licensed radiology technician will perform the DXA scans. There is no cost to you or your insurance for these scans. If you are pre-menopausal (not self-identified as post-menopausal or otherwise unable to become pregnant), you will complete a pregnancy test prior to completing your DXA scan. One will be provided to you with no cost to you or your insurance company. You will provide a small urine sample by peeing in a cup and then provide the sample to the researcher, who will conduct the pregnancy test to confirm that you are not pregnant prior to having the DXA scan.

In addition we will ask you to complete several questionnaires using a computer in our laboratory. The questionnaires will ask you about your quality of life, your feelings of energy and fatigue, your sleep quality, your stress levels, your physical activity history, and will also contain questions about your emotional and physical health and well-being. Next you will complete a series of tasks to measure your physical functional ability. These include sitting in chair and standing up as many times as you can in 30 seconds, standing from seated position and walking around a cone placed in front of you as quickly as possible, lifting a weighted crate and carrying it through a marked course, getting up and off the floor as quickly as possible, and walking for 6 minutes as quickly as you can. During the functional assessments we will ask you to rate your feelings of effort, fatigue, and pain. You can rest between each activity. Any risk of injury during the completion of these tasks will be minimized by having all sessions supervised by an research team member qualified to direct this type of testing.

Before you leave for the day, we will review how to wear your physical activity monitoring device for 7-10 days while you go about your normal daily routine. We will ask you to wear your physical activity monitor during all waking hours except when showering or swimming. We will also show you how to fill out your physical activity log. This will require you to write down the type of activity, the time of the activity, and how many minutes you completed of during each bout of planned, structured physical activity (e.g. 30 minutes of walking outside at $3: 30 \mathrm{pm}$ ). We will also review how to provide saliva samples and review the questionnaires that you will be asked to fill out at home in the time between visits 1 and 2 .

\begin{tabular}{lll}
$\begin{array}{l}\text { Tnt } \\
\text { UNIVERSITY }\end{array}$ & IRB NUMBER: & HU1516-206 \\
\hline & IRB APPROVAL DATE: & October 23, 2017 \\
\hline & IRB EXPIRATION DATE: & October 19, 2018
\end{tabular}


In between Visits 1 and 2 :

You will be asked to complete a series of questionnaires asking you about your physical activity history, your menopausal symptoms, how you feel about your body and age, social activities, and your daily feelings of energy at home. If you would like to complete these on your home computer, we will email a link to you from Qualtrics, an online survey tool, containing the questionnaires. If however, you would prefer to answer offline or do not have access to a computer, we will provide you with hard copies of all of the questionnaires. You will wear your physical activity monitor and record any planned physical activity/exercise sessions on your physical activity log. You will bring your completed physical activity log, your physical activity monitor, and completed questionnaires (if applicable) to the lab when you return for Visit 2 . You will also be asked to provide us with 10 saliva samples total ( 5 per day for 2 days). The saliva sample will provide us with information about how your body responds to stress. To create these samples you will simply chew on a cotton swab provided by the researchers and will spit it into a tube to be stored in the refrigerator. You will be asked to bring these with you to the lab on Visit 2.

Visit 2:

At Visit 2, we will collect your physical activity monitor and check and collect your physical activity log. If there are any missing information on your physical activity log we will ask you to try and fill it in as best as you can remember. We will also collect your saliva samples. We will also ask you to complete any unfinished questionnaires in our laboratory. When this is finished, we will test your hand grip strength by squeezing the lever on a small hand-held device, known as a hand grip dynamometer. This task is repeated three times with both the right and left hands. We will then test the strength of your upper leg. This involves being seated in a special machine that controls the speed with which you can move your leg and measures how much force you are able to produce while you kick and pull with your knee. Then we will check your muscular endurance. During each task you will receive real-time visual feedback on a computer monitor and verbal encouragement to help you. During the strength and endurance tests we will ask you to rate your feelings of effort, fatigue and pain. You can rest between each exercise.

\section{Risks or Discomfort}

It is possible that heart or blood vessel problems could arise during your participation in the study testing. Although highly unusual, it is possible that these problems could lead to a heart attack, stroke or even death. It is possible that these risks will not be eliminated completely, even with a medical evaluation prior to participation in the study. However, the investigators believe the risk of harm from study participation is relatively small and that the benefits of the study to you individually will likely outweigh any potential risks. You may experience some temporary muscle soreness as a result of the testing sessions. There is also a risk skeletal injury from testing. The investigators will use procedures designed to minimize this risk. Because some of the physical function tasks require some degree of balance, there is a risk of falling associated with completing these tasks. However, the investigators will take precautions to reduce the chance of falling. There is a risk of bruising, pain, and in rare cases, infection or fainting as a result of finger stick blood sampling. However, these risks to you will be minimized by allowing only qualified people to use the finger stick technique to take a small sample of your blood.

You understand that there will also be a very low total radiation dose for the DXA scans ( 9 millirem), which is well below the maximal annual radiation dose (5 rems) allowed for exposure

\begin{tabular}{|c|c|c|}
\hline \multirow{2}{*}{ 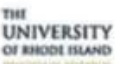 } & IRB NUMBER: & HU1516-206 \\
\hline & AL DATE: & October 23, 2017 \\
\hline$x=$ & TION DATE: & October 19,2018 \\
\hline
\end{tabular}


in the workplace. Naturally occurring radiation (cosmic radiation, radon gas, etc.) gives each person a whole body radiation dose of about 300 millirems per year. Therefore, the total dose of radiation exposure from DXA is considered low. The major risk from high radiation exposure is passing on damaged genes (genetic mutations) to offspring. Therefore, this risk is of primarily a concern for women who are of childbearing age.

In case there is any injury to the subject:

In the event of physical injury resulting from participation in this study, upon your consent, emergency treatment will be available at South County Hospital with the understanding that any injury requiring medical attention becomes your financial responsibility. URI will not provide any medical or hospitalization insurance coverage for participants in this research study, nor will they provide compensation for any injury sustained as a result of this research study, except as required by law.

\section{Benefits of this study:}

This study may help the investigators better understand which factors are most important in determining quality of life in middle-aged women. The results of this study may be used in the future to design effective interventions for improving physical and psychological health in middle-aged women. Additionally, as a participant in this study you will be provided with the results of your hemoglobin and hematocrit testing, a copy of your DXA scan, and the results of your muscular strength and physical function testing.

\section{Participant Compensation:}

For your participation in the study and after the study is completed, you will receive, free of charge, information about your blood test results, body composition, muscle strength, and physical function. Participants will be compensated $\$ 100$ total in the form of gift cards upon completion of all study requirements. For participants that withdraw from the study early, compensation will be prorated based on the time spent completing study materials. Pro-rating will occur as follows: for completion of the initial laboratory visit, you will receive $\$ 30$. For completion of at-home activities (questionnaires, wearing and returning accelerometer, collecting saliva samples) and visit 2, participants will receive $\$ 70$. For participants that withdraw early from the study, study equipment must be returned to receive payment.

\section{Confidentiality:}

All information collected in this study is confidential, and your name will not be identified and linked to any electronic study data at any time to anyone other than the principal investigators of the study. Your data will be coded with an ID number only, which will be linked back to you only by the principal investigators of the study. Your part in this study is confidential within legal limits. The researchers and the University of Rhode Island will protect your privacy, unless they are required by law to report information to city, state or federal authorities, or to give information to a court of law. Otherwise, none of the information will identify you by name All study data, including this consent form, will be locked in a file cabinet and also stored in a study computer with a password secured in our locked study office (Independence Square building, Suite P, room 225). All study data will be kept for three years after study completion.

\begin{tabular}{|c|c|c|}
\hline $\begin{array}{l}\text { nut } \\
\text { UNIVE }\end{array}$ & IRB NUMBER: & HU1516-206 \\
\hline of soloot tswe & IRB APPROVAL DATE: & October 23,2017 \\
\hline intenses & IRB EXPIRATION DATE: & October 19,2018 \\
\hline
\end{tabular}


Decision to Quit at any Time:

It is your decision alone whether or not you participate in this study. You are free to ask questions about this study before you decide whether or not to participate. Also, if you consent to participate in the study you are free to quit at any time without penalty, or without any requirement that you provide an explanation about your decision to withdraw.

Rights and Complaints:

If you are not happy with the way this study was done, you may talk with Dr. Natalie Sabik or Dr. Christie Ward-Ritacco. They can be reached at (401) 874-5439 or (401) 874-5638, respectively. You can talk to either of them anonymously if you want to. In addition, if this study causes you any injury or if you have questions about your rights as a research subject you may contact the office of the Vice President for the Division of Research and Economic Development, Carlotti Administration Building, 2nd Floor, 75 Lower College Road, Suite 2, University of Rhode Island, Kingston, Rhode Island; telephone: (401) 874-4576.

Further, we would like to know if we can retain your contact information to potentially contact you to provide the opportunity to participate in future research. You can choose to participate in the current study and can opt to not be contacted in the future.

I would like to provide my contact information to be contact for future research studies.

Yes Phone:

Email:

No

You have read and understand the above information in the Consent Form and have been given adequate opportunity to ask the investigators any questions you have about the study. Your questions, if any, have been answered by the investigators to your satisfaction. Your signature on this form means that you understand the information and you agree to voluntarily participate in this study.

\begin{tabular}{llll}
\hline Signature of Participant & Date & Signature of Researcher & Date
\end{tabular}

Typed/printed Name

Typed/printed name

Please sign both consent forms, the research team will keep one copy and you will be given one for yourself. 


\section{Appendix C. Physical Activity Readiness Questionnaire (PAR-Q)}

Physical Activity Readiness Questionnaire - PAR-Q (revised 2002)

\section{PAR-Q \& YOU}

(A Questionnaire for People Aged 15 to 69)

Regular physical activity is fun and healthy, and increasingly more people are starting to become more active every day. Being more active is very safe for most people. However, some people should check with their doctor before they start becoming much more physically active.

If you are planning to become much more physically active than you are now, start by answering the seven questions in the box below. If you are between the ages of 15 and 69, the PAR-Q will tell you if you should check with your doctor before you start. If you are over 69 years of age, and you are not used to being very active, check with your doctor.

Common sense is your best guide when you answer these questions. Please read the questions carefully and answer each one honestly: check YES or NO.

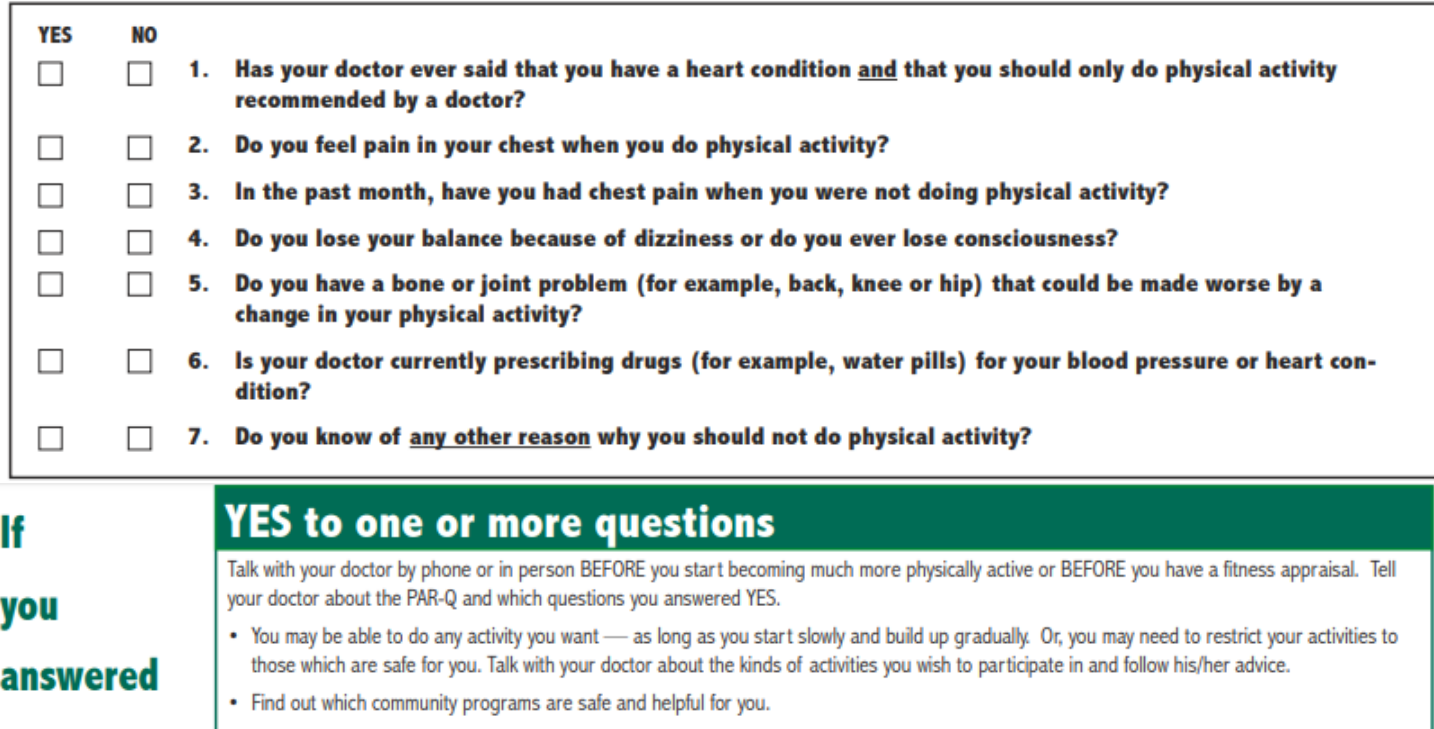

\section{NO to all questions}

If you answered NO honestly to all PAR-Q questions, you can be reasonably sure that you can: - start becoming much more physically active - begin slowly and build up gradually. This is the safest and easiest way to go.

- take part in a fitness appraisal - this is an excellent way to determine your basic fitness so that you can plan the best way for you to live actively. It is also highly recommended that you have your blood pressure evaluated. If your reading is over $144 / 94$, talk with your doctor before you start becoming much more physically active.

DELAY BECOMING MUCH MORE ACTIVE:

- if you are not feeling well because of a temporary illness such as a cold or a fever - wait until you feel better; or

- if you are or may be pregnant - talk to your doctor before you start becoming more active.

PLEASE NOTE: If your health changes so that you then answer YES to any of the above questions, tell your fitness or health professional. Ask whether you should change your physical activity plan.

Informed Use of the PAR-Q: The Canadian Society for Exercise Physiology, Health Canada, and their agents assume no liability for persons who undertake physical activity, and if in doubt after completing this questionnaire, consult your doctor prior to physical activity.

No changes permitted. You are encouraged to photocopy the PAR-Q but only if you use the entire form.
NOTE: If the PAR-Q is being given to a person before he or she participates in a physical activity program or a fitness appraisal, this section may be used for legal or administrative purposes.
"I have read, understood and completed this questionnaire. Any questions I had were answered to my full satisfaction."
SIGNATURE
SIGNATURE OF PARENT

or GUARDIAN (for participants under the age of majority)

Note: This physical activity clearance is valid for a maximum of 12 months from the date it is completed and becomes invalid if your condition changes so that you would answer YES to any of the seven questions.

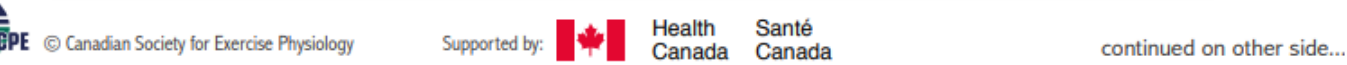


Appendix D. Mini-Mental Status Examination

\section{Mini-Mental State Examination (MMSE)}

Patient's Name:

Date:

Instructions: Ask the questions in the order listed. Score one point for each correct response within each question or activity.

\begin{tabular}{|c|c|c|}
\hline $\begin{array}{l}\text { Maximum } \\
\text { Score }\end{array}$ & $\begin{array}{c}\text { Patient's } \\
\text { Score }\end{array}$ & Questions \\
\hline 5 & & "What is the year? Season? Date? Day of the week? Month? \\
\hline 5 & & "Where are we now: State? County? Town/city? Hospital? Floor?" \\
\hline 3 & & $\begin{array}{l}\text { The examiner names three unrelated objects clearly and slowly, then } \\
\text { asks the patient to name all three of them. The patient's response is } \\
\text { used for scoring. The examiner repeats them until patient learns all of } \\
\text { them, if possible. Number of trials: }\end{array}$ \\
\hline 5 & & $\begin{array}{l}\text { "I would like you to count backward from } 100 \text { by sevens." }(93,86,79 \text {, } \\
72,65, \ldots) \text { Stop after five answers. } \\
\text { Alternative: "Spell WORLD backwards." (D-L-R-O-W) }\end{array}$ \\
\hline 3 & & $\begin{array}{l}\text { "Earlier I told you the names of three things. Can you tell me what those } \\
\text { were?" }\end{array}$ \\
\hline 2 & & $\begin{array}{l}\text { Show the patient two simple objects, such as a wristwatch and a pencil, } \\
\text { and ask the patient to name them. }\end{array}$ \\
\hline 1 & & "Repeat the phrase: 'No ifs, ands, or buts." \\
\hline 3 & & $\begin{array}{l}\text { "Take the paper in your right hand, fold it in half, and put it on the floor." } \\
\text { (The examiner gives the patient a piece of blank paper.) }\end{array}$ \\
\hline 1 & & $\begin{array}{l}\text { "Please read this and do what it says." (Written instruction is "Close } \\
\text { your eyes.") }\end{array}$ \\
\hline 1 & & $\begin{array}{l}\text { "Make up and write a sentence about anything." (This sentence must } \\
\text { contain a noun and a verb.) }\end{array}$ \\
\hline 1 & & $\begin{array}{l}\text { "Please copy this picture." (The examiner gives the patient a blank } \\
\text { piece of paper and asks him/her to draw the symbol below. All } 10 \\
\text { angles must be present and two must intersect.) }\end{array}$ \\
\hline 30 & & TOTAL \\
\hline
\end{tabular}

(Adapted from Rovner \& Folstein, 1987) 


\section{Instructions for administration and scoring of the MMSE}

Orientation (10 points):

- Ask for the date. Then specifically ask for parts omitted (e.g., "Can you also tell me what season it is?"). One point for each correct answer.

- Ask in turn, "Can you tell me the name of this hospital (town, county, etc.)?" One point for each correct answer.

Registration (3 points):

- Say the names of three unrelated objects clearly and slowly, allowing approximately one second for each. After you have said all three, ask the patient to repeat them. The number of objects the patient names correctly upon the first repetition determines the score (0-3). If the patient does not repeat all three objects the first time, continue saying the names until the patient is able to repeat all three items, up to six trials. Record the number of trials it takes for the patient to leam the words. If the patient does not eventually learn all three, recall cannot be meaningfully tested.

- After completing this task, tell the patient, "Try to remember the words, as I will ask for them in a little while."

Attention and Calculation ( 5 points):

- Ask the patient to begin with 100 and count backward by sevens. Stop after five subtractions (93, $86,79,72,65)$. Score the total number of correct answers.

- If the patient cannot or will not perform the subtraction task, ask the patient to spell the word "world" backwards. The score is the number of letters in correct order (e.g., dlrow=5, dlorw=3).

\section{Recall ( 3 points):}

- Ask the patient if he or she can recall the three words you previously asked him or her to remember. Score the total number of correct answers (0-3).

\section{Lanquage and Praxis (9 points):}

- Naming: Show the patient a wrist watch and ask the patient what it is. Repeat with a pencil. Score one point for each correct naming $(0-2)$.

- Repetition: Ask the patient to repeat the sentence after you ("No ifs, ands, or buts."). Allow only one trial. Score 0 or 1.

- 3-Stage Command: Give the patient a piece of blank paper and say, "Take this paper in your right hand, fold it in half, and put it on the floor." Score one point for each part of the command correctly executed.

- Reading: On a blank piece of paper print the sentence, "Close your eyes," in letters large enough for the patient to see clearly. Ask the patient to read the sentence and do what it says. Score one point only if the patient actually closes his or her eyes. This is not a test of memory, so you may prompt the patient to "do what it says" after the patient reads the sentence.

- Writing: Give the patient a blank piece of paper and ask him or her to write a sentence for you. Do not dictate a sentence; it should be written spontaneously. The sentence must contain a subject and a verb and make sense. Correct grammar and punctuation are not necessary.

- Copying: Show the patient the picture of two intersecting pentagons and ask the patient to copy the figure exactly as it is. All ten angles must be present and two must intersect to score one point. Ignore tremor and rotation.

(Folstein, Folstein \& Mchugh, 1975) 


\section{Appendix E. ActiGraph Accelerometer Instructions}

\section{ActiGraph Accelerometer Instructions}

Thank you for participating in our study!

\section{What is an accelerometer?}

This activity meter records general movement and will allow us to get a better idea of your overall activity level. This device will measure the physical activity you perform by detecting the movements that are made as well as the acceleration of those movements, but will not be able to tell us exactly what activity you are doing. It is easy to use and can be worn on your belt or on the waist band of your clothing. It may feel slightly awkward at first, but after a few hours you will barely know it's there. They are also quite pricey, so please be careful!

\section{Instructions:}

You will be given an accelerometer at your study visit by your assigned number. Please do NOT switch accelerometers with anyone!

Please wear the ActiGraph with the belt clip fastened around the waist with the unit positioned over the right hip bone.

You can wear your activity monitor over or under clothing, whichever is most comfortable to you! The meter does not need to be in direct contact with the body. However, it is essential that the ActiGraph be 用口 positioned snugly enough against the body that it cannot flop around.

If you take it off for any reason, please write that on your tracking log. You will keep track of the time the accelerometer was worn using the Accelerometer Log form.

Please do not wear this device in any other way, including:

- NOT in any pockets of clothing

- NOT in a backpack or handbag

- NOT in a car glove compartment or trunk

During the week-long wear period, you will be given the accelerometer at your first visit. You will wear it during the visit and for the rest of the day. For the rest of the week it will be worn during all waking hours until you return it at your second study visit. 
Appendix F. ActiGraph Accelerometer Record of Wear

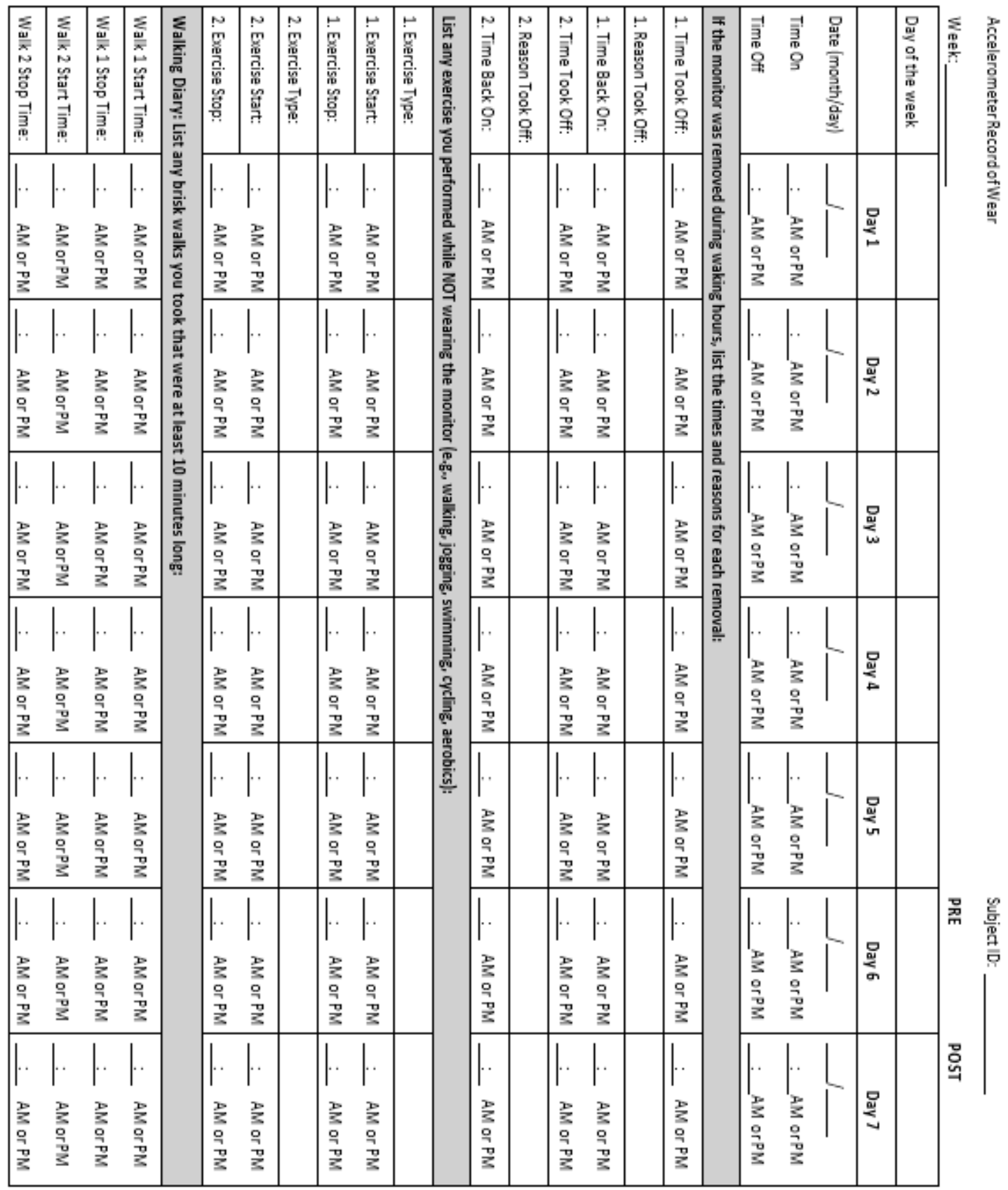


Appendix G. 36-Item Short Form Survey (SF-36)

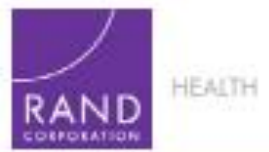

RAND > RAND Health > Surveys > RAND Medical Outcomes Study > 36-ltem Short Form Survey $($ SF-36) $>$

\section{6-Item Short Form Survey Instrument (SF-36)}

\section{RAND 36-Item Health Survey 1.0 Questionnaire Items}

\section{Choose one option for each questionnaire item.}

1. In general, would you say your health is:
1 - Excellent
2-Very good
3-Good
4-Fair
5-Poor

2. Compared to one year ago, how would you rate your health in general now?
1- Much better now than one year ago
2-Somewhat better now than one year ago
3- About the same
4-Somewhat worse now than one year ago
5-Much worse now than one year ago 
The following items are about activities you might do during a typical day. Does your health now limit you in these activities? If so, how much?

\begin{tabular}{|c|c|c|c|}
\hline & $\begin{array}{l}\text { Yes, } \\
\text { limited a } \\
\text { lot }\end{array}$ & $\begin{array}{l}\text { Yes, } \\
\text { limited a } \\
\text { little }\end{array}$ & $\begin{array}{l}\text { No, not } \\
\text { limited at } \\
\text { all }\end{array}$ \\
\hline $\begin{array}{l}\text { 3. Vigorous activities, such as running, lifting heavy objects, } \\
\text { participating in strenuous sports }\end{array}$ & $\bigcirc_{1}$ & $\mathrm{O}_{2}$ & $\mathrm{O}_{3}$ \\
\hline $\begin{array}{l}\text { 4. Moderate activities, such as moving a table, pushing a } \\
\text { vacuum cleaner, bowling, or playing golf }\end{array}$ & $\bigcirc_{1}$ & $\mathrm{O}_{2}$ & 3 \\
\hline 5. Lifting or carrying groceries & $D_{1}$ & $\mathrm{O}_{2}$ & 3 \\
\hline 6. Climbing several flights of stairs & $\bigcirc_{1}$ & $\mathrm{O}_{2}$ & $\mathrm{O}_{3}$ \\
\hline 7. Climbing one flight of stairs & $\bigcirc_{1}$ & $\mathrm{O}_{2}$ & 3 \\
\hline 8. Bending, kneeling, or stooping & $\bigcirc_{1}$ & $\mathrm{O}_{2}$ & 3 \\
\hline 9. Walking more than a mile & $\bigcirc_{1}$ & $\mathrm{O}_{2}$ & $\mathrm{O}_{3}$ \\
\hline 10. Walking several blocks & $\bigcirc_{1}$ & $\mathrm{O}_{2}$ & $\mathrm{O}_{3}$ \\
\hline 11. Walking one block & $\bigcirc_{1}$ & $\mathrm{O}_{2}$ & $\mathrm{O}_{3}$ \\
\hline 12. Bathing or dressing yourself & 1 & 2 & 3 \\
\hline
\end{tabular}


During the past 4 weeks, have you had any of the following problems with your work or other regular daily activities as a result of your physical health?

13. Cut down the amount of time you spent on work or other activities Yes No

14. Accomplished less than you would like

12

15. Were limited in the kind of work or other activities

12

16. Had difficulty performing the work or other activities (for example, it took extra effort)

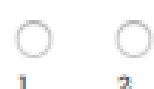

12

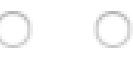

12

During the past 4 weeks, have you had any of the following problems with your work or other regular daily activities as a result of any emotional problems (such as feeling depressed or anxious)?

17. Cut down the amount of time you spent on work or other activities $\mathrm{N}_{1}$ Yes

20. During the past 4 weeks, to what extent has your physical health or emotional problems interfered with your normal social activities with family, friends, neighbors, or groups?
1 - Not at all
2- Slightly
3-Moderately
4-Quite a bit
5-Extremely 
21. How much bodily pain have you had during the past 4 weeks?
1- None
2 - Very mild
3 -Mild
4-Moderate
5-Severe
6 - Very severe

22. During the past 4 weeks, how much did pain interfere with your normal work (including both work outside the home and housework)?
$1-$ Not at all
2 - A little bit
3-Moderately
4-Quite a bit
5-Extremely 
These questions are about how you feel and how things have been with you during the past 4 weeks. For each question, please give the one answer that comes closest to the way you have been feeling.

How much of the time during the past 4 weeks_.

23. Did you feel full of pep?

24. Have you been a very nervous person?

25. Have you felt so down in the dumps that nothing could cheer you up?

26. Have you felt calm and peaceful?

27. Did you have a lot of energy?

28. Have you felt downhearted and blue?

29. Did you feel worn out?

30. Have you been a happy person?

31. Did you feel tired?

$\begin{array}{ll}\text { All of } & \text { Most } \\ \text { the } & \text { of the } \\ \text { time } & \text { time }\end{array}$

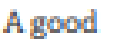

bit of the

time
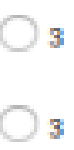

$\mathrm{O}_{1}$

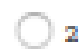

2
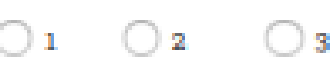

Some

of the time

A little of the time

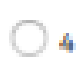

5

None

of the time

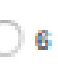

6

$\mathrm{O}_{4} \mathrm{5}_{5} \mathrm{6}_{6}$

O

3

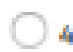

5

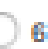

$\left(\frac{100}{20}\right.$

32. During the past 4 weeks, how much of the time has your physical health or emotional problems interfered with your social activities (like visiting with friends, relatives, etc.)?
1-All of the time
2 - Most of the time
3-Some of the time
4-A little of the time
5- None of the time 
How TRUE or FALSE is each of the following statements for you.

\begin{tabular}{|c|c|c|c|c|c|}
\hline & $\begin{array}{l}\text { Definitely } \\
\text { true }\end{array}$ & $\begin{array}{l}\text { Mostly } \\
\text { true }\end{array}$ & $\begin{array}{l}\text { Don't } \\
\text { know }\end{array}$ & $\begin{array}{l}\text { Mostly } \\
\text { false }\end{array}$ & $\begin{array}{l}\text { Definitely } \\
\text { false }\end{array}$ \\
\hline $\begin{array}{l}\text { 33. I seem to get sick a little easjer than } \\
\text { other people }\end{array}$ & 1 & 2 & 3 & 4 & 5 \\
\hline 34. I am as healthy as anybody I know & & 2 & 3 & 4 & 5 \\
\hline 35. I expect my health to get worse & & 2 & 3 & 4 & 5 \\
\hline 36. My health is excellent & & 2 & 3 & 4 & 5 \\
\hline
\end{tabular}

ABOUT

The RAND Corporation is a research organization that develops solutions to public policy challenges to help make communities throughout the world safer and more secure, healthier and more prosperous. RAND is nonprofit, nonpartisan, and committed to the public interest.

Sanla Monita, Califorria 90401-3208

RAND" is a registered trademark. Copyright 0 1994-20u6 RAND Corporation. 


\section{BIBLIOGRAPHY}

1. Painter P, Stewart A, Carey S. Physical functioning: Definitions, measurement, and expectations. Adv Ren Replace Ther. 1999;6(2):110-23.

2. Gardener EA, Huppert FA, Guralnik JM, Melzer D. Middle-aged and mobilitylimited: Prevalence of disability and symptom attributions in a national survey. $\mathbf{J}$ Gen Intern Med. 2006;21(10):1091-6.

3. Brown RT, Diaz-Ramirez LG, Boscardin WJ, Lee SJ, Steinman MA. Functional impairment and decline in middle age: A cohort study. Ann Intern Med. 2017;167(11):761.

4. Hartmann Rasmussen LJ, Caspi A, Ambler A, Broadbent JM, Cohen HJ, d'Arbeloff T, et al. Association of neurocognitive and physical function with gait speed in midlife. JAMA Netw Open. 2019;2(10):e1913123.

5. El Khoudary SR, Greendale G, Crawford SL, Avis NE, Brooks MM, Thurston $\mathrm{RC}$, et al. The menopause transition and women's health at midlife: a progress report from the Study of Women's Health Across the Nation (SWAN). Menopause. 2019;26(10):1213-27.

6. Lachman ME, Teshale S, Agrigoroaei S. Midlife as a pivotal period in the life course: balancing growth and decline at the crossroads of youth and old age. Int $\mathbf{J}$ Behav Dev. 2015;39(1):20-31.

7. Spoelstra SL, Sikorskii A, Gitlin LN, Schueller M, Kline M, Szanton SL. Dissemination of the CAPABLE model of care in a Medicaid waiver program to improve physical function. J Am Geriatr Soc. 2019;67(2):363-70.

8. Manini TM, Pahor M. Physical activity and maintaining physical function in older adults. Br J Sports Med. 2009;43(1):28-31.

9. Leigh L, Byles JE, Mishra GD. Change in physical function among women as they age: findings from the Australian Longitudinal Study on Women's Health. Qual Life Res. 2017;26(4):981-91.

10. Spartano NL, Lyass A, Larson MG, Tran T, Andersson C, Blease SJ, et al. Objective physical activity and physical performance in middle-aged and older adults. Exp Gerontol. 2019;119:203-11.

11. Sternfeld B, Colvin A, Stewart A, Dugan S, Nackers L, El Khoudary SR, et al. The effect of a healthy lifestyle on future physical functioning in midlife women. Med Sci Sports Exerc. 2017;49(2):274-82. 
12. Zunzunegui MV, Alvarado BE, Guerra R, Gómez JF, Ylli A, Guralnik JM, et al. The mobility gap between older men and women: The embodiment of gender. Arch Gerontol Geriatr. 2015;61(2):140-8.

13. Whitson HE, Landerman LR, Newman AB, Fried LP, Pieper CF, Cohen HJ. Chronic medical conditions and the sex-based disparity in disability: The Cardiovascular Health Study. J Gerontol A Biol Sci Med Sci. 2010;65A(12):1325-31.

14. Mitnitski A, Song X, Rockwood K. Improvement and decline in health status from late middle age: Modeling age-related changes in deficit accumulation. Exp Gerontol. 2007;42(11):1109-15.

15. Burger HG, Hale GE, Robertson DM, Dennerstein L. A review of hormonal changes during the menopausal transition: focus on findings from the Melbourne Women's Midlife Health Project. Hum Reprod Update. 2007;13(6):559-65.

16. Bondarev D, Laakkonen EK, Finni T, Kokko K, Kujala UM, Aukee P, et al. Physical performance in relation to menopause status and physical activity: Menopause. 2018;25(12):1432-41.

17. Costello JT, Bieuzen F, Bleakley CM. Where are all the female participants in sports and exercise medicine research? Eur J Sport Sci. 2014;14(8):847-51.

18. McCollough CH, Schueler BA, Atwell TD, Braun NN, Regner DM, Brown DL, et al. Radiation exposure and pregnancy: When should we be concerned? RadioGraphics. 2007;27(4):909-17.

19. Tendais I, Figueiredo B, Mota J, Conde A. Physical activity, health-related quality of life and depression during pregnancy. Cad Saúde Pública. 2011;27(2):219-28.

20. Ward-Ritacco CL, Adrian AL, Johnson MA, Rogers LQ, Evans EM. Adiposity, physical activity, and muscle quality are independently related to physical function performance in middle-aged postmenopausal women. Menopause. 2014;21(10):1114-21.

21. Watson KB, Carlson SA, Gunn JP, Galuska DA, O’Connor A, Greenlund KJ, et al. Physical inactivity among adults aged 50 years and older — United States, 2014. MMWR Morb Mortal Wkly Rep. 2016;65(36):954-8.

22. Lovejoy JC, Champagne CM, de Jonge L, Xie H, Smith SR. Increased visceral fat and decreased energy expenditure during the menopausal transition. Int $\mathbf{J}$ Obes. 2008;32(6):949-58.

23. Demerath EW, Rogers NL, Reed D, Lee M, Choh AC, Siervogel RM, et al. Significant associations of age, menopausal status and lifestyle factors with 
visceral adiposity in African-American and European-American women. Ann Hum Biol. 2011;38(3):247-56.

24. Sowers M, Tomey K, Jannausch M, Eyvazzadeh A, Nan B, Randolph J. Physical functioning and menopause states. Obstet Gynecol. 2007;110(6):1290-6.

25. Cooper R, Mishra G, Clennell S, Guralnik J, Kuh D. Menopausal status and physical performance in midlife: Findings from a British birth cohort study. Menopause. 2008;15(6):1079-85.

26. da Câmara SMA, Zunzunegui MV, Pirkle C, Moreira MA, Maciel ÁCC. Menopausal Status and physical performance in middle aged women: A crosssectional community-based study in northeast brazil. PLoS ONE. 2015;10(3):e0119480.

27. Kurina LM, Gulati M, Everson-Rose S, Chung P, Karavolos K, Cohen N, et al. The effect of menopause on grip and pinch strength: Results from the Chicago, Illinois, site of the Study of Women's Health Across the Nation. Am J Epidemiol. 2004;160(5):484-91.

28. Tseng LA, El Khoudary SR, Young EA, Farhat GN, Sowers M, Sutton-Tyrrell $\mathrm{K}$, et al. The association of menopause status with physical function: the Study of Women's Health Across the Nation. Menopause. 2012;19(11):1186-92.

29. El Khoudary SR, McClure CK, VoPham T, Karvonen-Gutierrez CA, Sternfeld B, Cauley JA, et al. Longitudinal assessment of the menopausal transition, endogenous sex hormones, and perception of physical functioning: The Study of Women's Health Across the Nation. J Gerontol A Biol Sci Med Sci. 2014;69(8):1011-7.

30. Toth MJ, Tchernof A, Sites CK, Poehlman ET. Menopause-related changes in body fat distribution. ann NY Acad Sci. 2006;904(1):502-6.

31. Greendale GA, Sternfeld B, Huang M, Han W, Karvonen-Gutierrez C, Ruppert $\mathrm{K}$, et al. Changes in body composition and weight during the menopause transition. JCI Insight. 2019;4(5):e124865.

32. Wing RR, Matthews KA, Kuller LH, Meilahn EN, Plantinga PL. Weight gain at the time of menopause. Arch Intern Med. 1991;151(1):97-102.

33. Pasquali R, Casimirri F, Labate A, Tortelli O, Pascal G, Gatto M, et al. Body weight, fat distribution and the menopausal status in women. Int J Obes Relat Metab Disord. 1994;18(9):614-21.

34. Duval K, Prud'homme D, Rabasa-Lhoret R, Strychar I, Brochu M, Lavoie J-M, et al. Effects of the menopausal transition on energy expenditure: A MONET group study. Eur J Clin Nutr. 2013;67(4):407-11. 
35. Sowers M, Zheng H, Tomey K, Karvonen-Gutierrez C, Jannausch M, Li X, et al. Changes in body composition in women over six years at midlife: Ovarian and chronological aging. J Clin Endocrinol Metab. 2007;92(3):895-901.

36. Derby CA, Crawford SL, Pasternak RC, Sowers M, Sternfeld B, Matthews KA. Lipid changes during the menopause transition in relation to age and weight: The Study of Women's Health Across the Nation. Am J Epidemiol. 2009;169(11):1352-61.

37. Matthews K, Abrams B, Crawford S, Miles T, Neer R, Powell L, et al. Body mass index in mid-life women: Relative influence of menopause, hormone use, and ethnicity. Int J Obes. 2001;25:863-73.

38. DeLillis Henderson K, Bernstein L, Henderson B, Kolonel L, Pike MC. Predictors of the timing of natural menopause in the multiethnic cohort study. Am J Epidemiol. 2008;167(11):1287-94.

39. Trikudanathan S, Pedley A, Massaro JM, Hoffmann U, Seely EW, Murabito JM, et al. Association of female reproductive factors with body composition: The Framingham Heart Study. J Clin Endocrinol Metab. 2013;98(1):236-44.

40. Jaff NG, Norris SA, Snyman T, Toman M, Crowther NJ. Body composition in the Study of Women Entering and in Endocrine Transition (SWEET): A perspective of African women who have a high prevalence of obesity and HIV infection. Metabolism. 2015;64(9):1031-41.

41. Gold EB, Crawford SL, Avis NE, Crandall CJ, Matthews KA, Waetjen LE, et al. Factors related to age at natural menopause: Longitudinal analyses from SWAN. Am J Epidemiol. 2013;178(1):70-83.

42. Al-Safi ZA, Polotsky AJ. Obesity and menopause. Best Pract Res Clin Obstet Gynaecol. 2015;29(4):548-53.

43. Karvonen-Gutierrez C, Kim C. Association of mid-life changes in body size, body composition and obesity status with the menopausal transition. Healthcare. 2016;4(3):E42.

44. Randolph JF, Zheng H, Sowers MR, Crandall C, Crawford S, Gold EB, et al. Change in follicle-stimulating hormone and estradiol across the menopausal transition: Effect of age at the final menstrual period. J Clin Endocrinol Metab. 2011;96(3):746-54.

45. Paramsothy P, Harlow SD, Elliott MR, Yosef M, Lisabeth LD, Greendale GA, et al. Influence of race/ethnicity, body mass index, and proximity of menopause on menstrual cycle patterns in the menopausal transition: The Study of Women's Health Across the Nation (SWAN). Menopause. 2015;22(2):159-65. 
46. Ramezani Tehrani F, Bahri M, Gholami R, Hashemi S, Bs KN. Secular trend of menopausal age and related factors among Tehrani women born from 1930 to 1960; Tehran Lipid and Glucose Study. Arch Iran med. 2014;17(6):406-10.

47. Pakarinen M, Raitanen J, Kaaja R, Luoto R. Secular trend in the menopausal age in Finland 1997-2007 and correlation with socioeconomic, reproductive and lifestyle factors. Maturitas. 2010;66(4):417-22.

48. Avis NE, Colvin A, Bromberger JT, Hess R, Matthews KA, Ory M, et al. Change in health-related quality of life over the menopausal transition in a multiethnic cohort of middle-aged women: Study of Women's Health Across the Nation (SWAN). Menopause. 2009;16(5):860-9.

49. Gold EB, Colvin A, Avis N, Bromberger J, Greendale GA, Powell L, et al. Longitudinal analysis of the association between vasomotor symptoms and race/ethnicity across the menopausal transition: study of women's health across the nation. Am J Public Health. 2006;96(7):1226-35.

50. Namazi M, Sadeghi R, Behboodi Moghadam Z. Social determinants of health in menopause: An integrative review. Int J Womens Health. 2019;11:637-47.

51. Soules MR, Rebar R, Woods N. Executive summary: Stages of Reproductive Aging Workshop (STRAW). Fert Steril. 2001;76(5):5.

52. Gracia CR, Sammel MD, Freeman EW, Lin H, Langan E, Kapoor S, et al. Defining menopause status: Creation of a new definition to identify the early changes of the menopausal transition. Menopause. 2005;12(2):128-35.

53. Johnson BD, Bairey Merz CN, Braunstein GD, Berga SL, Bittner V, Keta Hodgson T, et al. Determination of menopausal status in women: The NHLBIsponsored Women's Ischemia Syndrome Evaluation (WISE) Study. J Women's Health. 2004;13(8):872-87.

54. Johnston JM, Colvin A, Johnson BD, Santoro N, Harlow SD, Merz CNB, et al. Comparison of SWAN and WISE menopausal status classification algorithms. J Women's Health. 2006;15(10):1184-94.

55. Brady AO, Straight CR, Evans EM. Body composition, muscle capacity, and physical function in older adults: An integrated conceptual model. J Aging Phys Act. 2014;22(3):441-52.

56. Collard RM, Boter H, Schoevers RA, Voshaar RCO. Prevalence of Frailty in Community-Dwelling Older Persons: A Systematic Review. Journal of the American Geriatrics Society. 2012;60(8):1487-92.

57. Velez MP, Rosendaal N, Alvarado B, da Câmara S, Belanger E, Pirkle C. Age at natural menopause and physical function in older women from Albania, Brazil, Colombia and Canada: A life-course perspective. Maturitas. 2019;122:22-30. 
58. Velez MP, Alvarado BE, Rosendaal N, da Câmara SM, Belanger E, Richardson $\mathrm{H}$, et al. Age at natural menopause and physical functioning in postmenopausal women: the Canadian Longitudinal Study on Aging. Menopause. 2019;26(9):958-65.

59. Tom SE, Cooper R, Patel KV, Guralnik JM. Menopausal characteristics and physical functioning in older adulthood in the National Health and Nutrition Examination Survey III: Menopause. 2013;19(3):283-9.

60. Riebe D. ACSM's Guidelines for Exercise Testing and Prescription. 10th ed. Philidelphia, PA: Wolters Kluwer; 2018. 1 p.

61. Pettee Gabriel K, Sternfeld B, Colvin A, Stewart A, Strotmeyer ES, Cauley JA, et al. Physical activity trajectories during midlife and subsequent risk of physical functioning decline in late mid-life: The Study of Women's Health Across the Nation (SWAN). Prev Med. 2017;105:287-94.

62. Straight CR, Brady AO, Evans EM. Muscle quality and relative adiposity are the strongest predictors of lower-extremity physical function in older women. Maturitas. 2015;80(1):95-9.

63. Paterson DH, Warburton DE. Physical activity and functional limitations in older adults: A systematic review related to Canada's Physical Activity Guidelines. Int J Behav Nutr Phys Act. 2010;7(38):22.

64. Prince SA, Adamo KB, Hamel M, Hardt J, Connor Gorber S, Tremblay M. A comparison of direct versus self-report measures for assessing physical activity in adults: a systematic review. Int J Behav Nutr Phys Act. 2008;5(1):56.

65. Cerin E, Cain KL, Oyeyemi AL, Owen N, Conway TL, Cochrane T, et al. Correlates of agreement between accelerometry and self-reported physical activity. Med Sci Sports Exerc. 2016;48(6):1075-84.

66. JafariNasabian P, Inglis JE, Reilly W, Kelly OJ, Ilich JZ. Aging human body: changes in bone, muscle and body fat with consequent changes in nutrient intake. J Endocrinol. 2017;234(1):R37-51.

67. Valentine RJ, Misic MM, Rosengren KS, Woods JA, Evans EM. Sex impacts the relation between body composition and physical function in older adults: Menopause. 2009;16(3):518-23.

68. Reynolds RF, Obermeyer CM. Age at natural menopause in Spain and the United States: Results from the DAMES project. Am J Hum Biol. 2005;17(3):331-40.

69. Gold EB, Sternfeld B, Kelsey JL, Brown C, Mouton C, Reame N, et al. Relation of demographic and lifestyle factors to symptoms in a multi-racial/ethnic population of women 40-55 years of age. Am J Epidemiol. 2000;152(5):463-73. 
70. Ng S, Fong S, Chan C, Fung F, Pang P, Tsang N, et al. Floor transfer test for assessing people with chronic stroke. J Rehabil Med. 2015;47(6):489-94.

71. Rose DJ, Jones CJ, Lucchese N. Predicting the probability of falls in communityresiding older adults using the 8-Foot Up-and-Go: A new measure of functional mobility. J Aging Phys Act. 2002;10(4):466-75.

72. Rikli RE, Jones J. Development and validation of a functional fitness test for community-residing older adults. J Aging Phys Act. 1999;7:129-61.

73. ATS Statement: guidelines for the six-minute walk test. Am J Respir Crit Care Med. 2002;166(1):111-7.

74. Ware JE, Donald Sherbourne C. The MOS 36-Item Short-Form Health Survey (SF-36): I. Conceptual framework and item selection. Med Care. 1992;30(6):473-83.

75. White DK, Wilson JC, Keysor JJ. Measures of adult general functional status. Arthritis Care Res. 2011;63(S11):S297-307.

76. Imboden MT, Welch WA, Swartz AM, Montoye AHK, Finch HW, Harber MP, et al. Reference standards for body fat measures using GE dual energy x-ray absorptiometry in Caucasian adults. PLoS One. 2017;12(4):e0175110.

77. Tudor-Locke C, Craig CL, Brown WJ, Clemes SA, De Cocker K, Giles-Corti B, et al. How many steps/day are enough? for adults. Int J Behav Nutr Phys Act. 2011;8:79.

78. Spartano NL, Demissie S, Himali JJ, Dukes KA, Murabito JM, Vasan RS, et al. Accelerometer-determined physical activity and cognitive function in middle-aged and older adults from two generations of the Framingham Heart Study. Alzheimers Dementia (N Y). 2019;5(1):618-26.

79. Pettee Gabriel K, Sidney S, Jacobs DR, Whitaker KM, Carnethon MR, Lewis $\mathrm{CE}$, et al. Ten-year changes in accelerometer-based physical activity and sedentary time during midlife. Am J Epidemiol. 2018;187(10):2145-50. 